RESEARCH

SERIES

NUMBER 87

September 2019

\section{GENDER, PENSIONS AND INCOME IN RETIREMENT}

\section{ANNE NOLAN, ADELE WHELAN, SEAMUS MCGUINNESS AND BERTRAND MAITTRE}

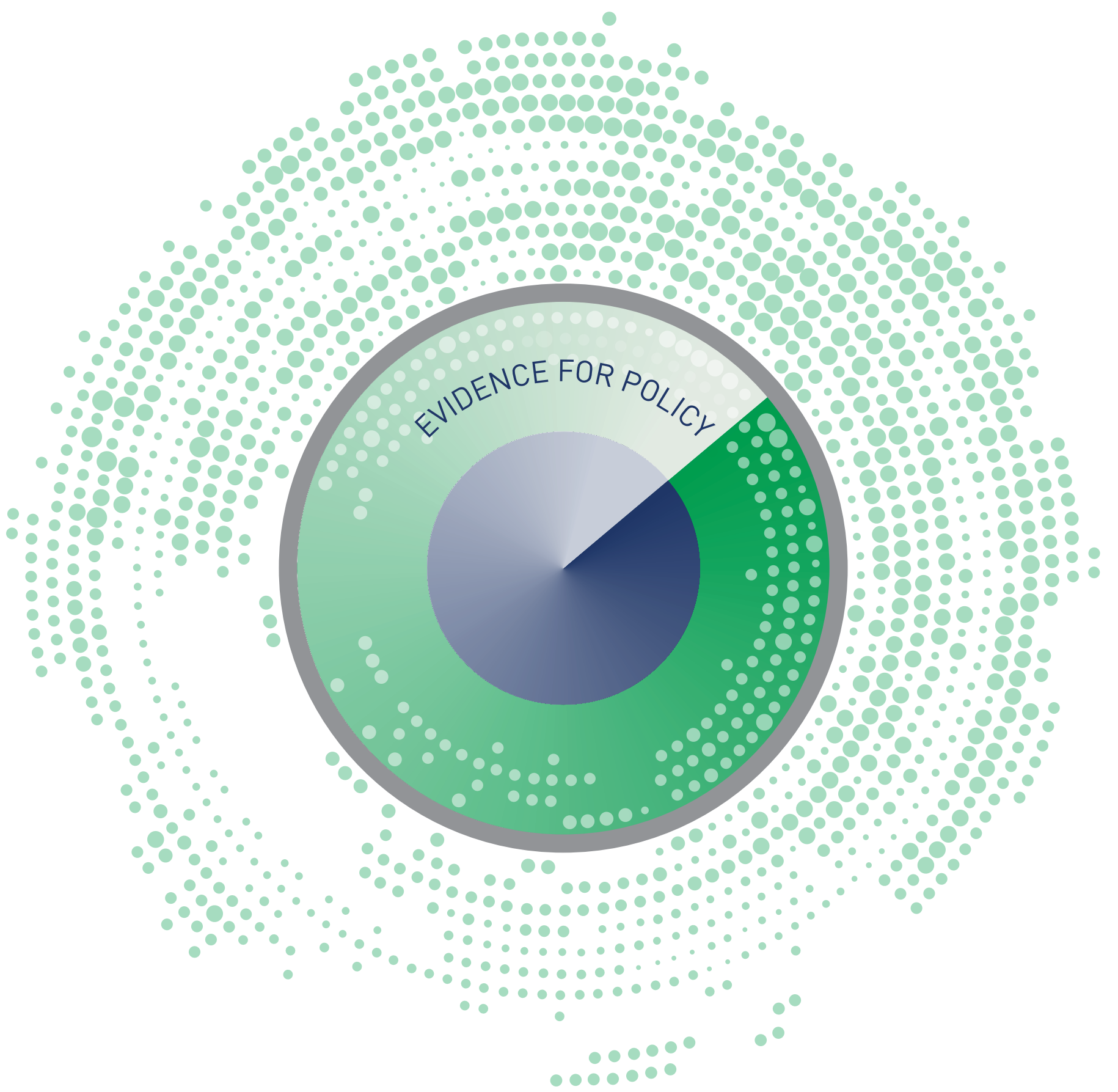

$\circ$ 


\section{GENDER, PENSIONS AND INCOME IN RETIREMENT}

Anne Nolan

Adele Whelan

Seamus McGuinness

Bertrand Maître

September 2019

\section{RESEARCH SERIES}

\section{NUMBER 87}

Available to download from www.esri.ie

(c) The Economic and Social Research Institute

Whitaker Square, Sir John Rogerson's Quay, Dublin 2

ISBN: 978-0-7070-0490-7

DOI: https://doi.org/10.26504/rs87

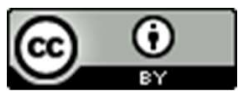

This Open Access work is licensed under a Creative Commons Attribution 4.0 International License (https://creativecommons.org/licenses/by/4.0/), which permits unrestricted use, distribution, and reproduction in any medium, provided the original work is properly credited. 


\section{ABOUT THE ESRI}

The mission of the Economic and Social Research Institute is to advance evidencebased policymaking that supports economic sustainability and social progress in Ireland. ESRI researchers apply the highest standards of academic excellence to challenges facing policymakers, focusing on 12 areas of critical importance to 21 stcentury Ireland.

The Institute was founded in 1960 by a group of senior civil servants led by $\mathrm{Dr}$ T.K. Whitaker, who identified the need for independent and in-depth research analysis to provide a robust evidence base for policymaking in Ireland.

Since then, the Institute has remained committed to independent research and its work is free of any expressed ideology or political position. The Institute publishes all research reaching the appropriate academic standard, irrespective of its findings or who funds the research.

The quality of its research output is guaranteed by a rigorous peer review process. ESRI researchers are experts in their fields and are committed to producing work that meets the highest academic standards and practices.

The work of the Institute is disseminated widely in books, journal articles and reports. ESRI publications are available to download, free of charge, from its website. Additionally, ESRI staff communicate research findings at regular conferences and seminars.

The ESRI is a company limited by guarantee, answerable to its members and governed by a Council, comprising 14 members who represent a cross-section of ESRI members from academia, civil services, state agencies, businesses and civil society. The Institute receives an annual grant-in-aid from the Department of Public Expenditure and Reform to support the scientific and public interest elements of the Institute's activities; the grant accounted for an average of 30 per cent of the Institute's income over the lifetime of the last Research Strategy. The remaining funding comes from research programmes supported by government departments and agencies, public bodies and competitive research programmes.

Further information is available at www.esri.ie 


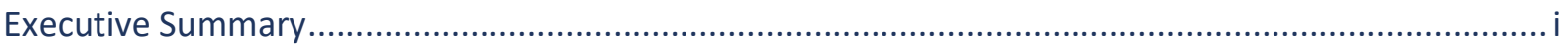

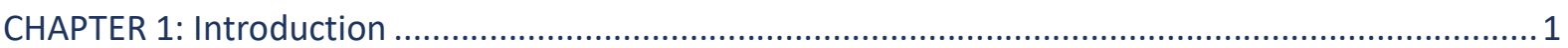

CHAPTER 2: Gender gap in retirement incomes ............................................................... 7

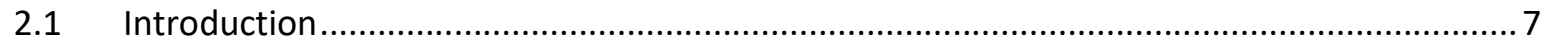

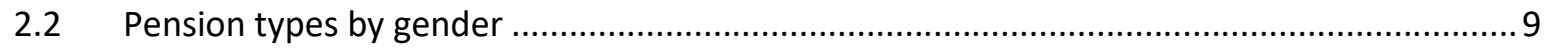

2.3 Previous literature ...................................................................................... 10

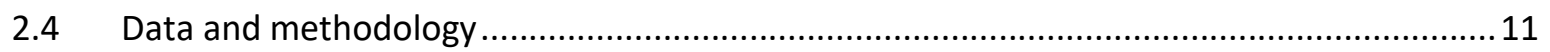

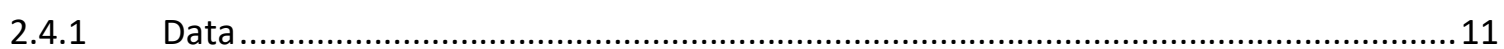

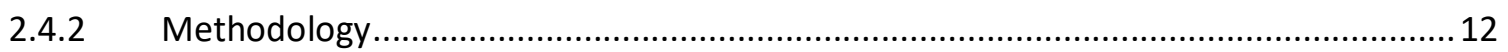

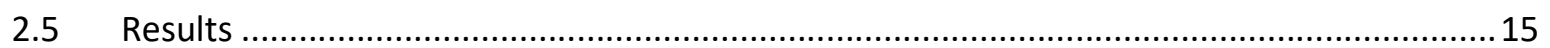

2.5.1 Men's and women's pension income ........................................................... 15

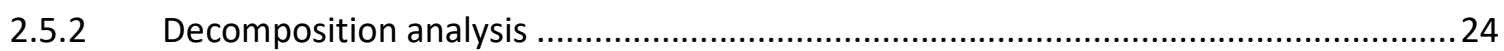

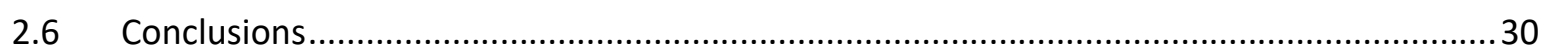

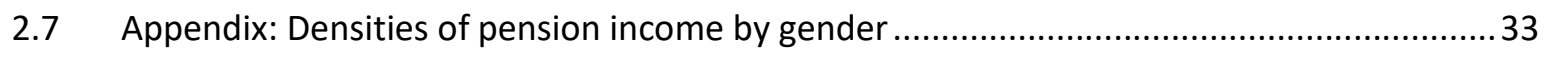

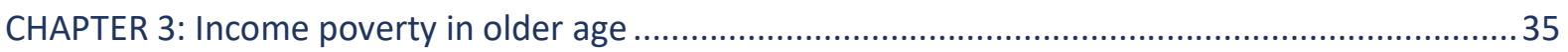

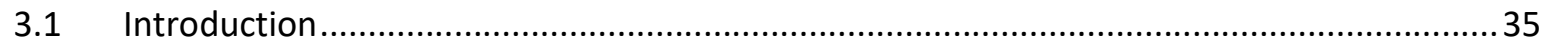

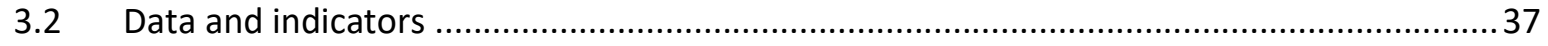

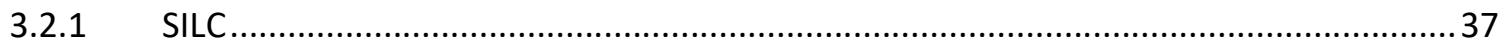

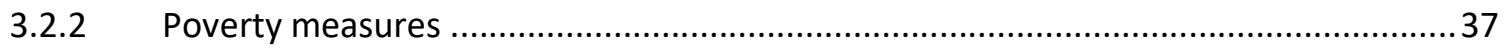

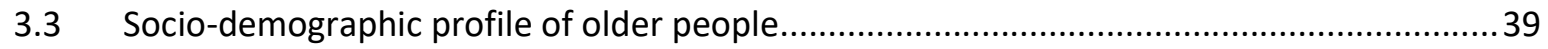

3.4 The experience of poverty among older people ................................................

3.4.1 Risk of poverty and deprivation ...................................................................4 41

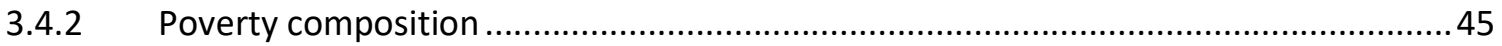

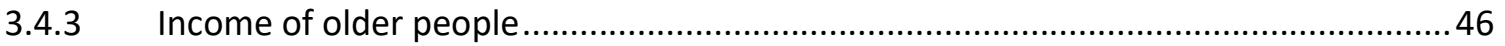

3.4.4 Household income sources of older people .....................................................47

3.4.5 Personal income sources of older people........................................................50

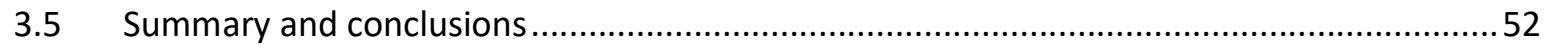

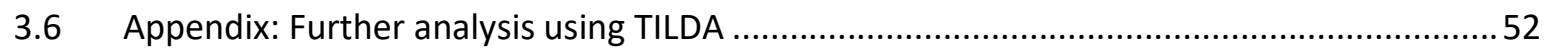

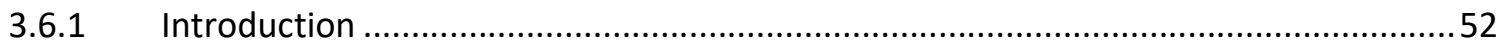

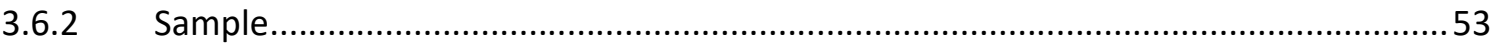

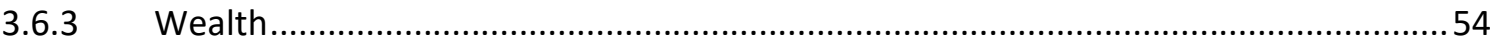

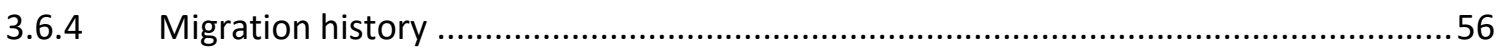

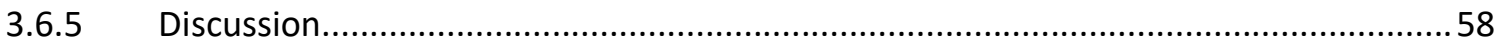

CHAPTER 4: Gender and financial decision-making.........................................................59 


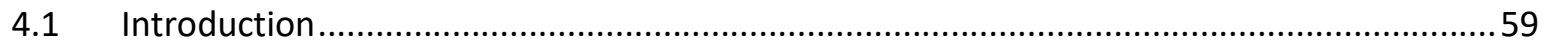

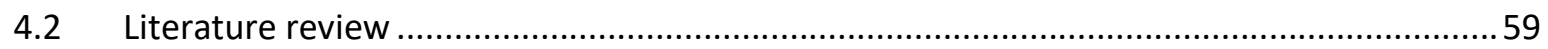

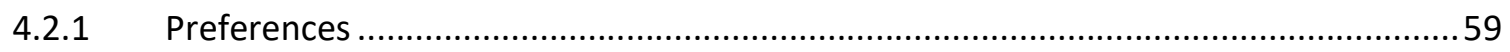

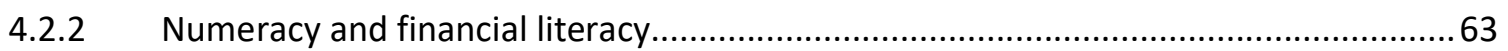

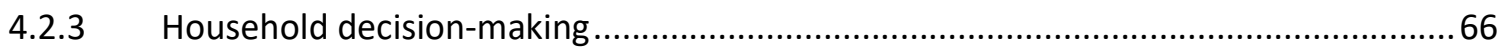

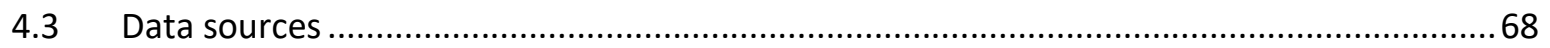

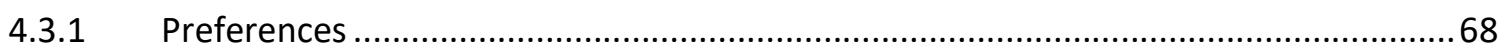

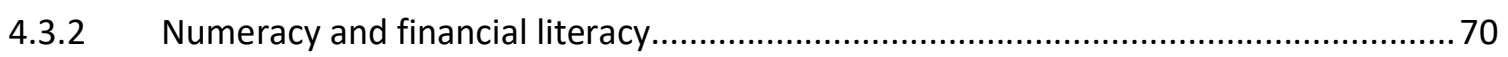

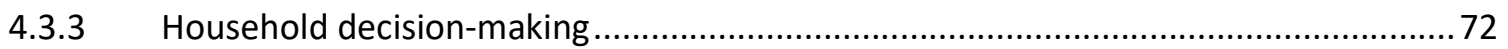

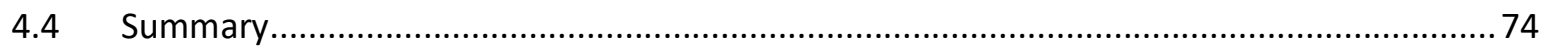

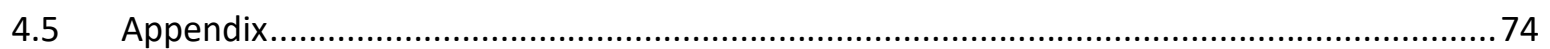

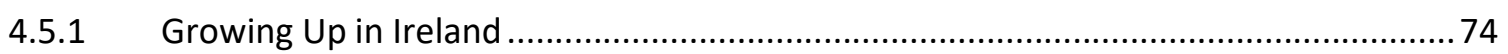

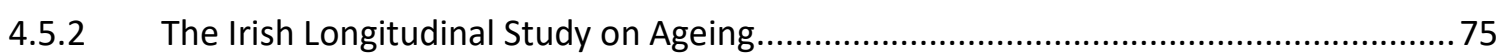

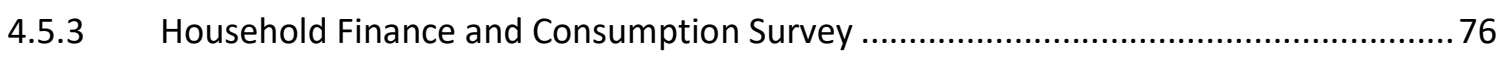

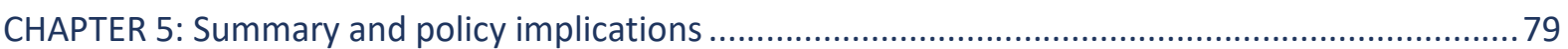

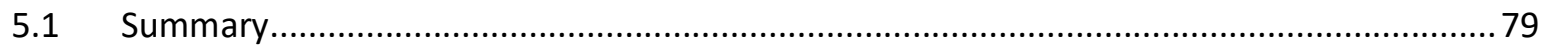

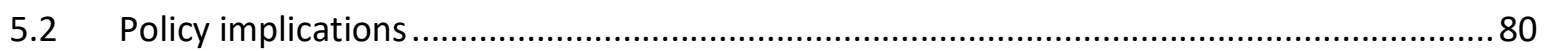

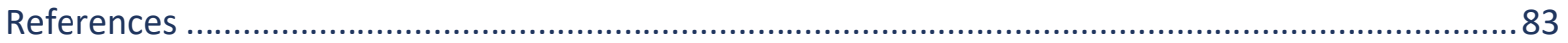




\section{LIST OF TABLES}

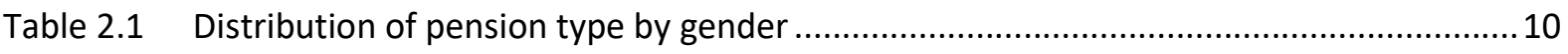

Table 2.2 Characteristics of men and women: (i) total sample, (ii) state pensions, and (iii)

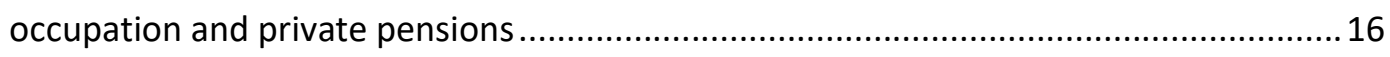

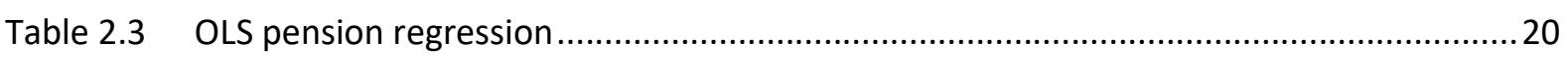

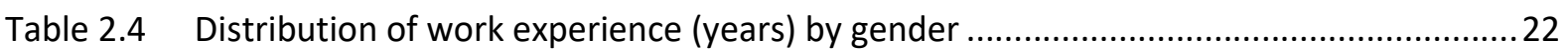

Table 2.5 Distribution of work experience (years) for occupation and private pension by gender. 22

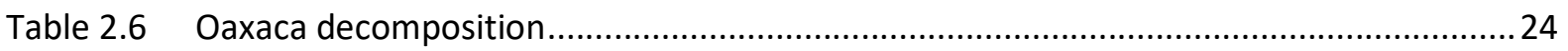

Table 2.7 Decile decomposition of occupational and private pensions income gap (restricted

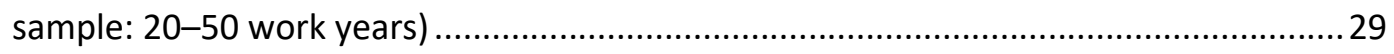

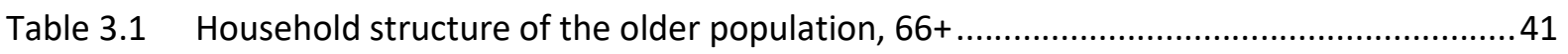

Table 3.2 Gross household income source receipt and mean gross income by income poverty status of older people ........................................................................................... 49

Table 3.3 Annual gross individual income source receipt and mean gross income by gender and

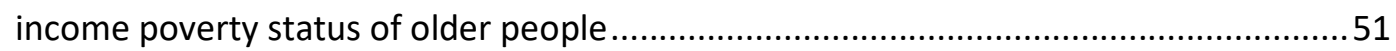

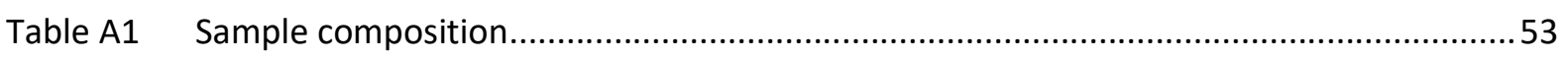

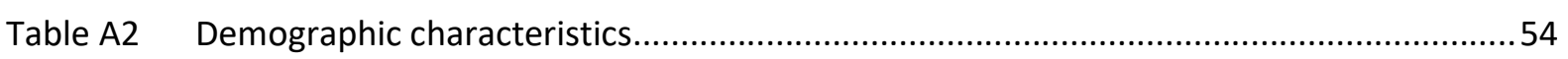

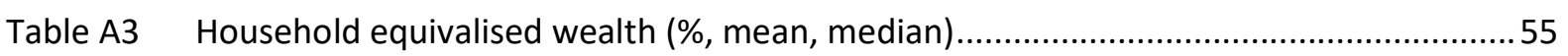

Table A4 Components of financial equivalised wealth (\%, mean, median).....................................55

Table A5 Components of financial equivalised wealth (\%, mean, median) ....................................55

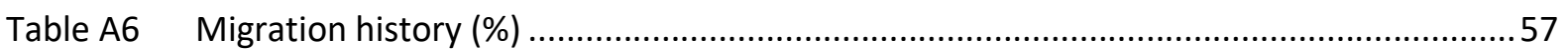

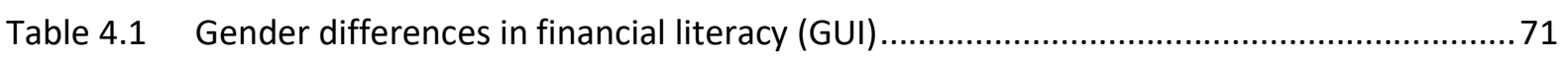

Table 4.2 Gender differences in financial literacy (TILDA) .......................................................... 71

Table 4.3 Gender differences in family/financial respondent roles (TILDA) (\%) .............................73

Table 4.4 Family/financial respondent roles and numeracy/financial literacy (TILDA) (\%) .............73 


\section{LIST OF FIGURES}

Figure 2.1 Distributions of total income (state, occupational and private) by gender..................17

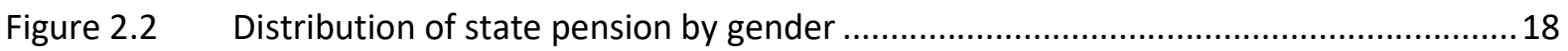

Figure 2.3 Distribution of occupational and private pension income by gender .........................18

Figure 2.4 Distribution of logged occupational and private pension incomes ( $€$ /week) by work

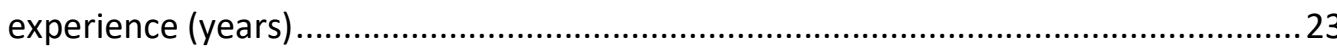

Figure 2.5 Distribution of occupational and private pension incomes ( $€$ /week) by work experience (years)

Figure 2.6 Gender differential of total pension income (state, occupational and private) by decile

Figure 2.7 Gender differential of occupational and private pension income by decile (restricted

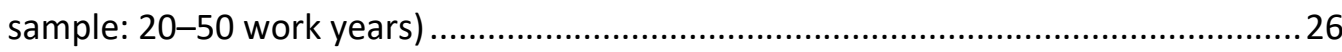

Figure 2.8 Gender differential of total pension income by decile ...............................................27

Figure 2.9 Gender differential of occupational and private pension income by decile (restricted

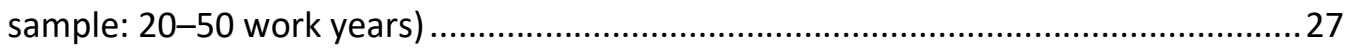

Figure A1 Densities of total pension income (state, occupational and private) by gender ...........33

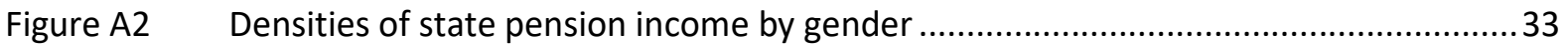

Figure A3 Densities of occupational and private pension income by gender ..............................34

Figure A4 Densities of occupational and private pension income for those with work experience of between 20 and 50 years by gender ................................................................. 34

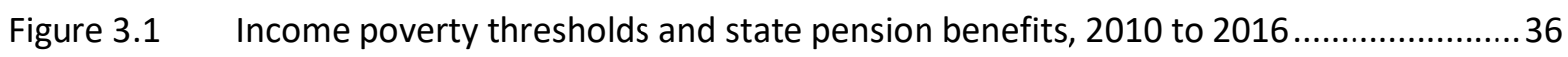

Figure 3.2 Age distribution of the older population, 66+, by gender .......................................... 40

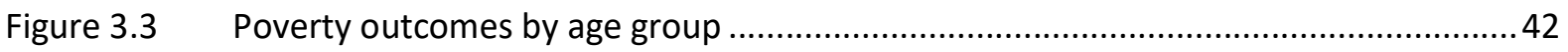

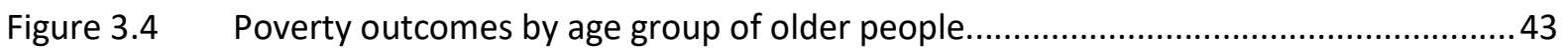

Figure 3.5 Poverty outcomes by household type of older people..............................................44

Figure 3.6 Poverty outcomes by household type and gender of older people ..............................45

Figure 3.7 Poverty composition for income poverty and deprivation by household type of older

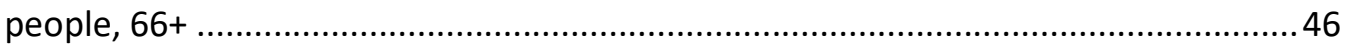

Figure 3.8 Annual mean equivalised disposable household income by socio-demographic characteristics of older people

Figure 4.1 Gender differences in attitudes towards financial risk (HFCS) ..................................69

Figure 4.2 Gender differences in attitudes to risk (ESS) .......................................................... 70 


\section{THE AUTHORS}

Anne Nolan is an Associate Research Professor, Adele Whelan is a Research Officer, Seamus McGuinness is a Research Professor and Bertrand Maître is a Senior Research Officer at the Economic and Social Research Institute (ESRI). All also hold adjunct positions at Trinity College Dublin (TCD).

\section{ACKNOWLEDGEMENTS}

The research was funded by the Pensions Council under a Research Programme on 'Gender and Pensions'. The authors thank the Central Statistics Office (CSO) for access to Growing Up in Ireland (GUI), Household Finance and Consumption Survey (HFCS) and Survey of Income and Living Conditions (SILC) data, and the Irish Longitudinal Study on Ageing (TILDA) for access to the TILDA data. They also thank Philip O'Connell (UCD Geary Institute) for assistance with queries in relation to the European Social Survey (ESS). Thanks also to the members of the Pensions Council, and to the members of the Research Programme Steering Committee (Sinead Ryan and Brendan Kennedy for the Pensions Council; Helen McDonald and Darragh Doherty for the Department of Employment Affairs and Social Protection; and Karina Doorley for the ESRI) for helpful comments and guidance on the research.

This report has been accepted for publication by the Institute, which does not itself take institutional policy positions. All ESRI Research Series reports are peer reviewed prior to publication. The author(s) are solely responsible for the content and the views expressed. 


\section{ABBREVIATIONS}

\begin{tabular}{|c|c|}
\hline AROP & at risk of poverty \\
\hline $\mathrm{CSO}$ & Central Statistics Office \\
\hline ESRI & Economic and Social Research Institute \\
\hline ESS & European Social Survey \\
\hline EU-SILC & European Union Survey of Income and Living Conditions \\
\hline GPG & gender pension gap \\
\hline GSOEP & German Socioeconomic Panel \\
\hline GUI & Growing Up in Ireland \\
\hline $\mathrm{HFCN}$ & Household Finance and Consumption Network \\
\hline HFCS & Household Finance and Consumption Survey \\
\hline HRP & household reference person \\
\hline HRS & Health and Retirement Study \\
\hline IF & influence function \\
\hline OECD & Organisation for Economic Co-operation and Development \\
\hline OLS & ordinary least squares \\
\hline \multirow[t]{2}{*}{ PIACC } & Programme for the International Assessment of Adult \\
\hline & Competencies \\
\hline PISA & Programme for International Student Assessment \\
\hline PRSA & Personal Retirement Savings Account \\
\hline PRSI & Pay-Related Social Insurance \\
\hline RAC & Retirement Annuity Contract \\
\hline RIF & re-centred influence function \\
\hline Rol & Republic of Ireland \\
\hline SHARE & Survey of Health, Ageing and Retirement in Europe \\
\hline SIF & Social Insurance Fund \\
\hline SILC & Survey of Income and Living Conditions \\
\hline SPA & state pension age \\
\hline TILDA & the Irish Longitudinal Study on Ageing \\
\hline
\end{tabular}




\section{EXECUTIVE SUMMARY}

\section{INTRODUCTION}

This report examines key dimensions of the policy debate around gender and pensions in Ireland, namely the gender pension gap, income poverty, and financial decision-making. The research summarises three studies carried out as part of a programme of research at the Economic and Social Research institute (ESRI) funded by the Pensions Council.

Women may face a number of potential issues both before and during retirement that can have a cumulative impact resulting in significantly lower financial security in retirement than men. In retirement, pension income accounts for most of the income of men and women in Ireland (Central Statistics Office (CSO), 2013). A woman aged 65-79 in the EU-28 received a pension that was on average 38 per cent lower than her male counterpart in 2016; the corresponding figure for Ireland was 26 per cent (European Commission, 2018).

Overall, the older population has fared better than other age groups in terms of the experience of income poverty in Ireland in recent years. However, there remains a proportion (currently just under 9 per cent) who live in income poverty (CSO, 2018), despite the fact that the level of older age state benefits should be sufficient to keep this group out of income poverty.

Demographic trends mean that older women, who live longer than men, will make up a larger share of the population, and will be increasingly likely to live alone (European Commission, 2018). This means that older women will need to assume greater responsibility for their own financial security in older age. For any policy to tackle successfully gender differences in economic outcomes in older age, it is also important to understand how men and women may differ in terms of financial decision-making. Decisions about many aspects of economic life are shaped by attitudes to risk, time preferences and financial literacy skills, and there is evidence that men and women differ in some aspects of these key dimensions of decisionmaking.

The aim of the research is to inform policy by examining a number of key questions:

- What is the magnitude of the gender pension gap in Ireland? How does the gap vary across the pension income distribution? (Chapter 2)

- What are the characteristics of those living in income poverty in older age in Ireland? Are there gender differences? (Chapter 3) 
- What evidence is presented in the international literature on gender differences in financial decision-making? What data sources exist for Ireland that contain information on risk preferences, financial literacy and household decision-making roles that could potentially be used to examine gender and economic outcomes in older age? (Chapter 4)

\section{MAIN FINDINGS}

- An analysis of the gender pension gap in Ireland using data from the Irish Longitudinal Study on Ageing (TILDA) found that in 2010, 88 per cent of men and 93 per cent of women were in receipt of the state pension, while 55 per cent of men and 28 per cent of women were in receipt of occupational and private pensions.

- Average total weekly pension income in 2010 was $€ 280$ for women and $€ 433$ for men, implying a raw gender pension gap of approximately 35 per cent.

- No consistent evidence of a gender state pension gap was found.

- For occupational and private pensions, higher levels of female educational attainment are found to reduce the gender pension gap throughout the pension income distribution.

- In the top three deciles, where approximately 25 to 45 per cent of the raw gap is explained, the principal factor contributing to the gap is found to be the lower relative years of work experience among women.

- Using data from the Survey of Income and Living Conditions (SILC) for 2015 and 2016, the analysis of income poverty in older age found that almost 80 per cent of income-poor older individuals live in single or couple households (with no other household members). Thus, the hypothesis that the presence of other household members would impact on household equivalised income and thereby push the household below the poverty threshold is rejected.

- A more detailed analysis of household and personal income sources for the older population revealed their high dependence on old-age benefits (i.e. pensions), with an average 80 per cent of personal income derived from the contributory state and occupational pensions.

- In terms of gender differences, the rate of receipt and mean level of contributory pensions is much lower among older women. This is partly because their partners are likely to be in receipt of a qualified adult payment but also because more women could be in receipt of lower personal rates as a consequence of a lower lifetime attachment to the labour market.

- The review of the international evidence on gender differences in key dimensions of financial decision-making (preferences, financial literacy and household decision-making roles) demonstrates clearly that women are more risk-averse and have poorer numeracy/financial literacy skills than men. 
- There is also evidence that the intra-household wealth gap is higher in households in which the male 'holds the purse strings' in comparison with households characterised by joint decision-making.

\section{POLICY IMPLICATIONS}

Policy measures that increase female employment levels and ensure increased continuity in women's employment are the most important levers in reducing the gender gap in pensions. In this regard, polices regarding the provision of childcare supports and long-term care services can play a key role. Furthermore, for workers who experience interruptions in their career, it is important for policy to examine the best ways to facilitate the return to work and work transitions, i.e. both between jobs and between work statuses. Policy could also focus on measures to promote supplementary pension savings for women to reduce the observed differences in occupational and private pension coverage across genders.

The analysis of income poverty among the older population highlights a positive story. In contrast with other population groups, less than 10 per cent of the older population are income poor, reflecting the role that the state pension has played in keeping the majority of the older population out of income poverty. The analysis shows that income-poor older people are highly dependent on non-contributory pensions. The much lower level of receipt and mean level of contributory pensions of income-poor older people may be explained by weak previous attachment to the labour market (due to home duties, unemployment, etc.) and periods of emigration, as well as by persons not claiming their full entitlements.

Ensuring that women have the necessary skills to ensure their financial security in older age is crucial and requires an understanding of how financial decisions are made, and how men and women may differ in terms of financial decision-making. The low level of financial literacy among the older population is of concern, and the gender gap is particularly noteworthy, although not unusual internationally. While the evidence base is still developing, policies to enhance the concept of financial capability (which reflects not only skills, but also the accumulation of knowledge and experience, attitudes and motivations to act in a financially capable way) across the population will be an important complement to broader efforts to ensure that men and women have equal opportunities to participate in the labour market and accumulate sufficient resources to ensure financial security in retirement. 



\section{CHAPTER 1}

\section{Introduction}

This report summarises the research carried out on the broad theme of 'gender and pensions' as part of a programme of research at the Economic and Social Research Institute (ESRI) funded by the Pensions Council. The objective of the programme is to undertake and disseminate research on how pension income and cover differ by gender in Ireland and how such differences arise and impact on outcomes such as poverty.

It is widely acknowledged that gender differences in retirement pensions exist, and these issues have become a popular topic of research (Ginn, 2003; Jefferson, 2009) and political debate ( Bettio et al., 2013; European Commission, 2018; Organisation for Economic Co-operation and Development (OECD), 2014). The gender gap in pension income is defined as the percentage by which women's average pension income is lower than that for men. In 2016, a woman aged 65-79 in the EU-28 received an average pension that was 38 per cent lower than her male counterpart; the corresponding figure for Ireland was 26 per cent (European Commission, 2018). While the data for Ireland show a considerable decrease in the gender pension gap over the period 2009-2016 (from 38 per cent to 26 per cent), gender differences in pension coverage and income remain persistent. This is a remarkable reduction, possibly related to the fact that more recent cohorts of female pensioners have higher levels of education than the previous cohorts. Higher education is generally associated with stronger labour market attachment, more years in employment, higher earnings and, in turn, higher pension contributions.

Differences in income from pensions are one of the most important sources of income inequality among older people. Data from the Irish Survey of Income and Living Conditions (SILC) for 2011 show that just over 80 per cent of the gross income of the population aged 65+ comprises income from state, occupational and private pensions. Women are particularly reliant on pension income, with pensions comprising 83 per cent of the gross income of older women in comparison with 77 per cent for older men (Central Statistics Office (CSO), 2013).

Differences in employment characteristics between men and women, and in how pension systems calculate pension benefits, are considered to be the main explanations for the gender pension gap. Women are less likely than men to be employed, and when they are employed, they earn less, work fewer hours and have shorter careers. Pension system characteristics (e.g. how and if pension benefits take account of caring career breaks) may attenuate or exacerbate these differences (Bettio et al., 2013; Chłoń-Domińczak, 2017; European Commission, 2018). 
Another dimension of economic wellbeing in older age concerns the experience of those living in poverty. At an individual level, income poverty rates among the older population in Ireland have been lower than for other age groups, and there is no gender difference in the proportion of men and women at risk of poverty in Ireland (CSO, 2017c, 2018). Previous research on income poverty in Ireland for the period 2004 to 2007 showed also that the reduction in poverty was most pronounced for older people (Russell et al., 2010). For the past decade, the poverty rates for the older population have been on average 1.5 times lower than for the total population.

During the recession, welfare policies to maintain the basic pension rates of older people contributed to protecting them from the worst effects of the recession (Watson and Maitre, 2013). Indeed, unlike many social welfare benefits to support the working-age population or children, there has been no reduction in the state pension rates after 2009. However, in spite of welfare policies' efforts to protect older people, there remains a group of older people in poverty. Social welfare pension payments should generally be sufficient to keep people out of income poverty yet in 2016, 10.2 per cent over the over-65s were classified as 'at risk of poverty' and 13.1 per cent experienced basic deprivation (CSO, 2017b). The proportion of the over-65s in income poverty fell further in 2017, to 8.6 per cent, and the proportion experiencing basic deprivation fell to 9.7 per cent (CSO, 2018). Despite these positive trends, and the fact that the levels of the state pension have been very similar to the income poverty threshold over time, the question still arises as to why nearly 10 per cent of the over-65s are in income poverty.

A complex mix of personal preferences, household decision-making processes, social conditions and policy-driven factors shape the working lives of women and men and, by extension, their economic outcomes in older age. For any policy to tackle successfully gender differences in economic outcomes in older age, ${ }^{1}$ it is also important to understand how men and women may differ in terms of financial decision-making. Decisions about many aspects of economic life are shaped by attitudes to risk, time preferences, and financial literacy skills, and there is evidence that men and women differ in some aspects of these key dimensions of decision-making (Dohmen et al., 2011; Klapper et al., 2016). Men and women in couples also differ in the degree to which they allocate responsibility for making financial decisions, which in turn may influence their ability to accumulate and manage retirement resources (Fonseca et al., 2012; Smith et al., 2010).

Understanding the determinants of economic outcomes at older age is important for policy, particularly in light of demographic and policy changes. At present, the

While pensions are the predominant source of income in retirement for the older population, older individuals may also fund consumption in retirement by drawing down asset wealth (Modigliani, 1986). Gender differences in wealth have also been documented. Data on never-married older adults in Ireland show that men have significantly higher wealth levels than women (Barrett et al., 2011). Similarly, data from a number of Eurozone countries reveal that women have lower wealth than men, and invest in different types of assets (Sierminska, 2017). 
proportion of the population aged $65+$ in Ireland is 13 per cent (CSO, 2017a), below the EU-28 average of 19 per cent, but is projected to increase sharply to 18 per cent by 2030 (Wren et al., 2017). The state pension age was increased to 66 in 2014, and will increase further to 67 in 2021 and 68 in 2028 (Government of Ireland, 2010). This scheduled increase is considered to be rapid enough to compensate for projected increases in life expectancy and thus to keep the time spent in retirement relatively stable (OECD, 2014). However, women have longer life expectancy than men (although this gap has been narrowing over time) and they will therefore spend a longer time in retirement. ${ }^{2}$ In addition, women are more likely to be widowed, and to be living alone in older age (Barrett et al., 2011; Nivakoski and Nolan, 2019). Coupled with declines in the coverage and generosity of public and private pension schemes, this implies that older women will need to assume greater responsibility for their own financial security in older age.

The gender gap in pension cover and incomes is of policy concern both in Ireland and across the EU. The 2014 OECD Review of the Irish Pension System highlighted the importance of equity between men and women in the design of pension systems, while the 2010 National Pensions Framework noted that women are one of the priority groups targeted by the National Pensions Awareness Campaigns in attempts to increase pension cover (Government of Ireland, 2010; OECD, 2014). The EU has focused on gender issues in pensions in a number of publications in recent years (Bettio et al., 2013; Chłon-Domińczak, 2017; European Commission, 2018). The most recent European Commission report on pension adequacy notes that despite a fall in the gender pension gap since 2000 in most EU countries, the gap has remained persistently high in many countries since 2009. It notes that the gender pension gap mostly reflects gender pay inequalities (which lead to lifetime earnings inequality and result from differences in past employment, including work intensity and career breaks), and that pension system design characteristics manage to reduce these inequalities only to a limited extent (European Commission, 2018).

As the focus of this report is pensions and incomes in retirement, it is worth outlining briefly the key features of the Irish pension system. The system currently is a combination of three pillars: (i) state welfare pensions; (ii) occupational pensions; and (iii) private pensions. The state welfare pension aims to act as a safety net to keep retirees' incomes from falling below a certain threshold. The other two pillars are typically linked to earnings. State welfare pensions are flatrated and comprise the contributory and non-contributory state welfare pensions. To qualify for either of these, a person must have reached the state pension age (SPA) of 66 years. $^{3}$ Entitlements to contributory state welfare pensions are not means-tested and are determined over a person's career through the 
accumulation of Pay-Related Social Insurance (PRSI) contribution and credits. Contributory state pensions are financed through the Social Insurance Fund (SIF), which is funded by PRSI, with the Exchequer making up any shortfall.

The maximum contributory gross pension payable in 2010, when Wave 1 of the TILDA dataset was collected, was $€ 230.30$ per week, corresponding to $33.1 \%$ of average earnings (using the CSO Earnings and Labour Costs measure of average earnings). The non-contributory pension is means-tested and capped at a pre-tax rate of $€ 219$ per week. Furthermore, the non-contributory pension is not dependent on employment history and is financed through general taxation. In order to qualify for the non-contributory state welfare pension, a person must not be eligible for the contributory state welfare pension, must pass a means test based on both income and wealth, and must be habitually resident in Ireland (Nivakoski and Barrett, 2017).

Occupational pensions are common in the public sector and larger private sector firms; they are mainly statutory and the vast majority of the schemes are financed on a pay-as-you-go (PAYG) basis (Nivakoski and Barrett, 2017). There is no legal obligation for employers to provide occupational pension schemes. However, public service occupation pension schemes are in place for staff across the civil service, local authorities, Garda Síochána (Irish police), the defence forces, the health and education sectors and non-commercial state bodies. The private pension schemes are voluntary and include Retirement Annuity Contracts (RACs), which are commonly used by the self-employed, and Personal Retirement Savings Accounts (PRSAs), which were introduced in 2002 as an attempt to increase the pension coverage among low-coverage employee groups.

In this report, we focus on three key dimensions of the policy debate around gender and pensions in Ireland. Chapter 2 examines the gap in pension incomes of men and women and explores the causes for these differences using detailed decile decomposition methods and a unique dataset, the Irish Longitudinal Study on Ageing (TILDA), a nationally representative survey of persons aged 50 and over. ${ }^{4}$ Chapter 3 examines the characteristics of those living in income poverty in older age in Ireland, using data from the Survey of Income and Living Conditions (SILC) for 2015 and 2016. The analysis focuses in particular on the role that household composition may play in explaining why nearly 10 per cent of the over-65s are classified as income poor, despite social welfare payment levels that should be sufficient to keep older people above the poverty threshold. This chapter also examines in detail differences in income between older men and women in Ireland. Chapter 4 details the results of a literature review that summarises the international evidence on gender differences in key aspects of financial decision- 
making (preferences, financial literacy and household decision-making roles). This chapter also contains an overview of Irish data sources that contain information on preferences, financial literacy and household decision-making roles, and that may be used in future research on gender and economic outcomes in older age. ${ }^{5}$ Chapter 5 summarises the findings from the research programme, and draws out some implications for policy and future research.

5 A full examination of the extent to which gender differences in financial decision-making may also contribute to gender gaps in economic outcomes in older age is outside the scope of the current study. Previous literature provides some suggestions. For example, Neelakantan and Chang (2010) examine whether the unexplained portion of the gender gap in wealth at retirement can be attributed to gender differences in risk preferences. Using data from the US Health and Retirement Study (HRS), they show that the gender gap in wealth persists even when risk preferences are added to the set of controls. Sierminska (2017) shows that, with the exception of Italy, most of the gender gap in wealth in Eurozone countries can be explained by differences in the income, education and labour market characteristics of men and women. Ruel and Hauser (2013), using data from the Wisconsin Longitudinal Study on Ageing, show that most of the gender wealth gap is attributable to a lifetime of lower earnings for women. However, to the extent that there is also a gender wealth gap in married couple households, they argue that alternative explanations (such as gender differences in receipt of inheritances, and investment strategies) warrant further study. 



\section{CHAPTER 2}

\section{Gender gap in retirement incomes}

\subsection{INTRODUCTION}

Gender differences in earnings and wages have received vast consideration from both researchers and public policy. The issue of pension incomes receives much less attention than earnings despite shifting demographics making this an increasingly important issue for policy. The duration of working lives is rising over time and the duration of retirement is also expected to grow as life expectancy continues to increase. In the EU, on average the time spent in retirement is about half (51 per cent) of that spent in employment (European Commission, 2018). This ratio is expected to increase to 53 per cent by 2060 and this trend presents a challenge in terms of sustaining adequate pensions into the future. This chapter analyses the gender gap in pension income.

The gender gap in pensions is the percentage by which women's average pension income is lower than that for men. In 2016, a woman aged 65-79 in the EU-28 received a pension that was 38 per cent lower than that of her male counterpart; the corresponding figure for Ireland was 26 per cent (European Commission, 2018). Slight decreases in the gender pension gap have been observed in the EU on average since the financial crisis, from 41 per cent in 2009 to 38 per cent in 2016. A more pronounced decrease was shown for Ireland over the period 2009-2016 (from 38 per cent to 26 per cent). Nevertheless, gender differences in pension coverage and income remain persistent. The gender gap in pensions ranges from 2 per cent to 49 per cent across EU Member States. Cyprus, the Netherlands and Malta have the largest gaps (above 44 per cent), while the smallest gaps (below 10 per cent) are reported for Estonia, Denmark and Slovakia (European Commission, 2018).

An individual's pension income in retirement depends on a number of key factors, including (i) which type of pension they are entitled to (state, occupational, private), (ii) earnings, and (iii) pension contributions. However, other important life events can impact pension arrangements. For example, the onset of a permanent illness or disability that impedes an individual from working could have serious financial consequences in terms of pension income in retirement. The arrival of children could also lead to a parent taking time out of the workforce and/or shifting to working on a part-time basis, which could affect pension eligibility.

Pensions are an important determinant of economic independence. Older women are more likely than older men to live longer, live alone and have lower pension income (European Commission, 2018). As the EU population ages, the number and population share of older women (and single older women) will increase. The 
literature on gender pension gaps highlights the facts that women participate less in the labour market, work fewer hours and receive lower wages as the main contributing factors to the gender pension gap. Equal opportunities for women and men to obtain pension rights are influenced by both labour market and pension policies that support equal careers and earnings.

Although the gender pension gap is lower for new retirees, the gap has remained persistently high across many countries. The difference in career length is expected to narrow, but the effects of the multiple career gaps affecting women across numerous dimensions (pay, career duration, childcare breaks, part-time work, care for dependent adults) are likely to have a continued cumulative impact on the pension income of women into the future. Reducing the inequalities requires equal opportunity policies targeted at both women and men of working age in order to promote equal labour market access (for example, equal distribution of caring responsibilities, equal pay legislation and career break entitlements) and pension policies that adequately protect against care-related interruptions.

In this chapter, we utilise a unique nationally representative longitudinal study of adults in Ireland aged 50 and older, the Irish Longitudinal Study on Ageing (TILDA). The survey contains information on demographics, pension income and wealth, living arrangements, labour force and health status. This research makes the following contributions. First, we examine the pension income gap between men and women in Ireland. We find that the average total weekly pension income was $€ 280$ for females and €433 for males in 2010, implying a raw gender pensions earnings gap of approximately 35 per cent. The total gender pension gap is found to be mostly attributable to differences in incomes from private and occupational pensions.

Second, using the decomposition methods of Oaxaca (1973) and Blinder (1973), we explore the main causes for these pension income differences. For total pension income, the raw gender differential was 31 per cent, of which 7 per cent can be attributed to differences in the observable characteristics (age, nationality, human capital, labour market experience, marital status, number of children, location, etc.) of men and women. For occupational and private pensions, the raw gender differential was 43 per cent, of which 7 per cent can be attributed to differences in observable characteristics. Finally, when we restricted the sample to men and women with 20 or more years of work experience, the raw occupational and private gender pension gap fell to 38 per cent, of which 5 per cent can be explained by differences in observable characteristics.

Our final contribution is to carry out an unconditional decile decomposition on the gender pension gap using the technique devised by Firpo et al. (2009). Our decile analysis reveals that the total gender pension gap lies below the 31 per cent average in the lower deciles before increasing from 13 per cent at the fifth decile 
to 67 per cent at the sixth decile, and peaks at 77 per cent at the eighth decile. When we repeat the process for occupational and private pensions (restricting the sample to men and women with 20 or more years' work experience) we get a somewhat different picture: the gender pensions gap is greatest at 77 per cent in the first income decile and smallest at 18 per cent at the seventh decile. For occupational and private pensions, higher levels of female educational attainment had a declining impact on the gender pension gap in the upper deciles of the pension income distribution. ${ }^{6}$ In the seventh, eighth and ninth deciles, where approximately 25 to 45 per cent of the raw gap is explained, the principal factors contributing to the gap are found to be the lower relative years of work experience among women.

The remainder of the chapter is structured as follows. First, we provide a brief overview of the pension system in Ireland. In Section 2.3, we discuss the previous literature. Section 2.4 describes the data in more detail and how our samples are constructed. We also describe how we calculate the key variables of interest and the gender pension gap. In Section 2.5, we show the descriptive statistics and display the distribution of pension incomes of men and women. Furthermore, we present our findings from the decomposition methods for the mean using Oaxaca (1973) and Blinder (1973) techniques followed by the decile decomposition methods using the technique devised by Firpo et al. (2009). Section 2.6 gives a summary and some reflections on the policy implications.

\subsection{PENSION TYPES BY GENDER}

Chapter 1 described the Irish pension system, highlighting the key features of the system. Table 2.1 depicts the distribution of state, occupational and private pensions, and all forms of pension income combined by gender from the TILDA dataset. The first two columns in Table 2.1 relate to the entire TILDA Wave 1 dataset while the other columns relate to the reduced sample chosen for our analysis. Our sample accounts for 34 and 33 per cent of all men and women in Wave 1 of TILDA, respectively. This is due to our focus on those who are aged over 65 , retired and not currently employed. Of those in our sample, 88 per cent of men and 93 per cent of women were in receipt of the state pension; 55 per cent of men and 28 per cent of women were in receipt of occupational and private pensions. 


\begin{tabular}{|c|c|c|c|c|c|c|}
\hline \multirow[b]{2}{*}{ Pension type } & \multicolumn{2}{|c|}{$\begin{array}{c}\text { Total Wave } 1 \text { TILDA } \\
\text { Sample } \\
(\%)\end{array}$} & \multicolumn{2}{|c|}{$\begin{array}{c}\text { Sub-sample who are } 65+\text {, retired } \\
\text { and not employed } \\
(\%)\end{array}$} & \multicolumn{2}{|c|}{$\begin{array}{c}\text { Pension income } \\
\text { (€/week) }\end{array}$} \\
\hline & Men & Women & Men & Women & Men & Women \\
\hline State pension & 39 & 38 & 88 & 93 & 200 & 199 \\
\hline $\begin{array}{l}\text { Occupational and } \\
\text { private pensions }\end{array}$ & 29 & 15 & 55 & 28 & 233 & 82 \\
\hline $\begin{array}{l}\text { Any form of pension } \\
\text { income }\end{array}$ & 50 & 45 & 100 & 100 & 433 & 280 \\
\hline Observations & 3,655 & 4,307 & 1,257 & 1,410 & 1,257 & 1,410 \\
\hline
\end{tabular}

Source: $\quad$ The Irish Longitudinal Study on Ageing (TILDA), Wave 1 (age 66+, 2010).

Note: $\quad$ The sample chosen from the TILDA database includes those interviewed in Wave 1 in 2010, aged over 65, who are retired, not currently employed and did not receive a lump sum in this year (amounts to 34\% of Wave 1 participants, 2,667 of 7,962 observations).

The data show that the average weekly state pension income of men and women was broadly equal at approximately $€ 200$ per week (Table 2.1). However, a very substantial gap appears when we examine average weekly income from occupational and private pensions. At $€ 82$ per week, this income received by women was just over a third of the comparable average male payment. The much lower incidence of women in receipt of occupational and private pensions will certainly be a major factor in explaining the wide gender gap in weekly average incomes from this source. Finally, Table 2.1 indicates that the average total weekly pension income was $€ 280$ for women and $€ 433$ for men, implying a raw gender pensions earnings gap of approximately 35 per cent. It is obvious from the data that the total gender pension gap is largely attributable to the differences in average incomes generated by private and occupational pensions.

\subsection{PREVIOUS LITERATURE}

Given the vast literature related to the gender pay gap, ${ }^{7}$ relatively few studies have examined the factors that determine pension income for state, and occupational and private pensions separately. A comprehensive overview of pension differences between genders can be found in Bettio et al. (2013). The analysis conducted in this chapter is most similar to that of Even and Macpherson (1990), who explore the gap in occupational pensions in the US; Bardasi and Jenkins (2010), who examine the gap in private pensions in the UK; and Hanisch and Klos (2014), who investigate the gender pension gap in Germany.

Literature summaries and further information on gender differences in pay can be found in Plantega (2006) and Blau and Kahn $(2003,2006,2017)$. 
The results from the research to date are quite mixed. Even and Macpherson (1990) use probit and ordinary least squares (OLS) estimates to predict occupational pension coverage rates and benefit income levels when men and women assume the characteristics of one another, i.e. similar age, education, and work histories. They find a 45 per cent gender gap in pension income, which is not well explained without including income. ${ }^{8}$ However, if income is included, they find that gender differences in observed characteristics (income, job tenure, unionisation and full-time work status) explain between 69 and 81 per cent of the gap. ${ }^{9}$ Children and marriage were found to have a negative effect on female coverage among retirees (even after controlling for labour market characteristics); however, the negative effect is not observed among more recent groups of female employees. It is important to note that the data used in this study are from the 1980s and regression-based decomposition techniques are not employed. In contrast, Bardasi and Jenkins (2010) find a 76 per cent gap in pension income and that differences in returns, i.e. lower rewards for female characteristics, account for at least 80 per cent of the gap (only 20 per cent of the gap is explained) using Heckman selection models and Blinder-Oaxaca decomposition methods.

Hanisch and Klos (2014) use similar approaches to this chapter (OLS, BlinderOaxaca decomposition and quantile regressions) to analyse German data from 2007 , and report a gender pension gap of 60 per cent. They find that the explained component accounts for 26 per cent of the gap in mean pension income (employment and education contributing most to the explained gap). The magnitude of the gender pension gap is found to decline for increasing quantiles of the pension income distribution. Furthermore, the unexplained gap is larger than the explained gap in pension income, across the entire distribution. The proportion of the gap attributed to the explained component is largest at the bottom of the distribution. To the best of our knowledge, our study is the first to examine the gender pension gap using both regression-based decompositions and detailed decomposition techniques across deciles of the pension income distribution for Ireland.

\subsection{DATA AND METHODOLOGY}

\subsubsection{Data}

The data for this analysis come from TILDA, a nationally representative longitudinal study of adults in Ireland aged 50 and older. Approximately 8,000 individuals aged $50+$ were first surveyed in 2010, with a response rate of 62 per cent (Nivakoski and Barrett, 2017)..$^{10}$ The survey covers questions regarding demographics, income and

Even and Macpherson (1990) use income from the individual's longest job held as a control variable in three specific bands (less than $\$ 15,000, \$ 15,000-\$ 25,000$ and greater than $\$ 25,000$ ).

9 For those receiving a pension, they find a $\$ 3,260$ gender difference in the average benefit. If income is controlled for, $\$ 2,289$ of this gap can be explained by differences in labour market characteristics. Without income, only $\$ 736$ of the gap can be explained.

10 A further four waves of data collection occurred in 2012, 2014, 2016 and 2018. 
wealth, living arrangements, and labour force and health status. In this analysis, we use the first wave of TILDA to examine the gap in pension incomes of men and women and explore the causes for these differences using decomposition methods. Detailed information on the sources of pension income is collected within TILDA, making it an appropriate source of data for the purpose of this analysis.

We focus on respondents aged over 65 , who are retired and not currently employed. The total number of individuals in this category is 2,676. Another necessary restriction is to exclude people who received a pension lump sum in this year (due to how it is recorded within the weekly pension income), and for this reason our sample falls to 2,667 (which equates to 31 per cent of Wave 1 participants). This sample size is large enough to allow for a detailed examination of the pension income gap.

\subsubsection{Methodology}

The gender pension gap (GPG in equations below) is designed as a measure for the difference in pension income of women and men, following the research on the 'gender pay gap' that measures inequality in earnings (Flory, 2011). The gender pension gap measures the inequality of pension incomes as a percentage of the average female pension income in relation to the average male pension income:

$$
G P G=1-\left(\frac{\text { average own pension of women }}{\text { average own pension income of men }}\right) * 100
$$

Our analysis is based on the following pension income regression:

$$
\text { Ln Pension }_{i}=\alpha+P_{i} * \beta_{p}+H_{i} * \beta_{h}+\varepsilon_{i}
$$

where the log of weekly pension income of individual $i$ is regressed on a vector of personal $\left(P_{i}\right)$ and human capital $\left(H_{i}\right)$ variables. ${ }^{11}$ These include gender, age, education level, marital status, disability status, number of children, work experience (in years), nationality, living arrangements, location, and a dummy variable indicating time spent working abroad. The coefficient on gender from an OLS regression of Equation 2 gives an estimate of the gender pension gap, controlling for other personal, human capital and location characteristics.

11 We model the logarithm of pension income because the distribution is highly skewed with a long right tail, and taking logarithms makes the data approximately normally distributed. It is also conventional to use the natural logarithm of pension income in the regression analysis, rather than raw euro amounts, for easy interpretation of the statistical results. When the natural logarithm of pension income is regressed on respondents' characteristics in this way (as in Equation 2), the estimated coefficients give the approximate percentage change in pension income for a one-unit change in the explanatory factor. 
Based on our wage regression, we carry out two decomposition methods that are explained. The first is the classic decomposition by Oaxaca (1973) and Blinder (1973), which decomposes the mean pension incomes. Second is a method by Firpo et al. (2009) that decomposes the pension incomes in the spirit of Oaxaca and Blinder but can be applied at different deciles of the pension income distribution.

\section{Oaxaca-Blinder decomposition}

The methods of Oaxaca-Blinder (1973) decompose the mean gender pension gap into two parts: first, the part due to differences in the average endowments (e.g. education, employment years) and second, the part due to the differences in the returns to the endowments. These are usually referred to as the 'explained' and 'unexplained' parts, respectively.

For ease of exposition, let $X_{i}$ be a vector that includes both personal and human capital variables. By regressing the logarithm of pension income on the explanatory variables and rearranging the terms, we express the standard two-fold decomposition as

$G P G=\left(\bar{X}_{m}-\bar{X}_{f}\right) * \beta^{*}+\left[\bar{X}_{m} *\left(\hat{\beta}_{m}-\beta^{*}\right)+\bar{X}_{f}\left(\beta^{*}-\hat{\beta}_{f}\right)\right]$

where $\bar{X}_{m}$ and $\bar{X}_{f}$ represent the average endowments for men and women, and $\hat{\beta}_{m}$ and $\hat{\beta}_{f}$ represent the respective coefficient vectors for men and women from the pension income regressions. $\beta^{*}$ represents the objective 'non-discriminatory' coefficient vector. Setting $\beta^{*}=\hat{\beta}_{m}$ and choosing men as the reference group to investigate how women's pensions deviate from those of men, the Oaxaca-Blinder decomposition yields

$$
G P G=\left(\bar{X}_{m}-\bar{X}_{f}\right) * \hat{\beta}_{m}+\left(\hat{\beta}_{m}-\hat{\beta}_{f}\right) * \bar{X}_{f}
$$

where the average pension difference between men and women (GPG) decomposes into an 'explained' part due to differences in characteristics $\left[\left(\bar{X}_{m}-\bar{X}_{f}\right) * \hat{\beta}_{m}\right]$ and an 'unexplained' part due to gender differentials in the returns to average characteristics $\left[\left(\hat{\beta}_{m}-\hat{\beta}_{f}\right) * \bar{X}_{f}\right]$. The unexplained component is generally considered as evidence of discrimination; however, it is important to note that it also encapsulates gender differentials in any important variables (observables or unobservables) omitted from the model specification.

\section{Unconditional decile decomposition}

While the Oaxaca-Blinder technique allows us to decompose the gender pension gap at the mean, it does not allow us to assess the degree to which the gender pension gap, or the factors that determine it, vary across the pension 
distribution. To address this issue we employ a technique proposed by Firpo et al. (2009) to extend the methodology of Oaxaca and Blinder to decompose the pension gap across the entire pension distribution. For more detailed information on decomposition methods, focusing particularly on such decompositions beyond the mean, please see Fortin et al. (2011).

In a standard OLS regression, the $\beta$ coefficient can be interpreted as the effect of a change in $X$ on the unconditional mean of $Y$. As such, OLS regressions can be used in the Oaxaca decomposition to examine the unconditional mean difference in gender pensions. However, the $\beta$ coefficient from a quantile regression of $Y$ on $X$ gives the effect of a change in $X$ on the conditional quantile, thereby making the unconditional quantile decomposition less straightforward than a standard Oaxaca decomposition. The method proposed by Firpo et al. (2009) overcomes this difficulty.

The Firpo et al. (2009) technique can be outlined in three stages. In the first stage, the re-centred influence function (RIF) of the unconditional quantile of the dependent variable is calculated. Denoting $q_{\tau}$ as the $\tau^{t h}$ quantile of interest, the RIF is derived by first calculating the influence function (IF) as follows:

$$
I F=\left(\tau-1\left\{Y \leq q_{\tau}\right\}\right) / f_{y}\left(q_{\tau}\right)
$$

where $Y$ denotes the dependent variable, in our case the log of weekly pension income, $f_{y}\left(q_{\tau}\right)$ is the density at point $q_{\tau}$, and $1\left\{Y \leq q_{\tau}\right\}$ is a dummy variable indicating whether $Y$ is less than or equal to $q_{\tau}$. To get the RIF, one adds back the quantile to the IF, such that $R I F=q_{\tau}+I F$.

In the second stage, the RIF is used as a dependent variable in the wage regression. The resulting $\beta$ from the RIF regression captures the marginal effect of a change in $X$ on the unconditional quantile of $Y$. Finally, in the third stage, a standard Oaxaca decomposition is carried out on the RIF regression, which yields the unconditional quantile decomposition.

Unlike earlier decomposition approaches (for example, Machado and Mata (2005)), the Firpo et al. (2009) method not only allows for the estimation of the 'explained' and 'unexplained' gap but also allows us to break these down further to identify the contributions of the individual explanatory variables in a more straightforward way. 


\subsection{RESULTS}

\subsubsection{Men's and women's pension income}

Table 2.2 examines gender differences in key personal and labour market characteristics for the total sample and then separately for individuals in receipt of (a) the state pension and (b) occupational and private pensions. ${ }^{12}$ Within both the total sample and the sample restricted to individuals in receipt of the state pension there is a higher proportion of females aged 75 and above; the age profile of men and women in receipt of occupational and private pensions is more similar. Women in all three categories were more likely to be widowed and less likely to be married relative to their male counterparts. Consistent with this, women in receipt of both pensions are much more likely to be living alone.

For both categories of pension, men were more likely to be educated to primary level alone, while for those in receipt of an occupational and private pension, women were somewhat more likely to hold third-level qualifications. In terms of labour market variables, 3 per cent of men in the sample reported having never worked compared to 22 per cent of women. For those with positive work experience, 4 per cent of men have worked between 1 and 30 years compared to 45 per cent of women; 93 per cent of men have more than 30 years' work experience compared to 33 per cent of women. These gender-based variations in work histories are likely to explain the observed gap in both the incidence and value of occupational and private pensions and may have implications for state pensions, as the contributory component is calculated based on the number of years spent in the labour market (see Chapter 1 ).

12 In the TILDA dataset (Wave 1), some individuals in receipt of the state pension will also be in receipt of occupational and private pensions; most of the individuals in receipt of an occupational and private pension will also be in receipt of a state pension. 
TABLE 2.2 CHARACTERISTICS OF MEN AND WOMEN: (I) TOTAL SAMPLE, (II) STATE PENSIONS, AND (III) OCCUPATION AND PRIVATE PENSIONS

\begin{tabular}{|c|c|c|c|c|c|c|}
\hline \multirow[t]{2}{*}{ Category } & \multicolumn{2}{|c|}{ All } & \multicolumn{2}{|c|}{ State } & \multicolumn{2}{|c|}{$\begin{array}{l}\text { Occupational \& private } \\
\text { (restricted sample) }\end{array}$} \\
\hline & Men & Women & Men & Women & Men & Women \\
\hline Age (base: aged 65-69) & 0.32 & 0.28 & 0.29 & 0.27 & 0.40 & 0.39 \\
\hline Aged 70-74 & 0.30 & 0.28 & 0.30 & 0.28 & 0.29 & 0.29 \\
\hline Aged 75+ & 0.38 & 0.44 & 0.41 & 0.45 & 0.31 & 0.32 \\
\hline Education (base: primary) & 0.48 & 0.45 & 0.62 & 0.52 & 0.41 & 0.32 \\
\hline Secondary & 0.30 & 0.35 & 0.28 & 0.35 & 0.32 & 0.35 \\
\hline Third level & 0.22 & 0.20 & 0.10 & 0.13 & 0.27 & 0.33 \\
\hline Marital status (base: single) & 0.11 & 0.08 & 0.15 & 0.06 & 0.11 & 0.15 \\
\hline Married & 0.69 & 0.44 & 0.63 & 0.44 & 0.70 & 0.51 \\
\hline Separated or divorced & 0.04 & 0.03 & 0.04 & 0.04 & 0.04 & 0.05 \\
\hline Widow & 0.16 & 0.45 & 0.18 & 0.46 & 0.15 & 0.29 \\
\hline No. of children & 3.07 & 3.51 & 2.92 & 3.66 & 3.06 & 2.67 \\
\hline Not born in Ireland & 0.07 & 0.07 & 0.06 & 0.06 & 0.08 & 0.12 \\
\hline Lived abroad & 0.26 & 0.23 & 0.25 & 0.22 & 0.29 & 0.30 \\
\hline Living arrangements (base: alone) & 0.26 & 0.43 & 0.31 & 0.42 & 0.25 & 0.40 \\
\hline Living with spouse & 0.57 & 0.38 & 0.52 & 0.38 & 0.58 & 0.44 \\
\hline Living with others & 0.17 & 0.19 & 0.17 & 0.20 & 0.17 & 0.16 \\
\hline Location (base: Dublin) & 0.25 & 0.25 & 0.19 & 0.24 & 0.26 & 0.29 \\
\hline Other urban & 0.30 & 0.28 & 0.27 & 0.28 & 0.31 & 0.31 \\
\hline Rural & 0.45 & 0.47 & 0.54 & 0.48 & 0.43 & 0.40 \\
\hline Disability & 0.17 & 0.21 & 0.19 & 0.22 & 0.15 & 0.19 \\
\hline Never worked (0 years) & 0.03 & 0.22 & 0.03 & 0.25 & - & - \\
\hline \multicolumn{7}{|l|}{ Work experience (years) } \\
\hline $1-10$ years & 0.02 & 0.19 & 0.02 & 0.20 & - & - \\
\hline $11-20$ years & 0.00 & 0.14 & 0.00 & 0.15 & - & - \\
\hline 21-30 years & 0.02 & 0.12 & 0.03 & 0.12 & - & - \\
\hline $31-40$ years & 0.16 & 0.15 & 0.13 & 0.12 & - & - \\
\hline $41-50$ years & 0.50 & 0.13 & 0.46 & 0.10 & - & - \\
\hline $51+$ years & 0.27 & 0.05 & 0.33 & 0.06 & - & - \\
\hline Work years (20-35 years) & 0.07 & 0.21 & 0.07 & 0.19 & 0.10 & 0.50 \\
\hline Work years ( $35-50$ years) & 0.62 & 0.21 & 0.54 & 0.17 & 0.90 & 0.50 \\
\hline Observations & 1,257 & 1,410 & 772 & 1,162 & 955 & 690 \\
\hline
\end{tabular}

Source: The Irish Longitudinal Study on Ageing (TILDA), Wave 1 (age 66+, 2010).

Note: $\quad$ Sample is restricted to individuals with occupational and private pension income who have work experience of between 20 and 50 years. 


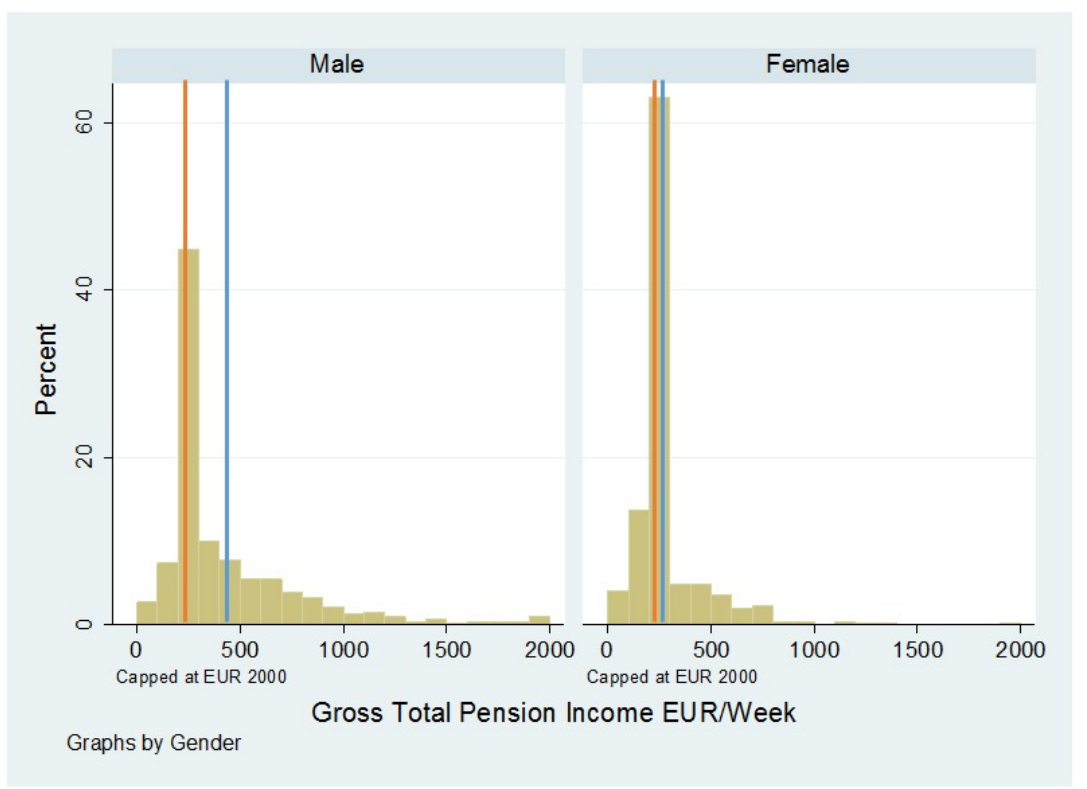

Source: The red lines indicate the Contributory State Pension in 2010 at $230 € /$ week; the blue lines indicate the mean pension income for males and females, separately.

Note: $\quad$ The Irish Longitudinal Study on Ageing (TILDA), Wave 1 (age 66+, 2010).

Figure 2.1 shows the distribution of weekly pension incomes for men and women. The male distribution of average weekly pension income lies well above the state pension level of $€ 230$, which reflects the high proportion of men in receipt of occupational and private pensions. Conversely, within the female distribution, the mean weekly pension income lies close to the state pension level, reflecting the fact that females are less likely than males to hold supplementary occupational and private pensions. The proportion of women with pension incomes above $€ 500$ per week is low compared to men, demonstrating that the occupational and private pensions received by women are, on average, lower than those received by men.

Figure 2.2 shows the distribution of state pension by gender. While the vast majority of both genders earn at or below the standard state pension level of $€ 230$, higher proportions of men receive incomes in excess of $€ 300$ per week, which is likely to reflect a higher incidence of additional payments for qualified adults. ${ }^{13}$ Higher proportions of women are also less likely to qualify for the full state pension, presumably due to the fact that they, on average, likely spend fewer years in employment compared to males. ${ }^{14}$ Figure 2.3 shows the distribution of occupational and private pensions and demonstrates that women are much more likely not to have any income from this source and much less likely to have weekly incomes from occupational and private pensions in excess of $€ 500$ per week.

13 These are likely to be spouses and the higher incidence reflects the finding that males in the sample are less likely to be widowed.

14 The level of contributory pension paid will depend on PRSI contributions made while in employment. Pensioners can also apply for non-contributory state pensions; however, the benefit is means-tested and may also result in a weekly payment below the maximum. 
Figures A1 to A4 in the appendix show the pension income densities of men and women overlapped to provide an alternative graphical representation of the relative pension distributions.

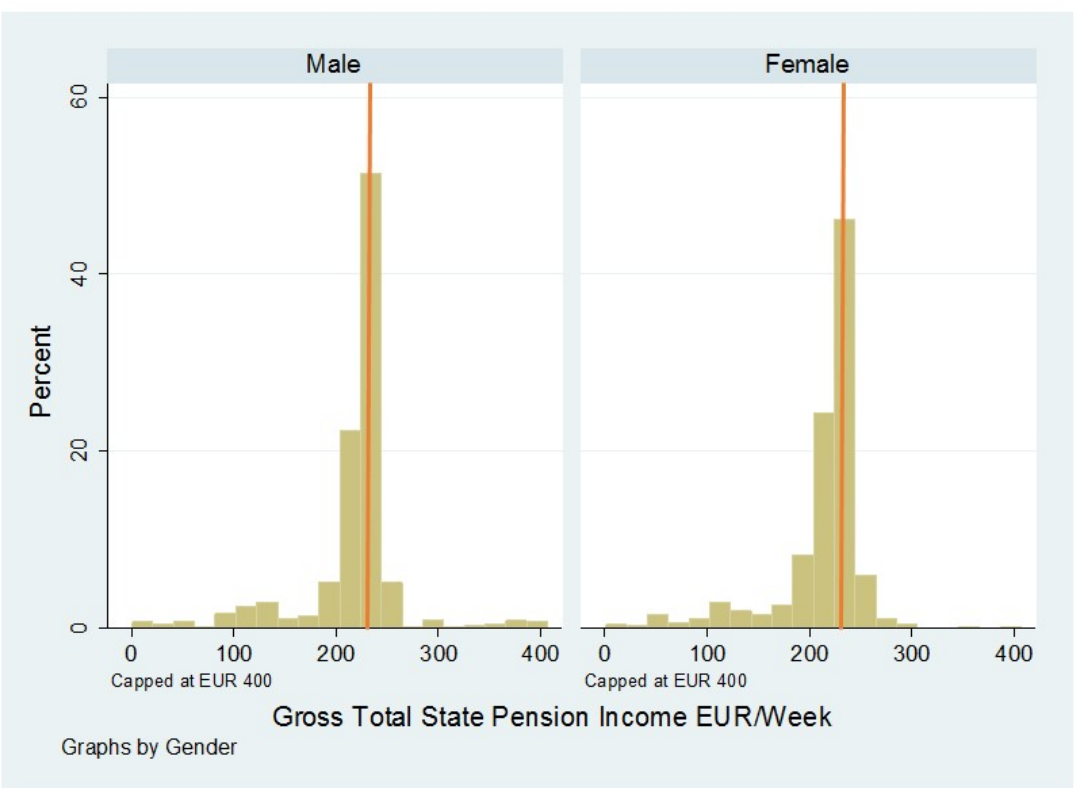

Source: $\quad$ The Irish Longitudinal Study on Ageing (TILDA), Wave 1 (age 66+, 2010).

Note: $\quad$ The red lines indicate the Contribution State Pension in 2010 at $€ 230 / w e e k$.

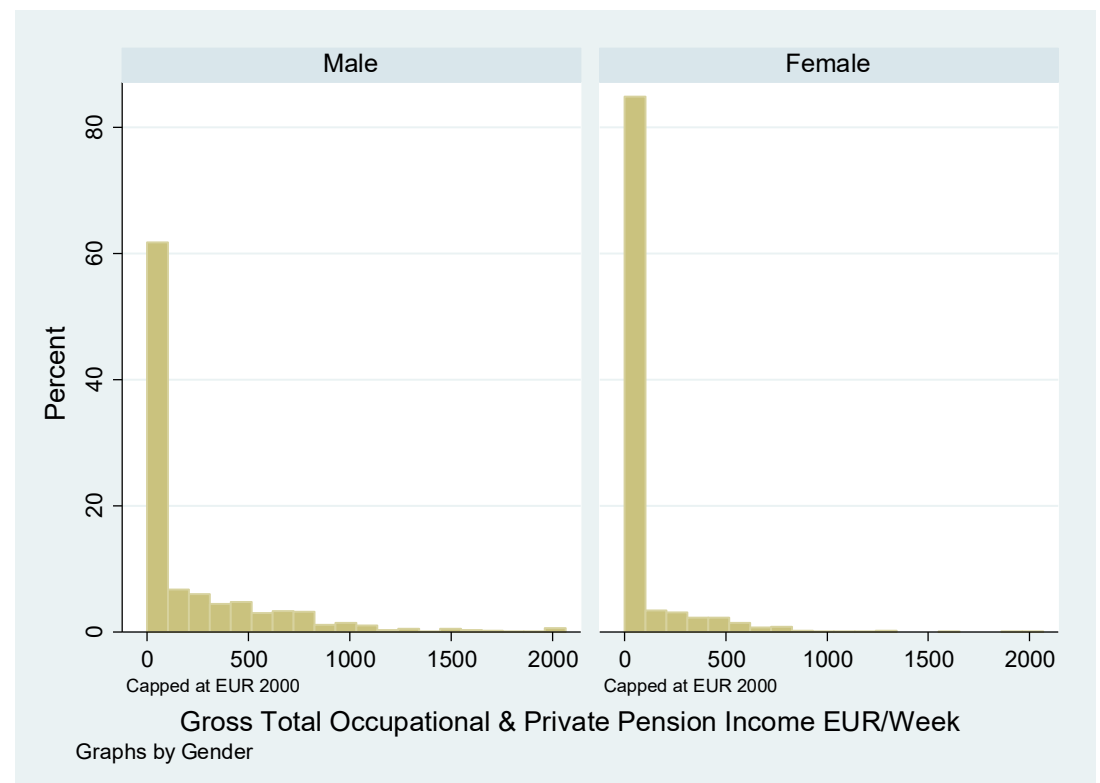

Source: $\quad$ The Irish Longitudinal Study on Ageing (TILDA), Wave 1 (age 66+, 2010). 
To get an initial indication of the personal and labour market characteristics that are important in determining pension incomes, and the extent to which gender differences remain after these characteristics are controlled for, we estimate pooled OLS models for the total pension, state pension, and occupational and private pension income samples in Table 2.3. Beginning with the model for total pension income (Column 1), the equation is well specified and explains 25 per cent of the total variation in incomes observed in the sample. The results show that the total pension income of individuals aged over 70 are 6 to 7 per cent lower than those in the 65 to 69 category. Compared to pensioners educated to primary level, total pension income was 17 per cent higher for those with secondary education and 57 per cent higher for graduates. With respect to marital status, compared to single pensioners, those who were separated or divorced (widowed) received 17 (9) per cent less (more). Relative to Irish nationals, the total pension incomes of those who were born outside Ireland was a third lower while those who had lived abroad experienced an 8 per cent income disadvantage. Pensioners residing in Dublin had higher incomes than those in other urban and rural areas; at 24 per cent the pension income disadvantage income was greatest for those in rural areas. As expected, the number of years spent in employment was an important determinant of total pension incomes.

Compared to pensioners with between 0 and 10 years' work experience, those with 31 to 40 and 41 to 50 years work experience received 16 and 12 per cent more each week respectively. After controlling for all these factors, the total weekly pension income of women was 30 per cent lower than that of men. 


\begin{tabular}{|c|c|c|c|}
\hline \multicolumn{2}{|l|}{ Dependent variable: Ln(pension income) } & \multicolumn{2}{|c|}{ ension type } \\
\hline Category & All & State & Occ./Priv. \\
\hline Female & $-0.30 * * *$ & $-0.04 *$ & $-0.44 * * *$ \\
\hline \multicolumn{4}{|l|}{ Age (base: aged 65-69) } \\
\hline Aged 70-74 & $-0.07 * * *$ & -0.02 & $-0.27 * * *$ \\
\hline Aged 75+ & $-0.06 * *$ & $-0.05^{* *}$ & $-0.21 * * *$ \\
\hline \multicolumn{4}{|l|}{ Education (base: primary) } \\
\hline Secondary & $0.17 * * *$ & $-0.04 * *$ & $0.65 * * *$ \\
\hline Third level & $0.57^{* * *}$ & $-0.07^{* *}$ & $1.36 * * *$ \\
\hline \multicolumn{4}{|l|}{ Marital status (base: single) } \\
\hline Married & 0.03 & -0.04 & 0.10 \\
\hline Separated or divorced & $-0.17 * * *$ & -0.04 & $-0.40 *$ \\
\hline Widow & $0.09 * *$ & -0.01 & 0.08 \\
\hline No. of children & $0.01 * *$ & 0.01 & 0.01 \\
\hline Not born in Ireland & $-0.34 * * *$ & $-0.09 * * *$ & $-0.51 * * *$ \\
\hline Lived abroad & $-0.08 * * *$ & $-0.09 * * *$ & $-0.18 * *$ \\
\hline \multicolumn{4}{|l|}{ Living arrangements (base: alone) } \\
\hline Living with spouse & -0.03 & -0.02 & -0.02 \\
\hline Living with others & -0.01 & -0.02 & -0.03 \\
\hline \multicolumn{4}{|l|}{ Location (base: Dublin) } \\
\hline Other urban & $-0.10 * * *$ & -0.04 & 0.08 \\
\hline Rural & $-0.24 * * *$ & $-0.06 * *$ & $-0.30 * * *$ \\
\hline Disability & $-0.07 * *$ & -0.01 & -0.11 \\
\hline \multicolumn{4}{|l|}{ Work experience (base: 0-10 years) } \\
\hline $11-20$ years & -0.07 & 0.03 & -0.23 \\
\hline $21-30$ years & -0.03 & -0.03 & -0.16 \\
\hline $31-40$ years & $0.16^{* * *}$ & 0.01 & $0.30 * *$ \\
\hline $41-50$ years & $0.12 * * *$ & -0.02 & $0.25^{*}$ \\
\hline $51+$ years & -0.05 & -0.02 & -0.16 \\
\hline Constant & $5.76 * * *$ & $5.49 * * *$ & $4.88 * * *$ \\
\hline Dependent var. (log pensions $€ /$ week) & 5.65 & 5.32 & 5.30 \\
\hline Adj. $R$-squared & 0.25 & 0.02 & 0.25 \\
\hline Sample size & 2,664 & 1,931 & 1,115 \\
\hline
\end{tabular}

Source: $\quad$ The Irish Longitudinal Study on Ageing (TILDA), Wave 1 (age 66+, 2010).

Note: $\quad * * *, * * *$ denote significance at the $10 \%, 5 \%$ and $1 \%$ significance levels.

When the models are estimated for state and private occupational pension incomes separately (Columns 3 and 4), it becomes apparent that the gender pension gap is driven entirely by differences in occupational and private pensions. Examining the state pension equation (Column 3 ) in closer detail, after controlling for other factors, weekly state pension payments for women were 4 per cent lower than men, however, the result was not statistically significant beyond a 10 per cent confidence level. Given this, we can conclude that there is no consistent evidence of a gender state pension gap. Nevertheless, other aspects of the state pension model are worth discussing. 
As expected, weekly state pension incomes were just under 10 per cent lower for individuals who either were born or worked abroad, due, presumably, to a lower accumulation of PRSI contributions. Interestingly, compared to those with primarylevel education, individuals with higher levels of schooling receive between 4 and 7 per cent less per week. The results on educational attainment could reflect the impacts of early retirement on the contributory state pension, or greater assets on the means tested non-contributory state pension. Finally, pensioners in rural areas receive 6 per cent less in payments compared to those in Dublin and, while no clear explanation exists, this effect may be partially driven by lower accumulated PRSI contributions among previously self-employed agricultural workers.

Turning to the occupational and private pension results (Column 4), these heavily correspond with the model for total pension incomes. Occupational and private income are positively related to education and years of work experience, and negatively related to age and having been born, or lived, abroad. After controlling for all other factors, female weekly occupational and private pensions were 44 per cent lower than those of their male equivalents.

The results from the multivariate analysis confirm that there is little evidence of a gender gap in state pension payments, with the significantly lower total pension incomes of women explained almost entirely by deficits in occupational and private pension income. For the remainder of the chapter we largely focus on decomposing the income from occupational and private pensions in order to get some sense of the potential determinants of the observed pension income gap.

As could be seen from our earlier models, the number of years worked is a key determinant of occupational and private incomes and, by extension, total pension income. Table 2.4 shows that 55 per cent of women in the total sample have between 0 and 20 years' work experience compared to just 5 per cent of males. Of these, 22 per cent of women and 3 per cent of men had zero years of work experience (see Table 2.2), suggesting that 33 per cent of women and just 1 per cent of men had between 1 and 20 years of labour market experience. Such an imbalance in work-life histories will, almost by definition, generate a substantial gender gap in occupational and private pension incomes. Consequently, it is more informative to examine the data using a sample with overlapping work-life profiles when decomposing the gender gap in occupation and private pension income. 


\begin{tabular}{|l|c|c|c|c|c|c|}
\hline Work experience & \multicolumn{5}{|c|}{ Pension type } \\
\hline & Men & Women & Men & Women & Men & Women \\
\hline Average work years & 44.66 & 20.70 & 45.29 & 18.87 & 44.37 & 19.82 \\
\hline Work experience (years) & & & & & & \\
\hline $\mathbf{0 - 1 0}$ & 0.05 & 0.41 & 0.05 & 0.45 & 0.05 & 0.43 \\
\hline $\mathbf{1 1 - 2 0}$ & 0.00 & 0.14 & 0.00 & 0.15 & 0.00 & 0.14 \\
\hline $\mathbf{2 1 - 3 0}$ & 0.02 & 0.12 & 0.03 & 0.12 & 0.02 & 0.11 \\
\hline $\mathbf{3 1 - 4 0}$ & 0.16 & 0.15 & 0.13 & 0.12 & 0.17 & 0.14 \\
\hline $\mathbf{4 1 - 5 0}$ & 0.50 & 0.13 & 0.46 & 0.10 & 0.50 & 0.13 \\
\hline $\mathbf{5 1 +}$ & 0.27 & 0.05 & 0.33 & 0.06 & 0.26 & 0.05 \\
\hline Total & 100.0 & 100.0 & 100.0 & 100.0 & 100.0 & 100.0 \\
\hline Sample size & 1,257 & 1,410 & 772 & 1,162 & 1,389 & 1,719 \\
\hline
\end{tabular}

Source: $\quad$ The Irish Longitudinal Study on Ageing (TILDA), Wave 1 (age 66+, 2010)

TABLE 2.5 DISTRIBUTION OF WORK EXPERIENCE (YEARS) FOR OCCUPATION AND PRIVATE PENSION BY GENDER

\begin{tabular}{|l|c|c|c|c|}
\hline \multicolumn{5}{|c|}{$\begin{array}{c}\text { Occupational \& private pensions } \\
\text { (restricted sample) }\end{array}$} \\
\hline Work experience (years) & Men & Women & Total & Sample size \\
\hline $\mathbf{2 0 - 3 5}$ & 0.22 & 0.78 & 100.0 & 444 \\
\hline $\mathbf{3 6 - 5 0}$ & 0.71 & 0.29 & 100.0 & 1,201 \\
\hline Total & 0.58 & 0.42 & 100.0 & 1,645 \\
\hline
\end{tabular}

Source: $\quad$ The Irish Longitudinal Study on Ageing (TILDA), Wave 1 (age 66+, 2010).

From Figures 2.4 and 2.5, which plot years worked against weekly occupational and private pension income, we can see that there are virtually no cases of males in the data with less than 20 work years and, consequently, we use this as our cut-off point for our restricted sample for occupation and private pensions. 
FIGURE 2.4 DISTRIBUTION OF LOGGED OCCUPATIONAL AND PRIVATE PENSION INCOMES (€/WEEK) BY WORK EXPERIENCE (YEARS)

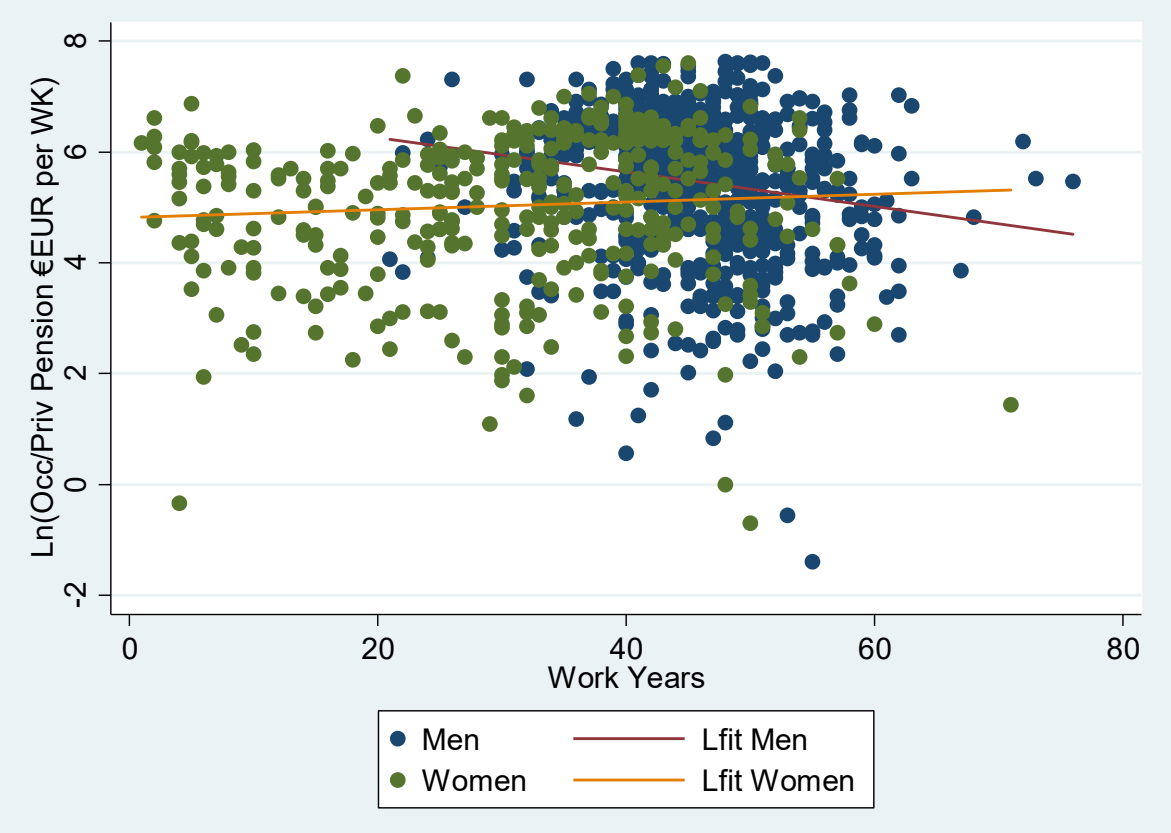

Source: The Irish Longitudinal Study on Ageing (TILDA), Wave 1 (age 66+, 2010).

FIGURE 2.5 DISTRIBUTION OF OCCUPATIONAL AND PRIVATE PENSION INCOMES (E/WEEK) BY WORK EXPERIENCE (YEARS)

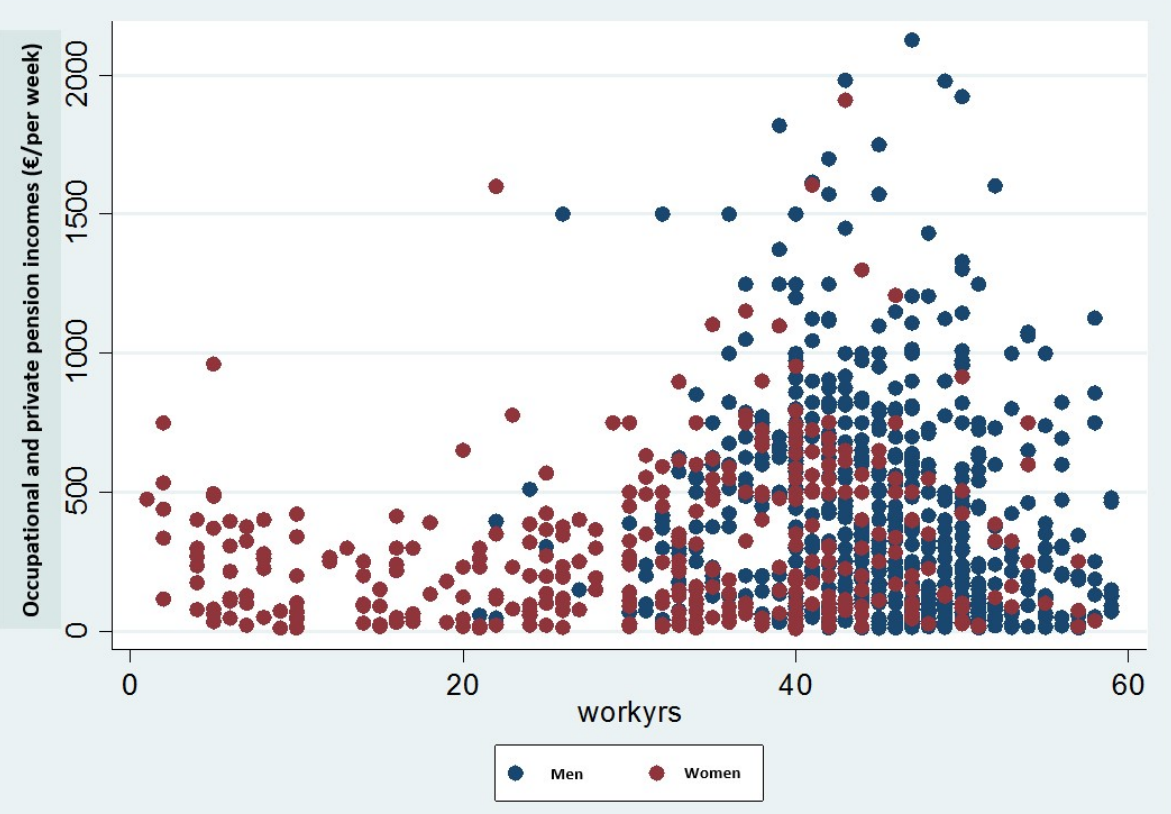

Source: $\quad$ The Irish Longitudinal Study on Ageing (TILDA), Wave 1 (age 66+, 2010). 


\subsubsection{Decomposition analysis}

\section{Results of the decomposition at the mean}

The results from the Oaxaca decomposition are presented in Table 2.6. With respect to total pension income, the raw gender differential was 30.7 per cent, ${ }^{15}$ of which 6.6 per cent can be attributed to differences in the observable characteristics of men and women, leaving an unexplained total gender pension gap of 24.1 per cent. ${ }^{16}$

For the sample of individuals in receipt of occupational and private pensions, the raw gender differential was 42.6 per cent, of which 7.4 per cent can be attributed to differences in observable characteristics, leaving an unexplained gap of 35.2 per cent. Finally, when we restrict the sample to individuals with 20 or more years' work experience, the raw occupational and private gender pension gap was 38.3 per cent, of which 5.3 per cent can be explained, leaving an unexplained gender gap of 33 per cent.

\begin{tabular}{|c|c|c|c|}
\hline Pension type & All & $\begin{array}{l}\text { Occupational \& } \\
\text { private }\end{array}$ & $\begin{array}{l}\text { Occupational \& private } \\
\text { (restricted sample) }\end{array}$ \\
\hline Raw differential & 30.7 & 42.6 & 38.3 \\
\hline Explained & 6.6 & 7.4 & 5.3 \\
\hline \multicolumn{4}{|l|}{ Unexplained } \\
\hline Due to coefficients & 0.8 & 35.3 & -9.0 \\
\hline Due to shift coefficient & 23.3 & -0.0 & 42.0 \\
\hline
\end{tabular}

\section{Results for the decile decomposition}

The above decompositions measure the gender pensions gap at the sample mean only and ignore the possibility that the measure will vary across the pension income distribution.

Figure 2.6 presents the estimated raw gender gap in total pension incomes generated by an unconditional decile regression. The total gender pension gap lies below the 31 per cent average in the lower deciles before increasing from 13.4 per

15 The raw gender wage gap is shown here in log points, which can be interpreted as an approximation of the percentage difference. Using the transformation $\left(e^{\beta-1}\right)$ when interpreting the coefficients, the implied exact percentage increase of the estimate is 35 per cent. The approximation is a lower bound.

16 In comparing the regression outputs for men and women, it is clear that men have higher constants and this is reflected in the $23.3 \%$ shift coefficient. 
cent at the fifth decile to 67.4 per cent (driven by the occupational and private pension income) at the sixth decile. The total pension gender income gap peaks at 76.5 per cent at the eighth decile.

When we repeat the process for occupational and private pensions (restricted sample) we get a somewhat different picture (Figure 2.7). The gender pension gap is greatest at 77.2 per cent in the 1 st decile and smallest at 18.1 per cent at the 7 th income decile.

\section{FIGURE 2.6 GENDER DIFFERENTIAL OF TOTAL PENSION INCOME (STATE, OCCUPATIONAL AND PRIVATE) BY DECILE}

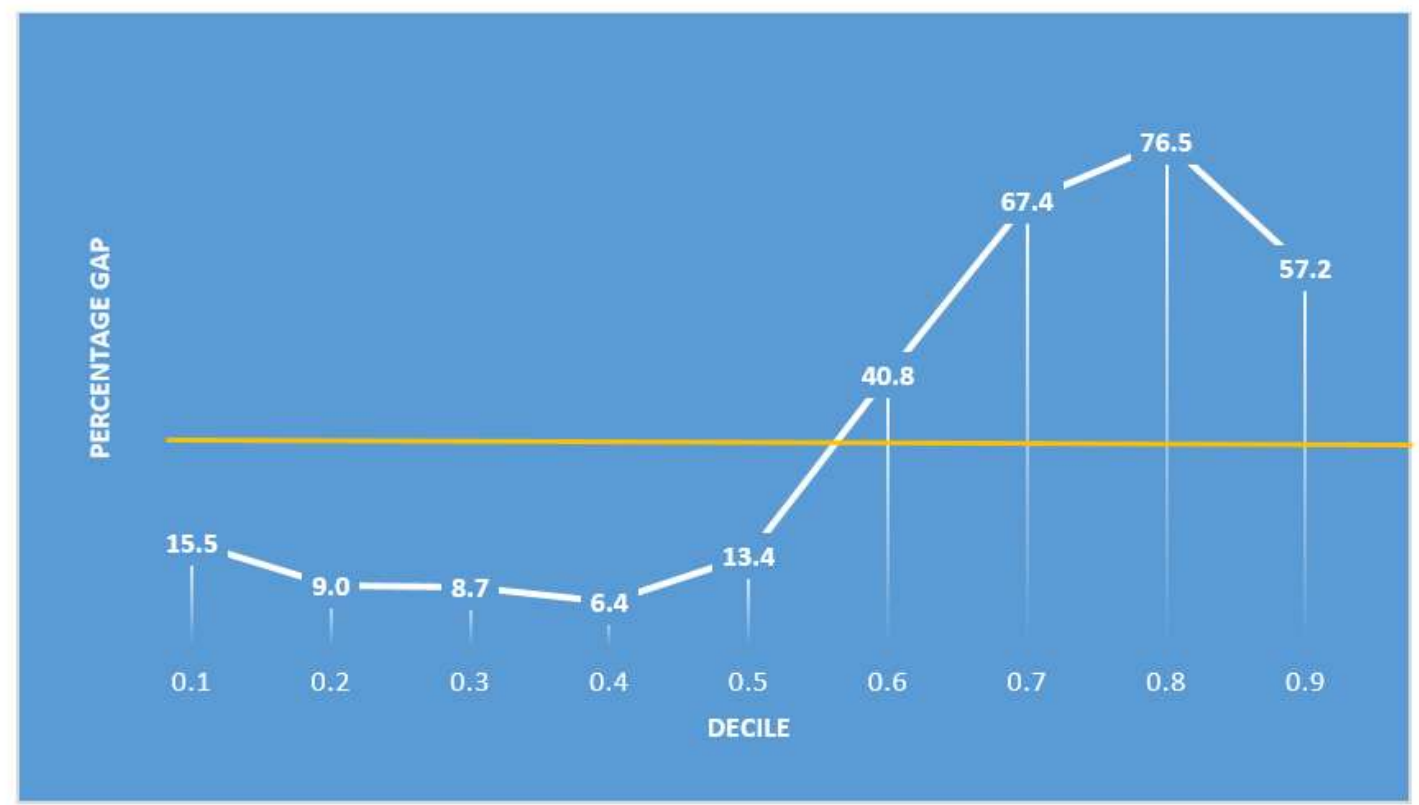

Source: The Irish Longitudinal Study on Ageing (TILDA), Wave 1 (age 66+, 2010). 
FIGURE 2.7 GENDER DIFFERENTIAL OF OCCUPATIONAL AND PRIVATE PENSION INCOME BY DECILE (RESTRICTED SAMPLE: 20-50 WORK YEARS)

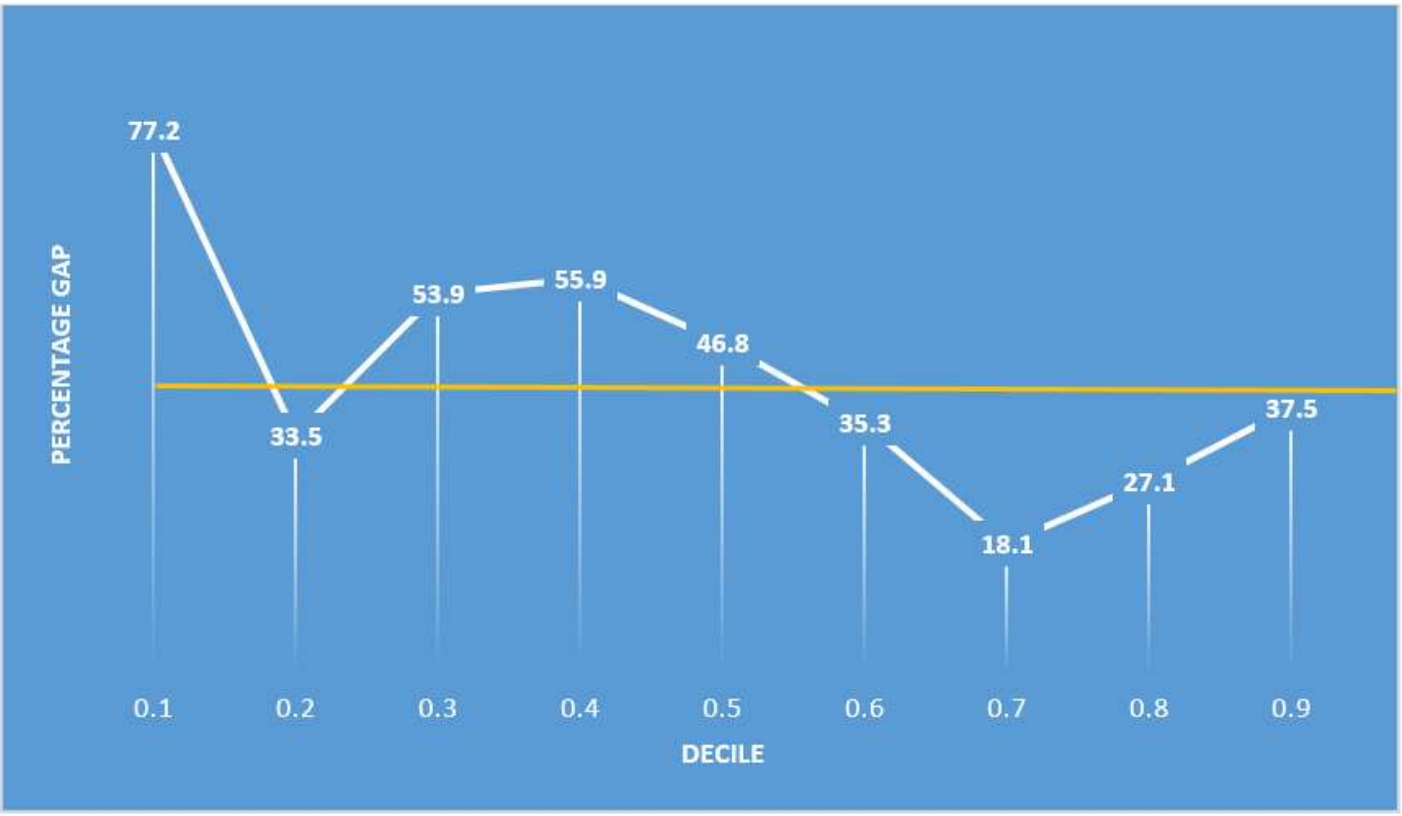

Source: The Irish Longitudinal Study on Ageing (TILDA), Wave 1 (age 66+, 2010).

Note: $\quad$ The sample is restricted to individuals with occupational and private pension income who have work experience of between 20 to 50 years.

Figures 2.8 and 2.9 plot the raw and unexplained gap by decile; the difference between the two represents the proportion of the gender pension gap that is explained by differences in the observable characteristics of men and women.

Figure 2.8 shows that the raw and unexplained gap component of the total gender pension gap is relatively constant at around 5 percentage points throughout the distribution; however, the percentage of the raw gap explained is lower in the upper quantiles by virtue of the fact that the raw gap tends to be larger in those regions. Figure 2.9 shows that differences in observable characteristics explain some of the occupational and private gender pension gap in the first two deciles, very little (or none) of the gap in the third to sixth decile range and a more substantial proportion of the gap at the seventh, eighth and ninth deciles. 


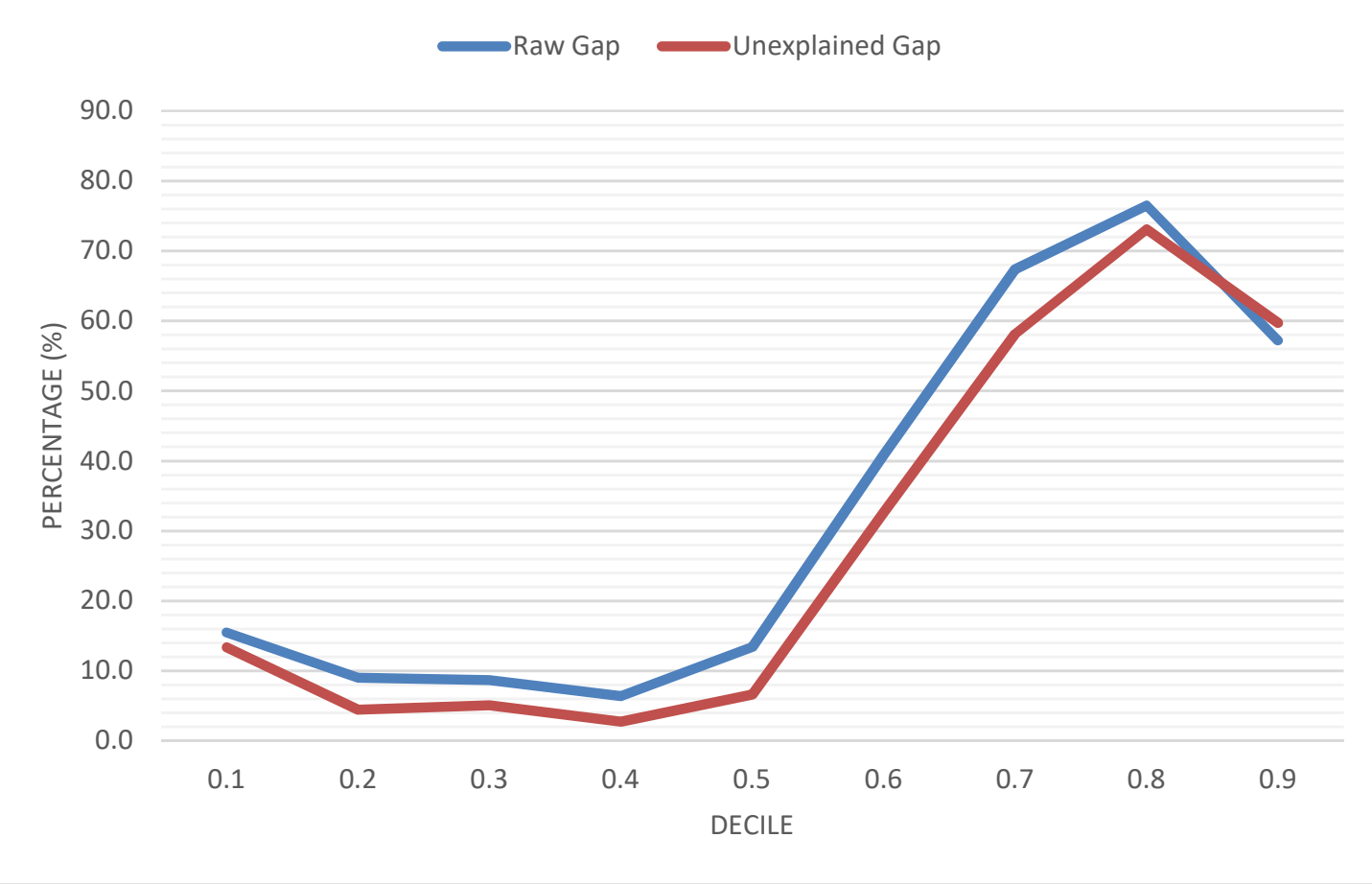

Source: $\quad$ The Irish Longitudinal Study on Ageing (TILDA), Wave 1 (age 66+, 2010).

FIGURE 2.9 GENDER DIFFERENTIAL OF OCCUPATIONAL AND PRIVATE PENSION INCOME BY DECILE (RESTRICTED SAMPLE: 20-50 WORK YEARS)

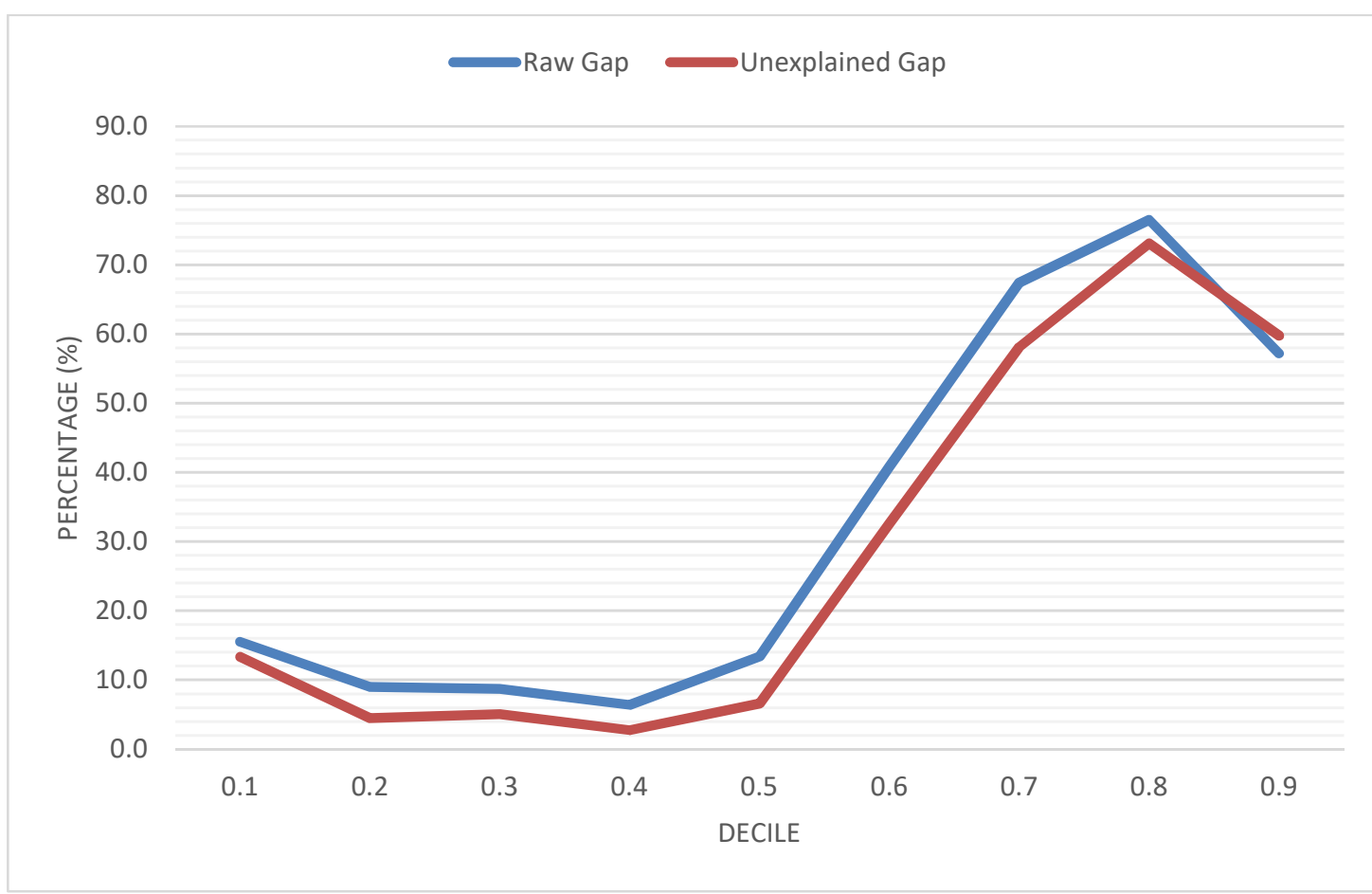

Source: $\quad$ The Irish Longitudinal Study on Ageing (TILDA), Wave 1 (age 66+, 2010).

Note: $\quad$ The sample is restricted to individuals with occupational and private pension income who have work experience of between 20 and 50 years. 
The detailed unconditional decile regression results for occupational and private pensions are presented in Table 2.7. It is obvious that higher levels of female educational attainment mitigated the gender pension gap throughout the pension income distribution. In the lower deciles the other factors that contribute to the gender pension gap are differences in the incidence of marriage, living arrangements and those not born in Ireland. In the seventh, eighth and ninth deciles, where between approximately 25 and 45 per cent of the raw gap is explained, the principal factors contributing to the gap are lower relative years of work experience among females. Interesting, in the third decile, the gender pension gap actually widens when observables are controlled for by virtue of the fact that women in this decile are more likely to have spent more years in the labour market compared to men in the third decile. 


\begin{tabular}{|c|c|c|c|c|c|c|c|c|c|}
\hline & Decile 1 & Decile 2 & Decile 3 & Decile 4 & Decile 5 & Decile 6 & Decile 7 & Decile 8 & Decile 9 \\
\hline Raw differential & 0.77 & 0.33 & 0.53 & 0.56 & 0.47 & 0.35 & 0.18 & 0.27 & 0.37 \\
\hline Explained (p.p.) & 0.12 & 0.12 & -0.09 & 0.01 & 0.03 & 0.04 & 0.08 & 0.09 & 0.09 \\
\hline Unexplained (p.p.) & 0.65 & 0.21 & 0.62 & 0.55 & 0.44 & 0.31 & 0.10 & 0.18 & 0.28 \\
\hline Explained (\% of raw differential) & 15.58 & 36.36 & -16.98 & 1.79 & 6.38 & 11.43 & 44.44 & 33.33 & 24.32 \\
\hline \multirow[t]{2}{*}{ Unexplained (\% of raw differential) } & 84.42 & 63.64 & 116.98 & 98.21 & 93.62 & 88.57 & 55.56 & 66.67 & 75.68 \\
\hline & Explained & Explained & Explained & Explained & Explained & Explained & Explained & Explained & Explained \\
\hline Category & (p.p.) & (p.p.) & (p.p.) & (p.p.) & (p.p.) & (p.p.) & (p.p.) & (p.p.) & (p.p.) \\
\hline Age & 0.01 & 0.00 & 0.00 & 0.00 & 0.00 & 0.00 & 0.00 & 0.00 & 0.00 \\
\hline Education & -0.17 & -0.16 & -0.20 & -0.19 & -0.17 & -0.15 & -0.14 & -0.11 & -0.06 \\
\hline Marital status & 0.48 & 0.27 & 0.06 & 0.03 & 0.12 & 0.04 & 0.00 & 0.03 & 0.10 \\
\hline No. of children & 0.03 & 0.03 & 0.01 & 0.01 & -0.01 & 0.02 & 0.02 & 0.01 & -0.00 \\
\hline Not born in Ireland & 0.05 & 0.04 & 0.06 & 0.05 & 0.05 & 0.04 & 0.04 & 0.03 & 0.01 \\
\hline Lived abroad & 0.02 & 0.02 & 0.01 & 0.01 & 0.01 & 0.00 & 0.00 & -0.00 & -0.01 \\
\hline Living arrangements & -0.31 & -0.12 & 0.06 & 0.05 & -0.02 & 0.02 & 0.04 & 0.03 & -0.06 \\
\hline Location & 0.01 & 0.02 & 0.01 & 0.02 & 0.01 & 0.01 & 0.01 & 0.00 & 0.01 \\
\hline Disability & 0.04 & 0.02 & 0.01 & 0.01 & 0.00 & 0.00 & 0.01 & 0.00 & 0.00 \\
\hline Work experience (20-35 years) & -0.02 & 0.00 & -0.06 & 0.01 & 0.02 & 0.03 & 0.05 & 0.05 & 0.05 \\
\hline Work experience (35-50 years) & -0.02 & 0.00 & -0.05 & 0.01 & 0.02 & 0.03 & 0.05 & 0.05 & 0.05 \\
\hline Total & 0.12 & 0.12 & -0.09 & 0.01 & 0.03 & 0.04 & 0.07 & 0.08 & 0.09 \\
\hline
\end{tabular}

Source: $\quad$ The Irish Longitudinal Study on Ageing (TILDA), Wave 1 (age 66+, 2010).

Note: $\quad T h e$ sample is restricted to individuals with occupational and private pension income who have work experience of between 20 and 50 years. 


\subsection{CONCLUSIONS}

Differences in income from pensions are one of the most important sources of income inequality among pensioners. Relative to earnings, the issue of pension incomes has received much less attention from researchers and public policy internationally, despite shifting demographics making this an increasingly important policy issue. Furthermore, there are substantial differences between the average pension incomes of older men and older women. A key element of this gap has been attributed to differences in occupational and private pensions across genders (Ginn and Arber, 1996).

Using TILDA, a unique nationally representative longitudinal study of adults in Ireland aged 50 and older, we examine the pension income gap between men and women. To the best of our knowledge, this is the first analysis to examine the gender pension gap in Ireland using both regression-based decompositions and detailed decomposition techniques across the deciles of the pension income distribution. In our sample, 88 per cent of men and 93 per cent of women were in receipt of the state pension; 55 per cent of men and 28 per cent of women were in receipt of occupational and private pensions. We find that the average total weekly pension income of women was $€ 280$ and $€ 433$ for men in 2010 , implying a raw gender pensions earnings gap of approximately 35 per cent. The total gender pension gap in Ireland is found to be mostly attributable to differences in incomes from private and occupational pensions.

For those in receipt of the state pension there is a higher proportion of women aged 75 and above, whereas the age profile of men and women in receipt of occupational and private pensions is more similar. For all pensioners, men were more likely to be educated to primary level alone, while for those in receipt of occupational and private pensions, women were somewhat more likely to hold third-level qualifications. In terms of labour market variables, 3 per cent of men in the sample reported having never worked compared to 22 per cent of women. For those with some work experience, 4 per cent of men have worked between 1 and 30 years compared to 45 per cent of women; 93 per cent of men have more than 30 years' work experience compared to 33 per cent of women.

In terms of the distribution of average weekly pension income, the distribution of pension income for men lies well above the state pension level of €230, which reflects the high proportion of men in receipt of occupational and private pensions. The proportion of women with pension incomes above $€ 500$ per week is low compared to men, demonstrating that the occupational and private pensions received by women are, on average, lower than those received by men. When pooled OLS models are estimated for state and private occupational pension income separately, it once again becomes apparent that there is no consistent 
evidence of a gender state pension gap, and the overall gender pension gap is driven predominantly by differences in occupation and private pensions.

Using the decomposition methods of Oaxaca (1973) and Blinder (1973), we explore in more depth the main causes for the pension income differences. For total pension income, the raw gender differential was 31 per cent, of which 7 per cent can be attributed to differences in the observable characteristics (age, nationality, human capital, labour market experience, marital status, number of children, location, etc.) of males and females. For occupational and private pensions, the raw gender differential was 43 per cent, of which 7 per cent can be attributed to differences in observable characteristics. Finally, when we restricted the sample to men and women with 20 or more years of work experience, the raw occupational and private gender pensions gap was 38 per cent, of which 5 per cent can be explained.

Our final contribution is to carry out an unconditional decile decomposition on the gender pension gap using the technique devised by Firpo et al. (2009). This decile analysis reveals that the total gender pension gap lies below the 31 per cent average in the lower deciles before increasing from 13 per cent at the fifth decile to 67 per cent at the sixth decile, and peaks at 77 per cent at the eighth decile. When we repeat the process for occupational and private pensions (restricting the sample to males and females with 20 or more years of work experience), we get a somewhat different picture: the gender pension gap is greatest at 77 per cent in the first decile and smallest at 18 per cent at the seventh income decile. For occupational and private pensions, higher levels of female educational attainment reduce the gender pension gap throughout the pension income distribution. In the seventh, eighth and ninth deciles, where approximately 25 to 45 per cent of the raw gap is explained, the principal factors contributing to the gap are found to be the lower relative years of work experience among women.

Slight decreases in the gender pension gap have been observed in the EU on average in recent years, from 41 per cent in 2009 to 38 per cent in 2016 (European Commission, 2018). Nevertheless, gender differences in pension coverage and income remain persistent across many countries. Across the EU, women work on average five years less in full-time jobs and more years in part-time employment, compared to their male counterparts (European Commission, 2018). Women also spend more time in retirement, as they live longer. Even when working in similar positions to men, women can face lower wages and lower promotion opportunities. Therefore, women are less likely than men to be employed, and when they are employed, on average, they earn less, work fewer hours and have shorter careers. Each of these labour market outcomes translates into divergences in pension income and a gender pension gap that is largely positive. 
A complex mix of personal desires, household decision-making processes, social conditions and policy-driven factors shape the working lives of women and men. The difference in career length between men and women is expected to narrow; however, the effects of the multiple career gaps affecting women across numerous dimensions (pay, career duration, childcare breaks, part-time work, care for dependent adults) is likely to have a continued cumulative impact on the pension income of women into the future. Given the significance of employment history for income prospects at older ages, increased female labour market participation across cohorts is likely to help reduce pension income inequality into the future. More recent cohorts of female pensioners have higher levels of education than the previous cohorts. Higher education is generally associated with stronger labour market attachment, more years in employment, higher earnings and, in turn, higher pension contributions.

In order to reduce the gender pension gap, policy measures that reduce the differences in occupational and private pension coverage across genders, raise female employment levels and ensure increased continuity in employment are most important. Substantial differences between the average pension incomes of older men and older women are due to differences in occupational and private pensions across genders. Therefore, policy measures to promote supplementary pension savings for women, based either on professional activity (occupational pensions) or on individual pension savings contracts (personal pensions), will provide additional retirement savings and complement statutory pensions for women and reduce the gender pension gap.

Reducing pension income inequalities requires equal opportunity policies targeted at both women and men of working age in order to promote equal labour market access (for example, equal distribution of caring responsibilities, equal pay legislation and career break entitlements) and pension policies that adequately protect against care-related interruptions. In this regard, polices regarding the provision of increased and more affordable childcare infrastructures and long-term care services can play a role to increase female employment levels and ensure increased continuity in employment (Redmond and McGuinness, 2019). For workers who experience interruptions in their career, it is important for policy to examine the best ways to facilitate the return to work and work transitions, i.e. both between jobs and between work statuses. Finally, although not directly analysed in this chapter, a deeper understanding of the collective effect of horizontal and vertical segregation and differing career patterns between men and women could also play a key role in explaining the gender pension gap. 


\subsection{APPENDIX: DENSITIES OF PENSION INCOME BY GENDER}

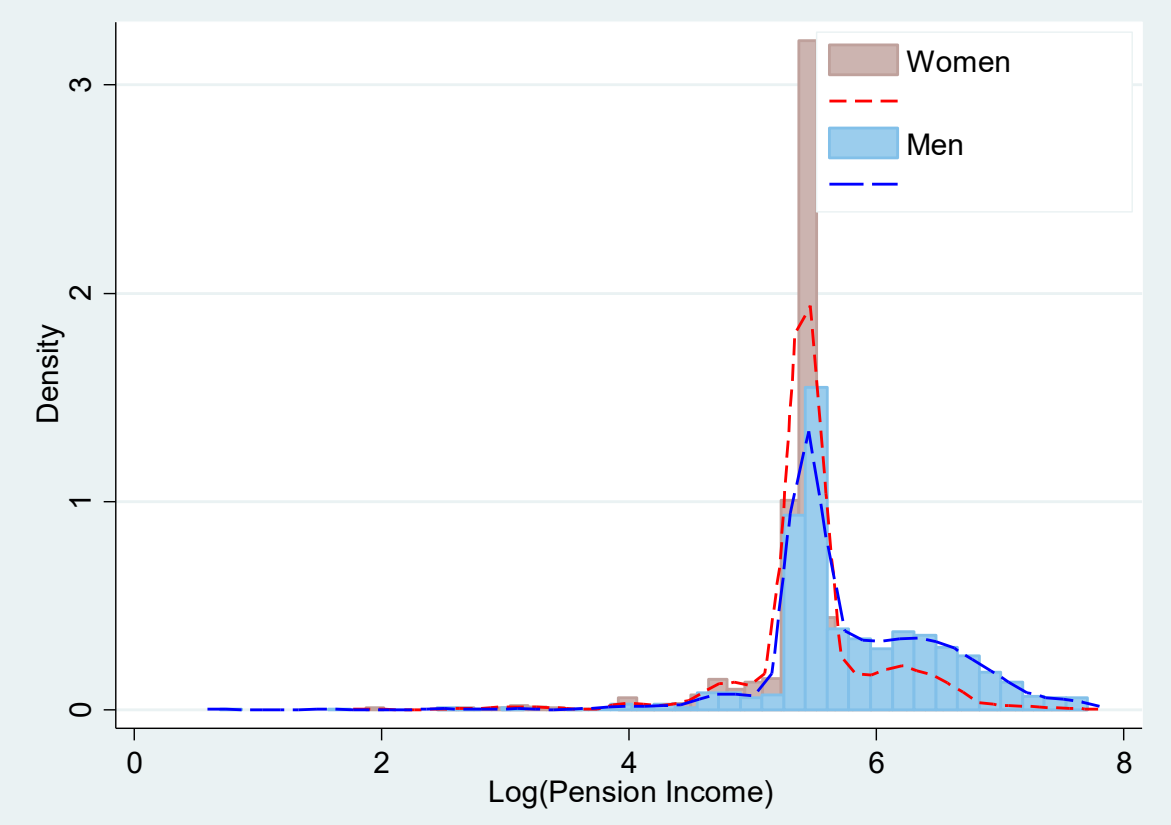

Source: The Irish Longitudinal Study on Ageing (TILDA), Wave 1 (age 66+, 2010).

FIGURE A2 DENSITIES OF STATE PENSION INCOME BY GENDER

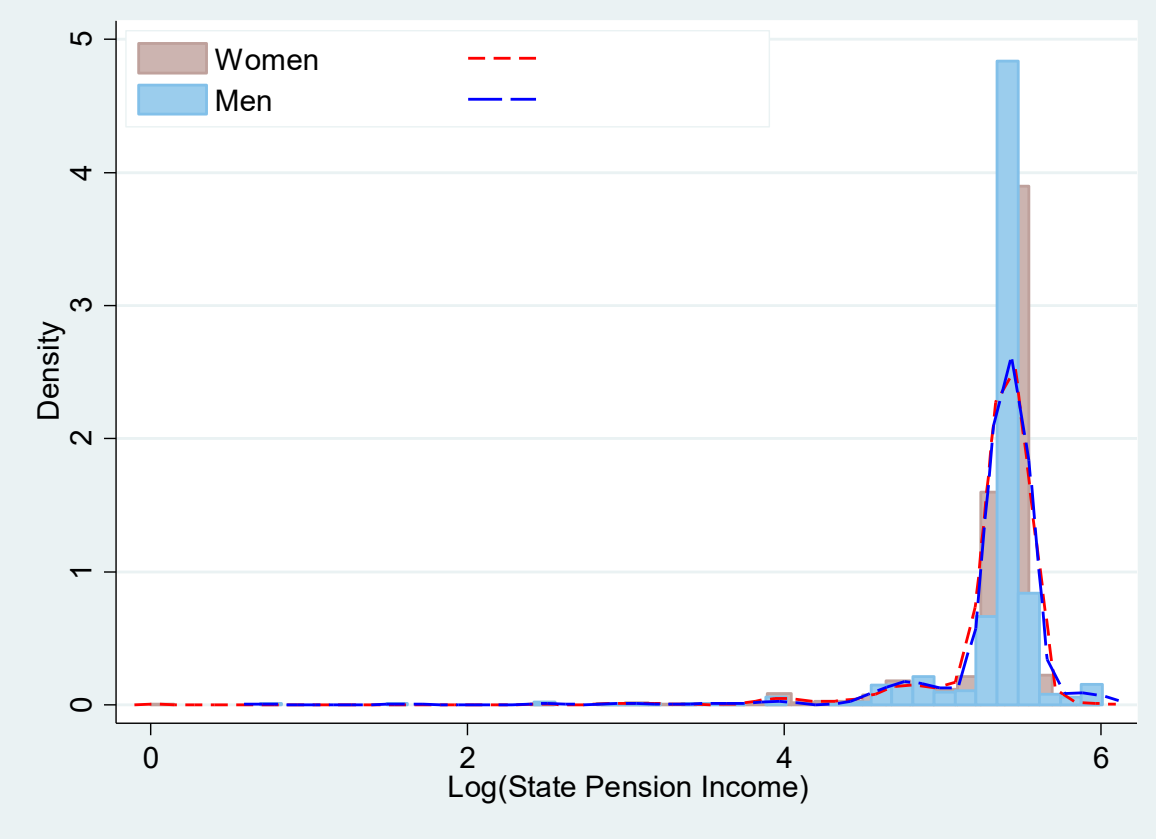

Source: The Irish Longitudinal Study on Ageing (TILDA), Wave 1 (age 66+, 2010). 


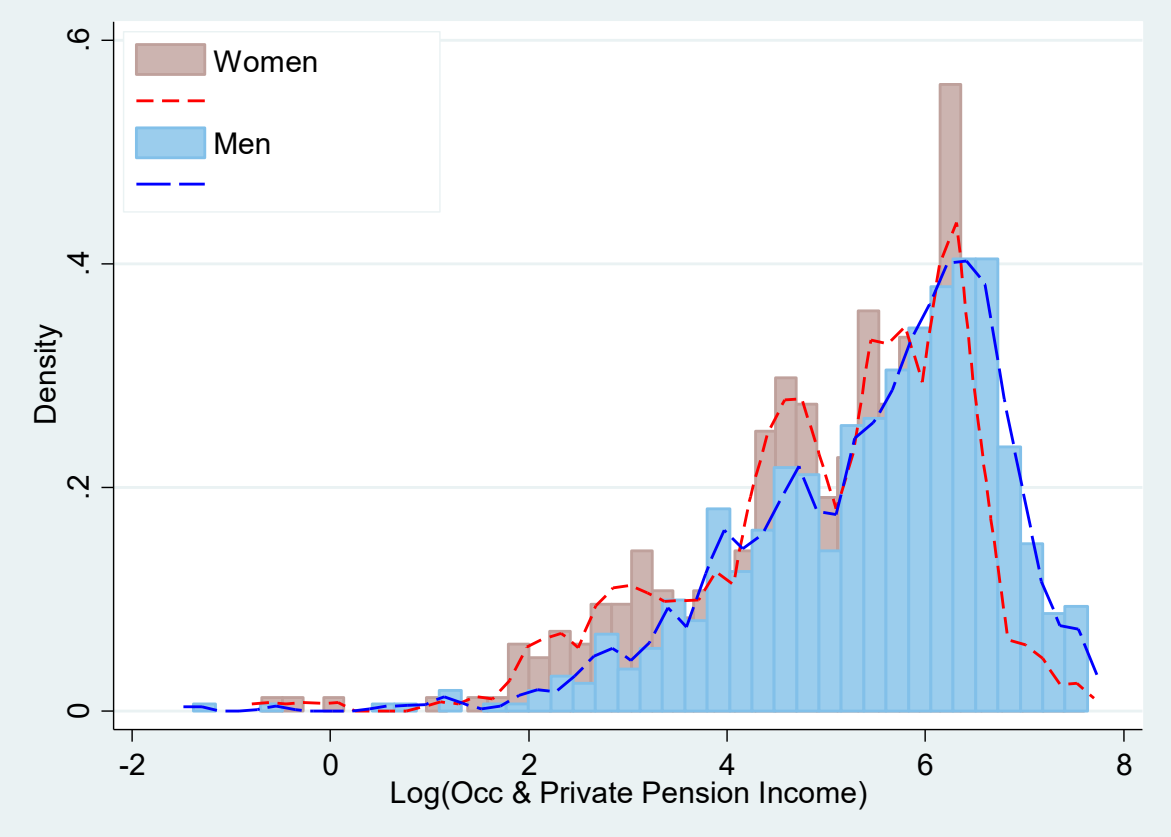

Source: $\quad$ The Irish Longitudinal Study on Ageing (TILDA), Wave 1 (age 66+, 2010).

FIGURE A4 DENSITIES OF OCCUPATIONAL AND PRIVATE PENSION INCOME FOR THOSE WITH WORK EXPERIENCE OF BETWEEN 20 AND 50 YEARS BY GENDER

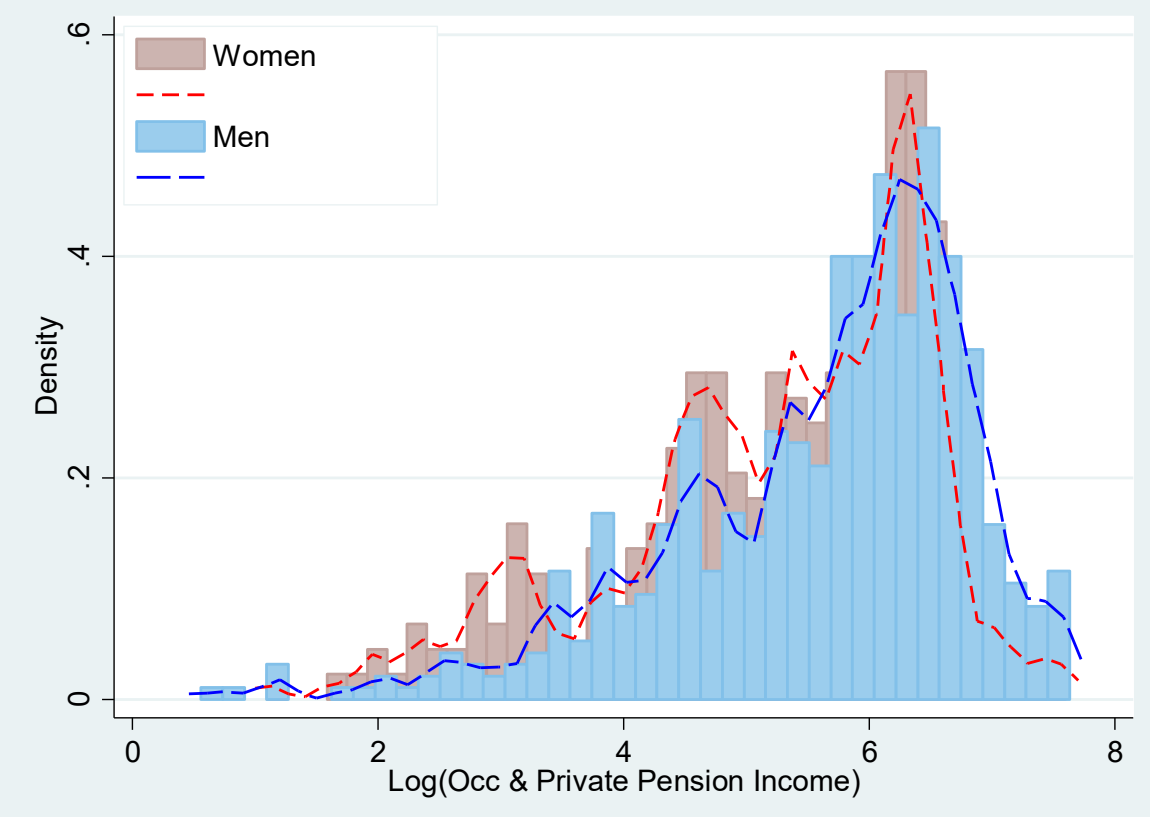

Source: $\quad$ The Irish Longitudinal Study on Ageing (TILDA), Wave 1 (age 66+, 2010). 


\section{CHAPTER 3}

\section{Income poverty in older age}

\subsection{INTRODUCTION}

We described briefly in Chapter 1 how older people in Ireland have fared better on measures of poverty and social exclusion than any other age groups of the population. Since 2008, the at risk of poverty (AROP) rate of older people has been consistently lower than for children (0-17 years) and for the working age population (18-64 years). The most recent figures from the CSO show that in 2017 the AROP rate of people over 65 was 8.6 per cent while it was 16.2 per cent for people of working age (18-64 years) and 18.4 per cent for children (0-17 years). Over the period 2004 to 2017 the deprivation rate of older people was also much lower than for the other age groups. In 2017, it was 9.7 per cent for people over 65, 19.1 per cent for working age people and a high 23 per cent for children (CSO, 2018).

Even during the period of the great recession, when many welfare payments were cut after 2009, government welfare policy aimed to protect older people from the impact of the recession by preserving social welfare pensions. ${ }^{17}$ Indeed, the data presented in Figure 3.1 show that the levels of the state pension (both contributory and non-contributory) have been very similar to the income poverty threshold over time, resulting in a much lower at risk-of poverty for the over-65s than for the overall population (Figure 3.1). While this is a very positive outcome, we still can raise the question as to why nearly 10 per cent of the over-65s are in income poverty.

17 However, following the National Pensions Framework changes, it is quite likely that the increase in 2012 in the number of paid contributions needed (from 260 to 520) affected the eligibility to the contributory pension (Department of Employment Affairs and Social Protection, 2017, p. 134). 


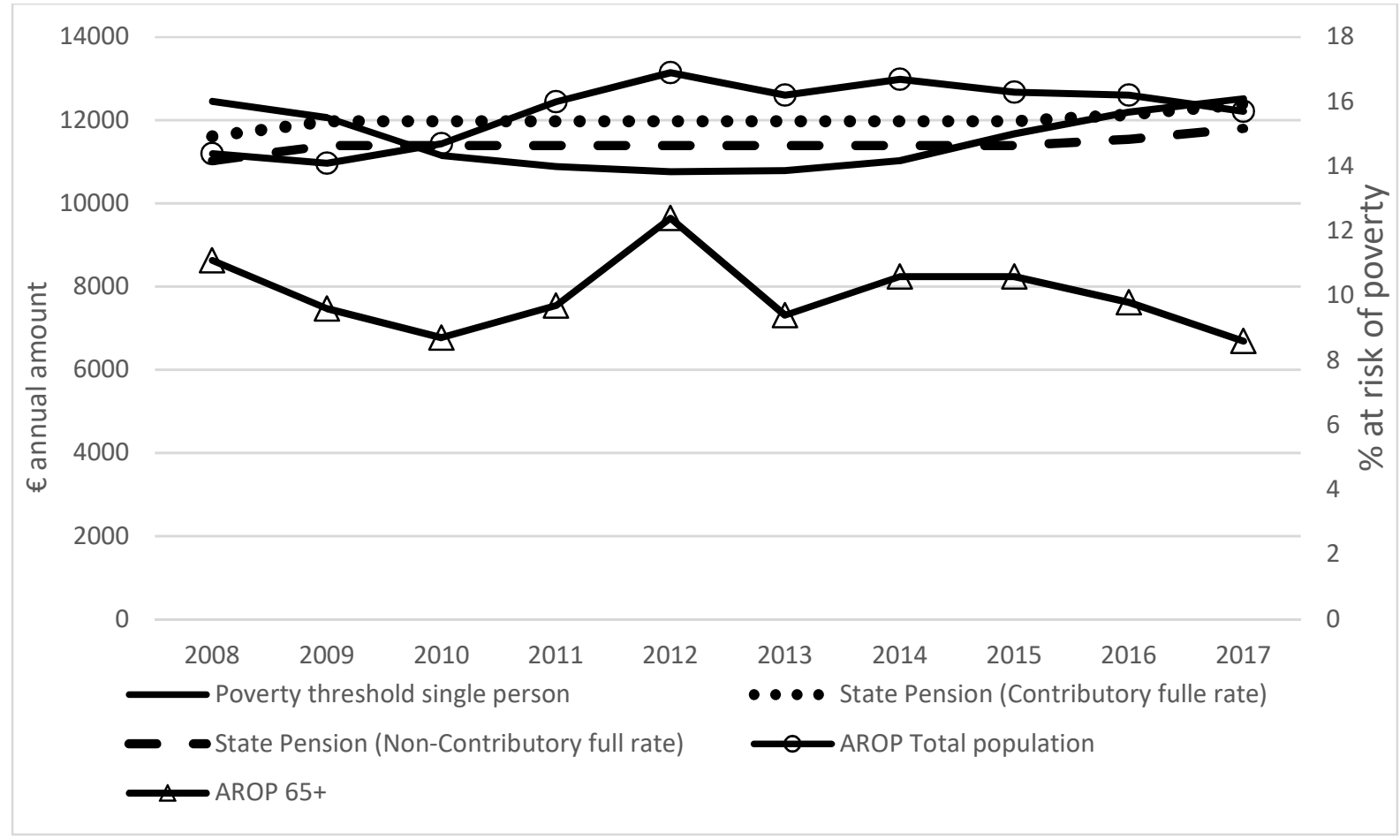

Source: $\quad$ Survey of Income and Living Conditions (SILC).

Among the hypotheses, we can think of the gender difference in labour market participation and associated impact on pension levels and entitlements. The household structure of older people could also be a contributing factor, as we know that, for example, single households for the working age population are experiencing higher poverty rates. Another contributing factor could be the presence of inactive adults of working age living in older households, bringing the overall household income per person below the income poverty line. We therefore address two research questions in this chapter:

- What is the extent of poverty across older people aged 66 and over and what are the characteristics of the older population who are income poor?

- What are the contributing factors to income poverty among older people?

The remainder of the chapter is organised as follows. In Section 3.2, we describe the data used in this chapter, from the Survey of Income and Living Conditions (SILC), and the indicators used for the analysis. Section 3.3 presents the sociodemographic profile of older people in terms of age and household structure. In Section 3.4 we examine successively the poverty outcomes and income types of older people. In Section 3.5 we summarise our results. The appendix (Section 3.6) presents additional analysis using the Irish Longitudinal Study on Ageing (TILDA), which contains information on aspects of older people's lives that are not available 
from SILC (namely, wealth and migration history) and that may be informative for analyses of income poverty in older age.

\subsection{DATA AND INDICATORS}

\subsubsection{SILC}

This chapter analyses data from the Irish Survey on Income and Living Conditions (SILC). The SILC is the official data source in Ireland for information on the income and living conditions of households. The survey collects a large range of sociodemographic information about household members, ranging from personal characteristics (age, gender, marital status, etc.) to personal income, labour market status, education and health status. It provides annual national poverty indicators such as the AROP rate, material deprivation rate and consistent poverty rate.

SILC is a survey of private households carried out by the Central Statistics Office (CSO). The first wave of the SILC survey started in 2003, with interviews carried out only on a six-month period from June to December. From 2004 onwards the survey was carried out annually, with data collection throughout the year. The number of households in the completed sample varied from 4,600 to 6,000 between 2004 and 2010. CSO uses a two-stage sampling design, with eight population density stratum groups (based on the Census of Population), random selection of sample and substitute households within blocks and the application of an appropriate calibration weight (CSO, 2018).

In this chapter we focus on analysis of the SILC 2015 and 2016. In order to achieve a large sample size with reliable estimates for some sub-groups of the population we are interested in, we pool SILC 2015 and 2016. ${ }^{18}$ In 2015, the total completed sample size was 5,452 households and 13,793 individuals and in 2016 it was 5,219 households and 13,186 individuals. In Ireland, state pensions (contributory and non-contributory) are payable to people aged 66 and over, so we focus on this group of the population. This leaves us with a sample of 4,736 individuals aged $66+$.

\subsubsection{Poverty measures}

In this chapter we focus on two of the official measures of poverty used in Ireland, the AROP rate and the material deprivation rate. The AROP (or income poverty) measure identifies households with equivalised disposable income below 60 per cent of the national median. ${ }^{19}$ Household disposable income is the total income

18 SILC is a four-year rotational panel survey where individuals can be present up to four years. The presence of duplicate cases in the two waves is not an issue as the descriptive results presented in this chapter are based on cross-sectional weighted data where each wave is representative of the total population.

19 For the purpose of comparison and in order to take account of different household size and composition, household income is equivalised using the Irish official equivalence scale. The first adult (age over 14) in the household receives a weight of 1 , then 0.66 for each subsequent adult and 0.33 for each child (age less than 14). The household equivalised income is then the household income divided by the household equivalence scale. 
from all sources and all persons within the household after taxes and social insurance contributions have been deducted.

During the SILC interview, all household members aged 16 and over have the option to provide their personal public service (PPS) number. On choosing this option the respondents do not have to answer the detailed section of the questionnaire about their incomes (and taxes) either from work or from social welfare. In this case, the CSO will get this information from administrative data from the Office of the Revenue Commissioners and from the Department of Employment Affairs and Social Protection. Overall, well over 90 per cent of SILC respondents supplied their PPS numbers, thereby avoiding any mistakes or omissions on their part during the course of the interviews. The very high rate of PPS numbers provided therefore makes the SILC income data extremely reliable and accurate. ${ }^{20}$ In the SILC data, income is measured at the household level over the 12 months preceding the interview, so for example in SILC 2016 the income reference period goes from January 2015 to December 2016. In SILC, income data are collected at individual level (employee income, for example) and household level (rent supplement, for example) and summed to produce the household income. ${ }^{21}$ The income values calculated from the pooled data and reported in the figures and tables in this chapter are in nominal terms. ${ }^{22}$

However, while most of the poverty research and official statistics on poverty relies on the sole use of low income to identify the poor, there has been growing concern about the ability of this single measure to capture fully the living conditions of the population. Consequently there has been a development of the use of nonmonetary indicators to capture the full extent of poverty and social exclusion, as promoted by the pioneering work of Townsend in Britain (Townsend, 1979).

Following this conceptual approach, in Ireland the ESRI has developed a measure of basic deprivation (Maitre et al., 2006) which has been adopted by the Irish government as an official measure of deprivation. The measure of basic deprivation identifies households that are experiencing an enforced lack of (due to inability to afford) two or more of a list of 11 basic goods and services that are regarded as essential to fully participate in the life of society. Among these items are adequate food, clothing, heating for the home, and having the ability to

\footnotetext{
See CSO (2017b) for quality report about the income data in SILC 2016.

See CSO (2017b) for a detailed list of the income components of household income.

The annual inflation rate (CPI) in 2016 was $0 \%$ (CSO, Statsbank).
} 
participate in social activities such as buying presents for the family or having an evening out for entertainment. ${ }^{23}$

However, there is also a large body of research in the international literature on poverty and social exclusion that highlights the discrepancy that might exist between living on low income and experiencing deprivation. Indeed, many of these studies across a wide range of countries, including Ireland, show that many people found below the poverty lines are not experiencing material deprivation, while the reverse can also be true (Callan et al., 1993). Part of the explanation relies on differences in households' command over resources through access to credit and savings, and getting financial support from family and friends, which would affect levels of deprivation without any impact on the level of income.

To overcome these limitations and to better identify the poor, the ESRI has developed a measure of consistent poverty by combining the experience of living on low income and reporting material deprivation. The measure of consistent poverty was officially adopted by the Irish government and used within the National Anti-Poverty Strategy (NAPS) (Government of Ireland, 1997).

\subsection{SOCIO-DEMOGRAPHIC PROFILE OF OLDER PEOPLE}

Before analysing the characteristics of older people in poverty in Ireland, in this section we provide an overview of the older population in general, including an analysis of the household composition of older individuals in SILC. The proportion of the older population has been relatively stable over the past decade in Ireland. The population aged 65 and over increased from 11.7 per cent in 2011 to 13.4 in 2016. In absolute terms, however, the population aged $65+$ experienced the largest relative increase, increasing by nearly 100,000 from 2011 to 2016 (from 531,600 to 629,800$).{ }^{24}$ Using the pooled SILC data for 2015 and 2016, we find a similar proportion of the population aged 66 and over at 12 per cent, followed by children (aged less than 18) at 27 per cent, while the largest group is composed of the working-age population (aged 18 to 65 ) at 61 per cent.

In Ireland, as in many countries, women's life expectancy is higher than men's. Recent figures from the OECD show that in 2017 men's life expectancy at birth was 79.9 years while women's was 83.6 years for and that at the age of 65 it was 18.6 years for men and 21.1 years for women. ${ }^{25}$ This gender life expectancy gap is also

23 The complete list of deprivation items is: 1 . Two pairs of strong shoes; 2 . A warm waterproof overcoat; 3. Buy new (not second-hand) clothes; 4 . Eat meal with meat, chicken, fish (or vegetarian equivalent) every second day; 5 . Have a roast joint or its equivalent once a week; 6 . Had to go without heating during the last year through lack of money; 7 . Keep the home adequately warm; 8. Buy presents for family or friends at least once a year; 9 . Replace any worn-out furniture; 10. Have family or friends for a drink or meal once a month. 11. Have had a morning, afternoon or evening out in the last fortnight, for entertainment.

24 See CSO Database Table (PEA01: Population Estimates (Persons in April) by Age Group, Sex and Year) for underlying data.

25 See https://data.oecd.org/healthstat/life-expectancy-at-65.htm\#indicator-chart 
somewhat apparent in Figure 3.2 when we focus on the age distribution of the older population by gender in SILC. We note that there is a greater proportion of men in the 66-70 age group (37 per cent, while it is 33 per cent for women). At the other end of the older age distribution, we note that 40 per cent of the older women are aged 76 and over, compared to 37 per cent for men.

\section{FIGURE 3.2 AGE DISTRIBUTION OF THE OLDER POPULATION, 66+, BY GENDER}

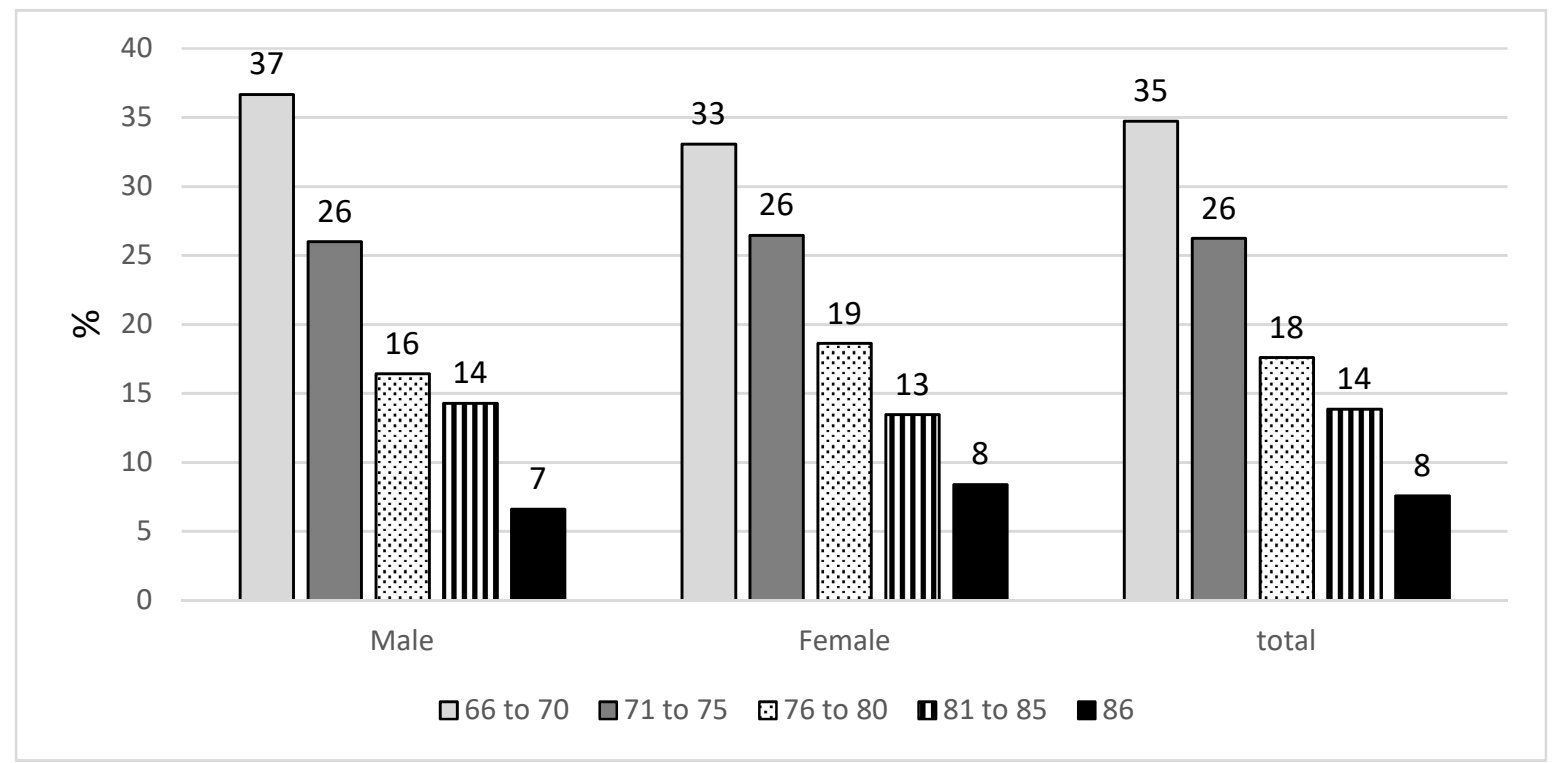

We saw in Section 3.2 that the incomes of all household members are added to generate the total household income. It is therefore important to identify the type of households in which the population aged 66 and over are living, as the presence of other members and their characteristics will affect the level of the household income.

In Table 3.1 we present the household structure of people aged 66 and over for the pooled SILC data, identifying mostly three groups: single older people, couples (married or in partnership) and older people living with others. We report the relative size of these groups and the aggregated categories that we will use for most of the analysis in order to have a large enough group for reporting robust statistics.

Table 3.1 shows that almost 45 per cent of people aged 66 and over are living in a couple household where both persons are 66 and over, and that just 6 per cent are living in a couple household where one partner is less than 66 . Single households are the second largest group at almost 31 per cent (10.4 per cent of male and 20.3 per cent of female). Therefore, almost 82 per cent of people aged 66 and over are either living in a couple household (with no other household members) or living alone. The remaining 18 per cent are almost equally divided into a group of one 
person aged 66+ living with other younger persons (children, siblings, non-related etc.) and a group of couples where at least one is over 66 and living with others.

\section{TABLE 3.1 HOUSEHOLD STRUCTURE OF THE OLDER POPULATION, 66+}

\begin{tabular}{|c|c|c|c|}
\hline Detailed category & $\begin{array}{l}\text { Size } \\
(\%)\end{array}$ & Aggregated category & $\begin{array}{l}\text { Size } \\
(\%)\end{array}$ \\
\hline 1. Single person $66+$ & 30.7 & 1. Single person $66+$ & 30.7 \\
\hline 2. Couple, one $66+$ and one $<66$ & 6.3 & 2. Couple, one $66+\&$ one $<66$ & 6.3 \\
\hline 3. Couple, both $66+$ & 44.7 & 3. Couple, both $66+$ & 44.7 \\
\hline $\begin{array}{l}\text { 4. One } 66+\text { living with one person } \\
<66 \text { (not couple) }\end{array}$ & 5.3 & $\begin{array}{l}\text { 4. One } 66+\text { living with one or more persons }<66 \\
\text { (not couple) }(4+8)\end{array}$ & 7.9 \\
\hline 5. Two 66+ (not couple) & 1.6 & 5. Other $(5+6+7+9)$ & 10.4 \\
\hline $\begin{array}{l}\text { 6. Couple, one } 66+\text { and one }<66 \\
\text { living with others }\end{array}$ & 2.5 & & \\
\hline 7. Couple $66+$ living with others & 5.8 & & \\
\hline 8. One person $66+$ living with others & 2.6 & & \\
\hline $\begin{array}{l}\text { 9. Several persons } 66+\text { living } \\
\text { together (not couple) }\end{array}$ & 0.5 & & \\
\hline Total & 100.0 & & 100.0 \\
\hline
\end{tabular}

\subsection{THE EXPERIENCE OF POVERTY AMONG OLDER PEOPLE}

\subsubsection{Risk of poverty and deprivation}

In Figure 3.3, we report the experience of poverty across three broad age groups, i.e. children, the working-age population and older people, using the poverty measures described in Section 3.2. Across the three age groups, children are the most exposed to income poverty, deprivation and consistent poverty and exposure is slightly lower for the working age population. For the older population the rate of poverty and deprivation is about half that of the overall population, and it is four and a half times lower for the consistent poverty rate, at a very low rate of 2 per cent. ${ }^{26}$ All three results indicate that older people are faring better than their younger counterparts, confirming the trend observed since the early 2000s (Watson and Maitre, 2013).

26 Due to the very low consistent poverty rate for older people, we are not able to proceed to detailed analysis with this measure in the chapter. 


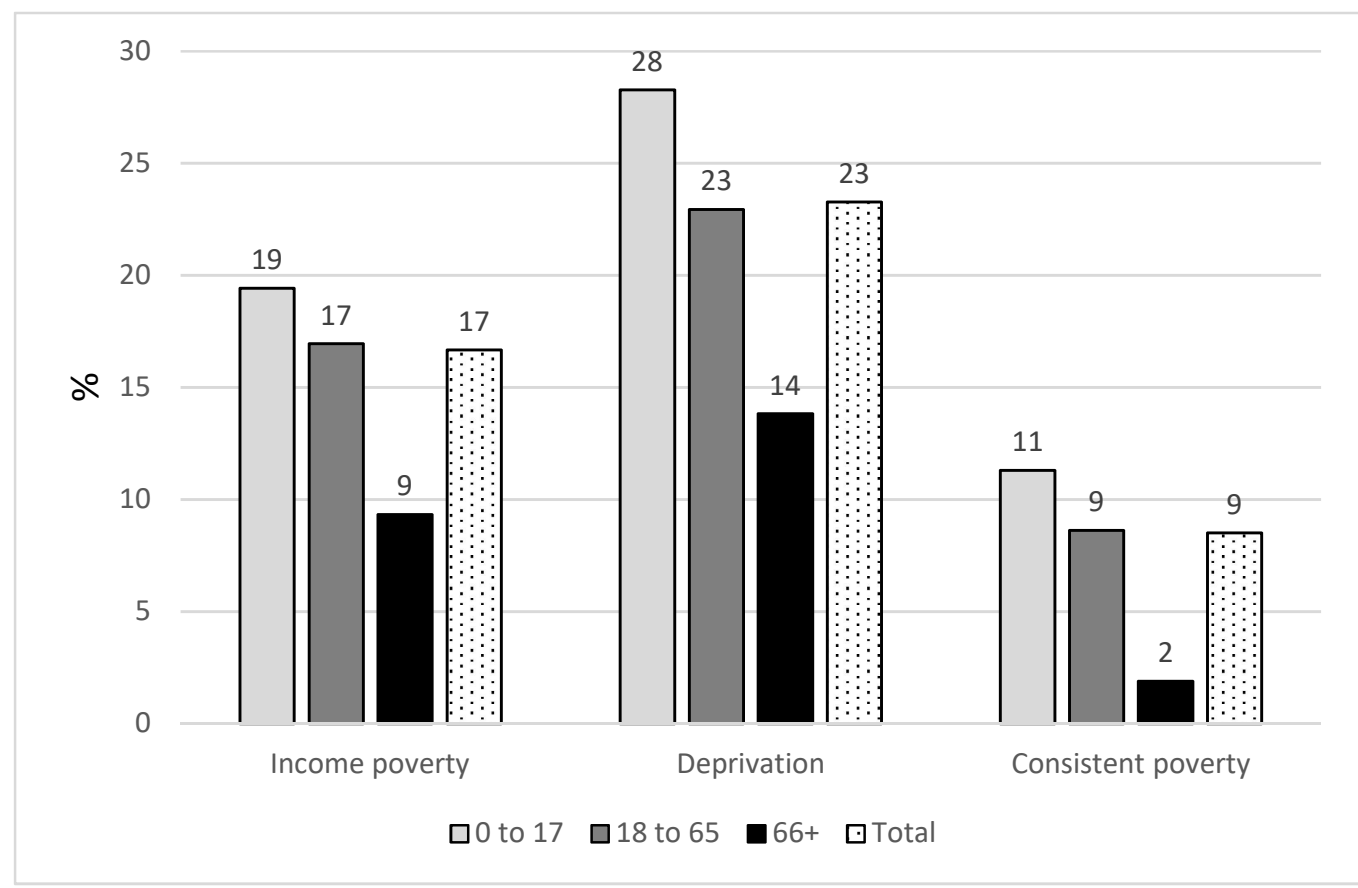

Pooled data, SILC 2015 and 2016.

Across all three poverty measures, there are almost no gender differences among older people. The income poverty rate is 9.7 per cent for males and 9.0 per cent for females; for deprivation it is 14.3 per cent and 13.3 per cent respectively, and it is 2.2 per cent and 1.6 per cent for consistent poverty (results available on request from the authors).

Focusing on people aged over 65, Figure 3.4 shows a further age breakdown by gender for income poverty and deprivation. The results show substantive variations across age groups but not so much between genders. The distribution of income poverty across age groups shows a similar $U$ shape for men and women. There are no gender differences in the level of income poverty for the first two age groups, but it is higher for older men than for older women at 14 per cent and 11 per cent respectively.

The pattern is different for material deprivation. For both men and women, the deprivation rates are highest for the first two age groups, with very little difference between these age groups and genders. Unlike income poverty, the situation is reversed for the oldest age group as women are now reporting a higher deprivation level than their male counterparts, respectively 12 per cent and 10 per cent. Not surprisingly, the proportion of single-person households increases as one moves from the youngest to the oldest age group (not shown here). As a result, 53 per cent of the income-poor people aged 81 and over are single-person households, 
compared to only 31 per cent among the income-poor people aged 66 to 70 . The corresponding figures for deprivation are 49 per cent and 27 per cent. ${ }^{27}$

\section{FIGURE 3.4 POVERTY OUTCOMES BY AGE GROUP OF OLDER PEOPLE}

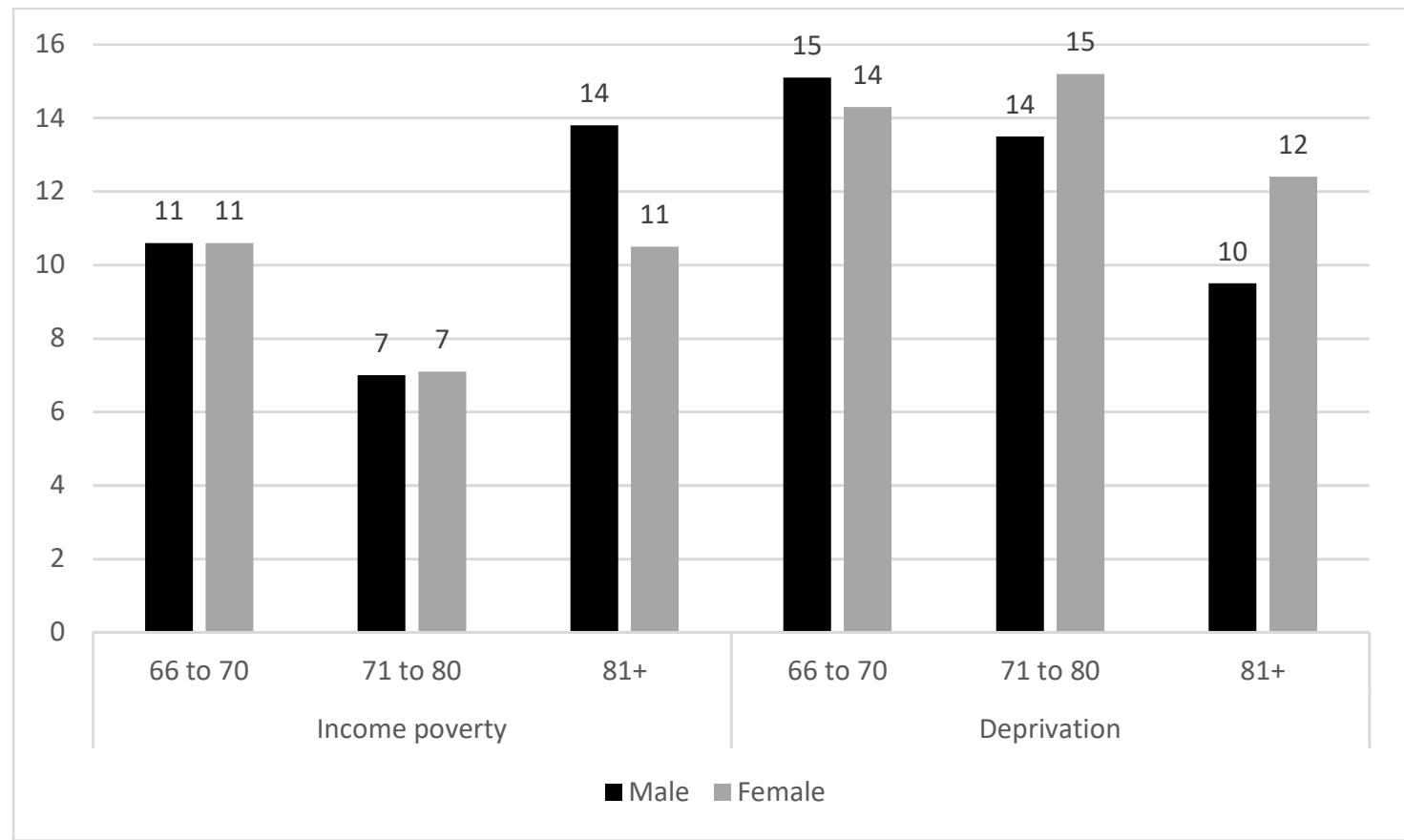

However, the overall positive outcomes for older people can hide very heterogeneous results for some groups of older people, as shown in Figure 3.5. Here we present income poverty and material deprivation rates across different household types of people aged 66 and over. ${ }^{28}$

The average income poverty rate across all individuals aged $66+$ is 9 per cent. Focusing on the income poverty results first, three household types have higher rates than the average for older people aged 66+. For couples where one member is less than 66 it is 17 per cent, twice the level of the overall 66+. It is slightly lower for households where a 66+ is living with others, at 14 per cent, and it is 12 per cent for single 66+. Couples where both members are aged 66+ have the lowest rates of all at 6 per cent, while it is the average for other type of households. Interestingly, we note that for couples there is large variation in the income poverty rate depending of the age of the two partners. It is 6 per cent when both partners are 66+ while it is 17 per cent when one partner is less than 66 years of age. The difference could be due to the fact that in the latter case the person over 66 is in receipt of a lower rate of increase for a qualified adult (when the other adult is aged less than 66) compared to the former case (where the rate for a 
qualified adult aged over 66 is greater) or both partners aged over 66 could be getting the contributory pension. The pattern is different for material deprivation, and with one exception, the level of deprivation is higher than for income poverty. Consistent with the income poverty results, individuals in households comprising one person aged 66+ living with others are among the most disadvantaged, at 24 per cent, followed by single households at 17 per cent and other households at 15 per cent.

Couple households are experiencing the lowest levels of deprivation, at 12 per cent (couple, one 66+) and 10 per cent (couple, both 66+). Couples where one partner is aged 66+ are the exception to the general pattern where the income poverty rate is lower than the rate of material deprivation; one possible reason for this is that access to credit may be easier for couples with younger partners than for other older households.

\section{FIGURE 3.5 POVERTY OUTCOMES BY HOUSEHOLD TYPE OF OLDER PEOPLE}

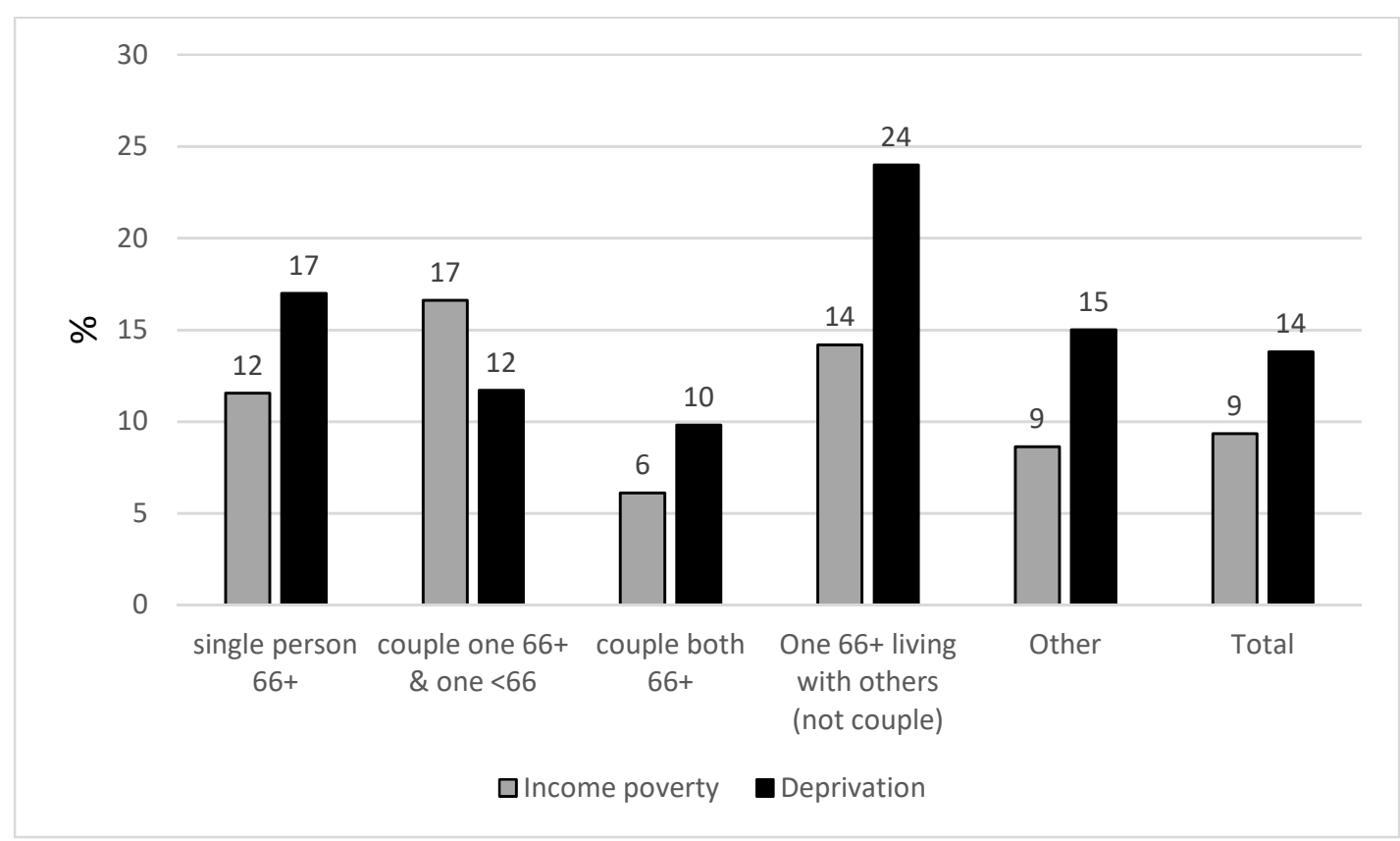

Figure 3.6 shows a further breakdown of poverty outcomes by household type and gender but only for two types of households as there are not enough cases to report reliable results for all household types. Single men report higher income poverty and deprivation rates than their female counterparts. For income poverty, the figure is 15 per cent for men and 10 per cent for women and for deprivation it is respectively 19 per cent and 16 per cent. By construction, the poverty and deprivation rates for men and women in couple households where both are aged 66 and over are identical at 6 per cent for income poverty and 10 per cent for deprivation. 


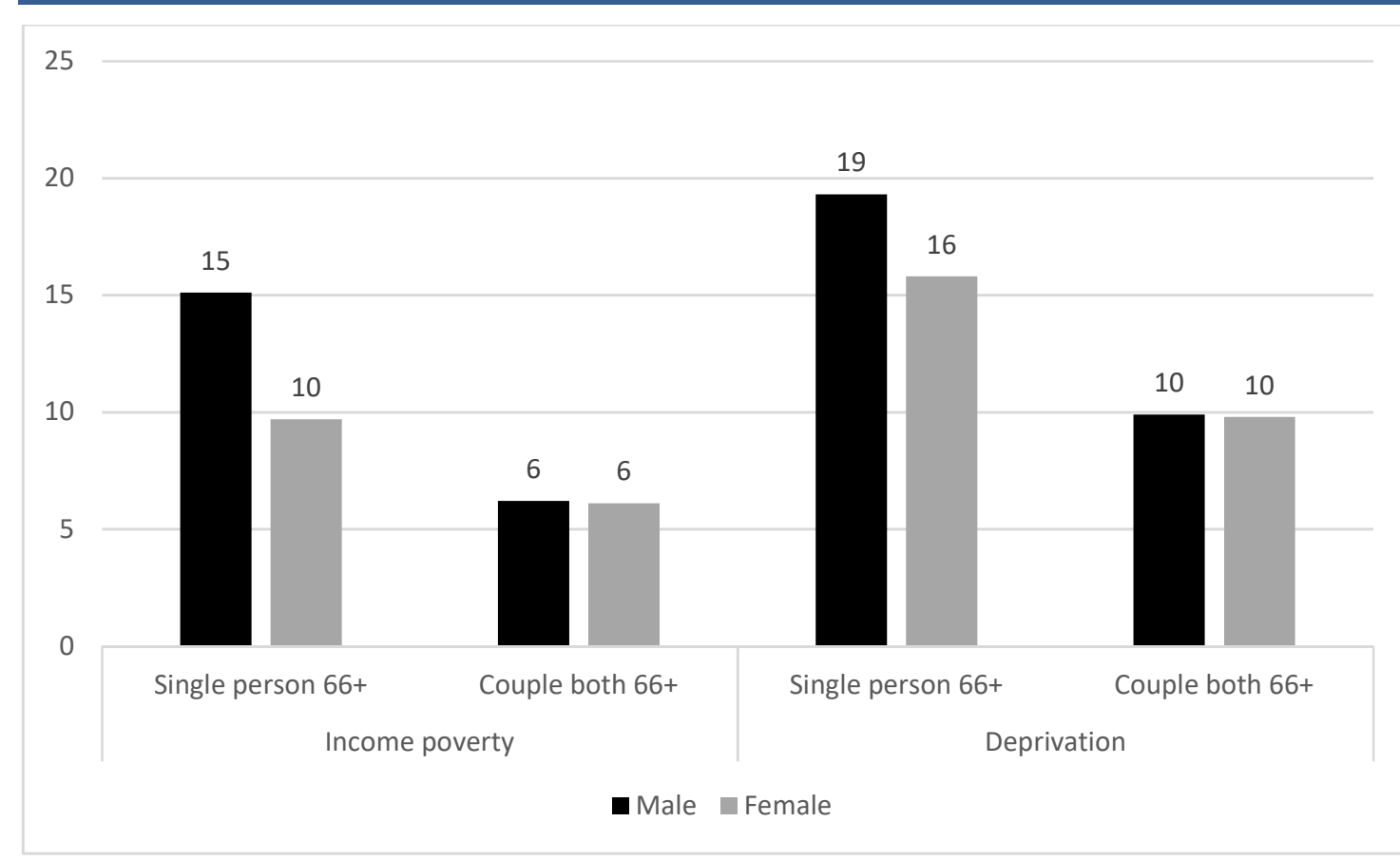

Source: Pooled data, SILC 2015 and 2016.

\subsubsection{Poverty composition}

Results in Table 3.1 and Figure 3.5 showed that the distribution of household types of older people and associated poverty risks can vary to a large extent. Taking account of the size of these groups and corresponding poverty risks, in this section we are looking at the household composition of poor older people $66+$, as shown in Figure 3.7.

Compared to Table 3.1, the left-hand bar in Figure 3.7, panel A, shows that there is an over-representation of single households among income-poor older people, at 38 per cent ( 31 per cent in Table 3.1), while this is the opposite at 29 per cent for couples where both members are 66 and over ( 45 per cent in Table 3.1). The other households contribute between 10 per cent and 12 per cent each to the overall group of poor older people. Overall, 78 per cent of the income-poor older population comprises single and couple households with no other members in the household. Figure 3.7, panel B, represents the same information but converted into percentage points of the overall income poverty rate for older people. It shows that single and couple households contribute 7.2 percentage points of the total income poverty rate of 9.3 per cent, leaving 2 percentage points explained by all other households.

The deprivation results patterns in Figure 3.7 are very similar to those observed for income poverty, where the main contributors to the deprivation rate for older people are single and couple households (with no other household members). 
FIGURE 3.7 POVERTY COMPOSITION FOR INCOME POVERTY AND DEPRIVATION BY HOUSEHOLD TYPE OF OLDER PEOPLE, 66+

Panel A

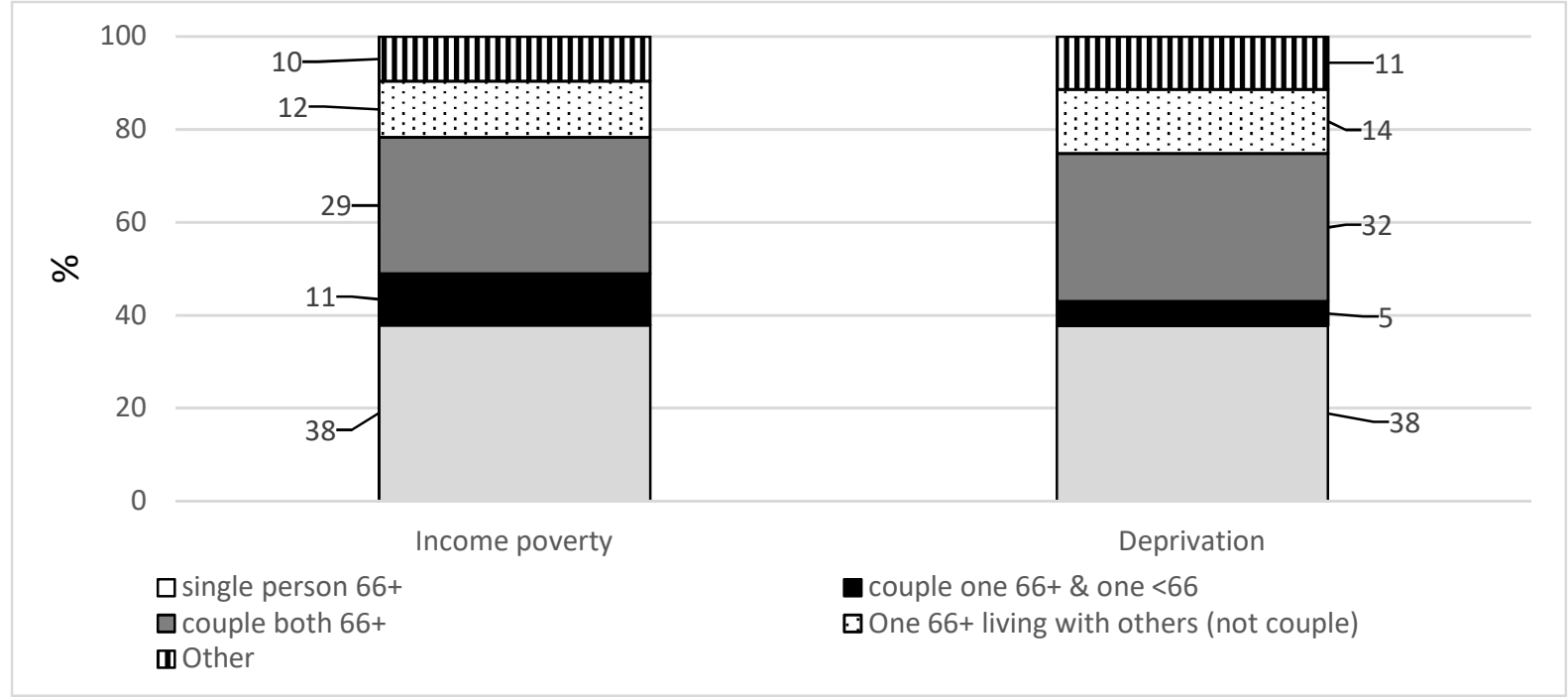

Panel B

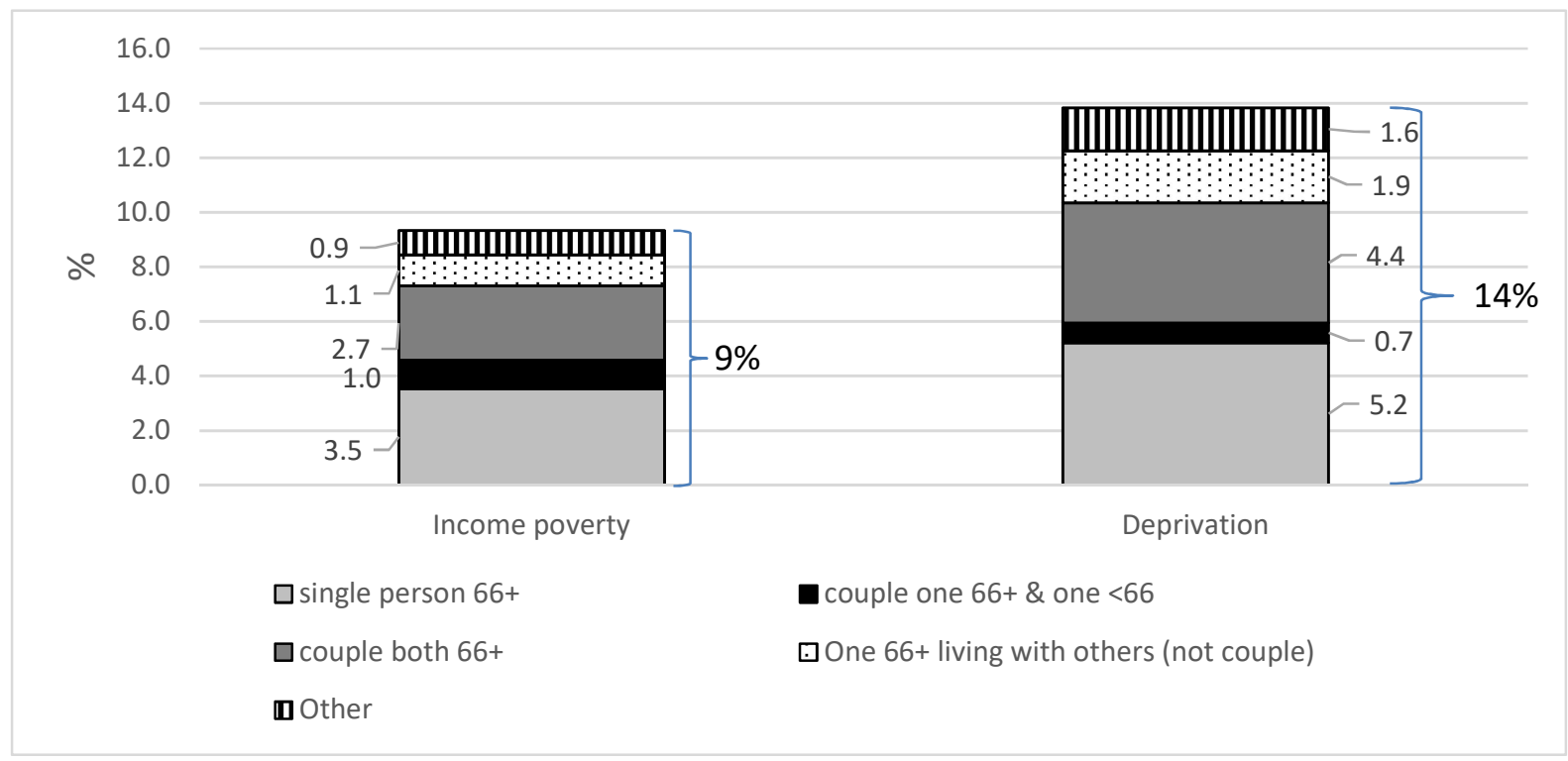

Source: Pooled data, SILC 2015 and 2016.

\subsubsection{Income of older people}

Figure 3.8 shows that the annual mean equivalised disposable household income of people aged 66 and over, while being the lowest at $€ 21,412$, is only 9 per cent lower than for the total population at $€ 23,576 .{ }^{29}$ Among those aged 66 and over, the mean income is also higher for the younger cohort of the $66-75 \mathrm{~s}$ than for the older cohort of the 76 and over. This could be partially explained by the fact that some of the younger group might still be working and therefore be in receipt of

29 The equivalised disposable income is calculated with the CSO equivalence scale. See footnote 19. 
higher income than those totally relying on pension benefits, but also that more women, who tend to have lower incomes, are in the older cohorts.

There is less variation across household types of older people. The mean income for the group of 'other' households is almost the same as for the total population at $€ 23,458$. This could be due to the presence of younger household members in receipt of income from work. Not surprisingly, we find the lowest mean income among single households, at $€ 19,072$, while it is in the narrow range of almost $€ 21,000$ to $€ 23,000$ for other households. Finally, the average income of poor older people is 2.8 times less than for the total population, and there is no gender difference in the average income of poor older people.

FIGURE 3.8 ANNUAL MEAN EQUIVALISED DISPOSABLE HOUSEHOLD INCOME BY SOCIO-DEMOGRAPHIC CHARACTERISTICS OF OLDER PEOPLE

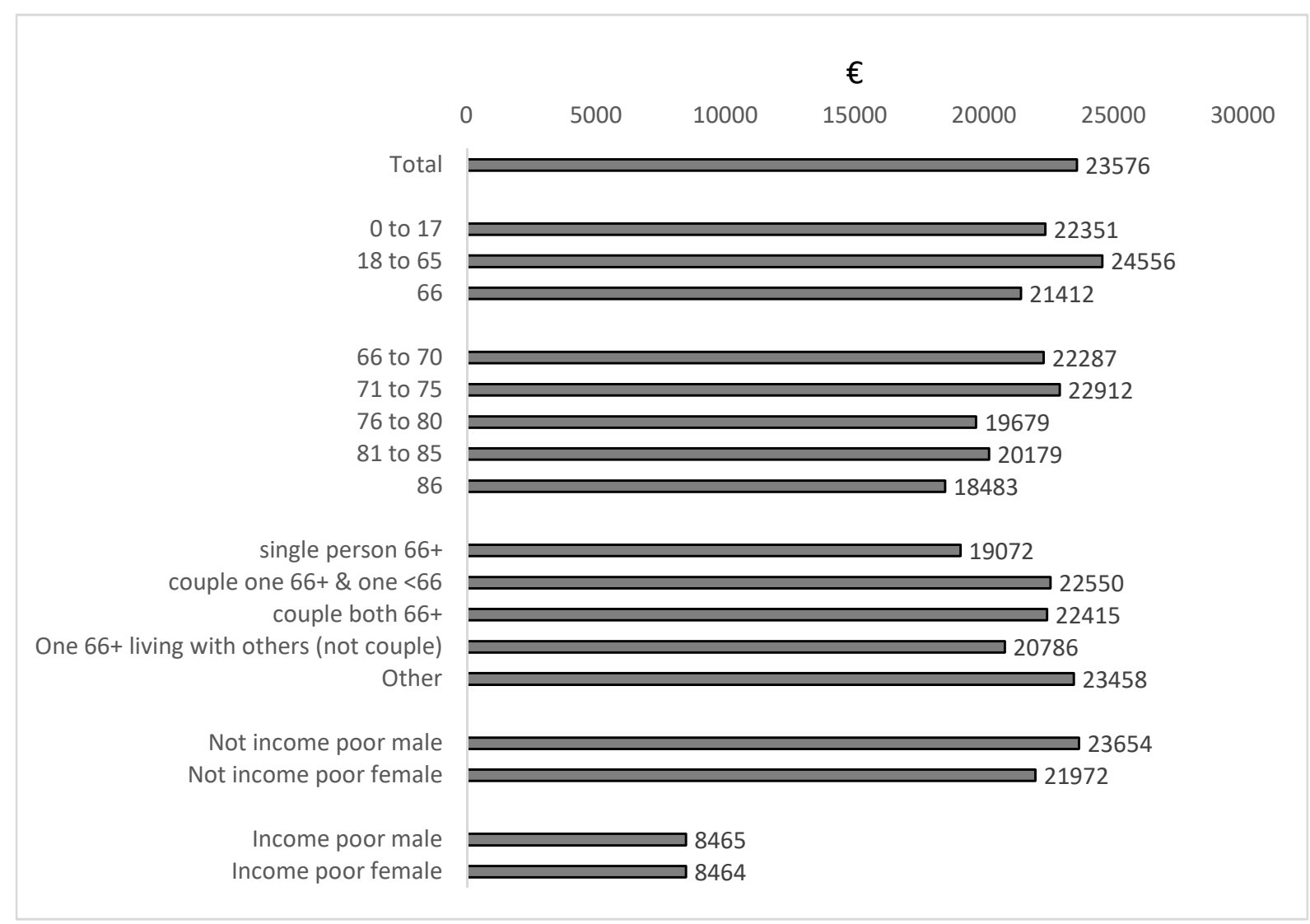

\subsubsection{Household income sources of older people}

In Table 3.2 we report the income sources of all households of people aged 66 and over as well as by income poverty status. For statistical reasons linked to the robustness of the results, we cannot report any statistics when the number of households in receipt of a specific income is too low. However, the sum of all the detailed incomes shown in Table 3.2 represents between 92 and 98 per cent of the total gross household income, so there is very little lost income information overall. 
Looking first at all households of people aged 66 and over, almost 87 per cent are in receipt of contributory pension income and 20 per cent of non-contributory pension income, for a respective annual average of $€ 22,845$ and $€ 2,689$. The former pension represents 62 per cent of the total gross household income while it is 7 per cent for the latter. While only 14 per cent of these households are in receipt of income from work, for an average of $€ 4,238$, it is their second largest source of income at almost 11 per cent. So income from work as well as contributory and non-contributory pensions represents 82 per cent of the total gross income of all households of older people, and the range of all other sources of income varies from less than 1 per cent to almost 7 per cent each.

Looking now at the income-poor households, the average gross household income at $€ 13,639$ is 2.7 times less than for all older households. ${ }^{30}$ We note that fewer poor households are in receipt of contributory pension income at 61 per cent (vs 87 per cent for all households) for an overall average of $€ 6,469$, which is 3.5 times less than for all households and contributes only 48 per cent of their total gross income (vs 62 per cent for all households). More poor households are also in receipt of non-contributory pension income, at 32 per cent, and they are more dependent on this type of benefit as it contributes 22 per cent of their total gross income. Finally, 13 per cent of poor households are receiving unemployment benefits amounting to 10 per cent of their gross income, while it is less than 2 per cent for all households aged $66+.{ }^{31}$

The much lower level of receipt and mean level of contributory pension of poor older people has several possible explanations: weak previous relationship to the labour market, due to periods of inactivity (home duties, unemployment); periods of emigration (working or not); as well as persons not claiming their full entitlements. 


\begin{tabular}{|c|c|c|c|c|c|c|c|c|c|}
\hline & \multicolumn{3}{|c|}{ All households with $66+$} & \multicolumn{3}{|c|}{ Not income poor } & \multicolumn{3}{|c|}{ Income poor } \\
\hline & $\begin{array}{c}\% \\
\text { receipt }\end{array}$ & Mean & $\begin{array}{l}\text { As \% of gross } \\
\text { income }\end{array}$ & $\begin{array}{c}\% \\
\text { receipt }\end{array}$ & Mean & $\begin{array}{l}\text { As \% of gross } \\
\text { income }\end{array}$ & $\begin{array}{c}\% \\
\text { receipt }\end{array}$ & Mean & $\begin{array}{l}\text { As \% of gross } \\
\text { income }\end{array}$ \\
\hline Employee cash or near-cash income & 14.2 & 4238 & 11.5 & 15.1 & 5397 & 13.4 & & & \\
\hline Cash benefits or losses from self-employment & 11.8 & 2422 & 6.6 & 12.1 & 2887 & 7.2 & 8.6 & 549 & 4.0 \\
\hline Pension from individual private plans & 9 & 1025 & 2.8 & 9.3 & 1075 & 2.7 & & & \\
\hline Unemployment benefits & 7.4 & 593 & 1.6 & 6.8 & 663 & 1.6 & 13.2 & 1361 & 10.0 \\
\hline Old age benefits (contributory)* & 86.6 & 22845 & 61.9 & 89.3 & 24337 & 60.5 & 60.5 & 6479 & 47.5 \\
\hline Old age benefits (non-contributory) & 20.4 & 2689 & 7.3 & 19.3 & 2528 & 6.3 & 31.7 & 2965 & 21.7 \\
\hline Disability benefits (Contributory) & 2.6 & 196 & 0.5 & 2.8 & 234 & 0.6 & & & \\
\hline Disability benefits (non-contributory) & 2.6 & 272 & 0.7 & 2.7 & 298 & 0.7 & & & \\
\hline Income from rental of a property or land & 6.1 & 432 & 1.2 & 6.3 & 467 & 1.2 & & & \\
\hline Family/children related allowances & 10.2 & 885 & 2.4 & 10.1 & 939 & 2.3 & 11.1 & 574 & 4.2 \\
\hline Social exclusion not elsewhere classified & 1.9 & 35 & 0.1 & 2 & 35 & 0.1 & & & \\
\hline Housing allowances & 75.7 & 562 & 1.5 & 76.7 & 553 & 1.4 & 66.6 & 420 & 3.1 \\
\hline $\begin{array}{l}\text { Interest, dividends, profit from capital investments in } \\
\text { unincorporated business }\end{array}$ & 20.7 & 637 & 1.7 & 21.6 & 712 & 1.8 & 12.1 & 208 & 1.5 \\
\hline Total gross household income & & 36,918 & 100.0 & & 40,215 & 100.0 & & 13,639 & 100.0 \\
\hline
\end{tabular}

Source: Pooled data, SILC 2015 and 2016.

Note: $\quad$ *Old age benefits (contributory) includes state and occupational contributory pensions. 'Income poor' means that the household income is below the 60\% income poverty line while 'not income poor' is when the household income is above the $60 \%$ income poverty line (see Section 3.2.2). 


\subsubsection{Personal income sources of older people}

Table 3.2 presents data on all the sources of income within households of older people. In Table 3.3, we focus on the individual incomes of older people by gender and poverty status. Overall, with an annual gross average of $€ 14,602$, contributory pensions are the main source of income for older people (80 per cent of their total income) and 76 per cent of older people are in receipt of such income. However, there are large disparities across gender in terms of level of receipt and average income. Indeed, while 86 per cent of older men are in receipt of contributory pension, the figure is only 68 per cent for women. The corresponding income for older men is $€ 19,007$, and it is almost 1.8 times more than for older women at $€ 10,822$.

The gender difference in the mean contributory pension can be explained partially by the fact that men (when qualified) might be in receipt of an increase for a qualified adult but also that more women could be in receipt of lower personal rates. Regarding the non-contributory pension, more women are in receipt of this scheme and women also receive a slightly greater amount compared to men. Men are more likely to receive income from self-employment and from individual private pension schemes, both types of income accounting for almost 14 per cent of their total gross income while it is less than 4 per cent for women.

The contrast with poor men and women is very sharp. The mean personal income of all men, at $€ 24,853$, is 2.6 times more than for poor men, at $€ 9,715$. Only 62 per cent of poor men are in receipt of contributory pension (vs 86 per cent for all men) for an annual amount three times less than for all men. Poor older men are also more dependent on income from non-contributory pensions in terms of level of receipt ( 27 per cent vs 14 per cent for all men) and share of income compared to all men. We find a similar but more pronounced pattern for poor older women. Less than half of poor women (41 per cent) are in receipt of contributory pension, for an annual amount three times less than for all women. More poor older women are also in receipt of non-contributory pension (31 per cent vs 20 per cent for all women) and their level of dependence on this scheme is very high, as it represents 43 per cent of their total income (vs 15 per cent for all women). 


\begin{tabular}{|c|c|c|c|c|c|c|c|c|c|c|}
\hline & \multicolumn{2}{|c|}{ All 66+ } & \multicolumn{2}{|c|}{ Men 66+ } & \multicolumn{2}{|c|}{ Women 66+ } & \multicolumn{2}{|c|}{ Income-poor men 66+ } & \multicolumn{2}{|c|}{ Income-poor women 66+ } \\
\hline & $\%$ receipt & Mean & $\%$ receipt & Mean & $\%$ receipt & Mean & $\%$ receipt & Mean & $\%$ receipt & Mean \\
\hline Employee income & $2.9 \%$ & 605 & $2.7 \%$ & 829 & $3.1 \%$ & 412 & $*$ & $*$ & * & $*$ \\
\hline Self-employment income & $6.9 \%$ & 1202 & $11.8 \%$ & 2240 & $2.7 \%$ & 311 & $*$ & $*$ & $*$ & $*$ \\
\hline Pension from private plans & $5.9 \%$ & 630 & $9.5 \%$ & 1136 & $2.9 \%$ & 196 & $*$ & $*$ & $*$ & $*$ \\
\hline Unemployment benefits & $1.3 \%$ & 69 & $1.9 \%$ & 112 & $*$ & $*$ & $*$ & $*$ & $*$ & $*$ \\
\hline Old age benefits (contr.) & $76.4 \%$ & 14,602 & $86.4 \%$ & 19,007 & $67.8 \%$ & 10,822 & $61.6 \%$ & 6465 & $40.9 \%$ & 3,349 \\
\hline Old age benefits (non-contr.) & $16.8 \%$ & 1870 & $13.7 \%$ & 1529 & $19.6 \%$ & 2162 & $26.5 \%$ & 2392 & $30.5 \%$ & 2,610 \\
\hline Total individual gross income** & & 18,978 & & 24,853 & & 13,935 & & 9,715 & & 6,060 \\
\hline
\end{tabular}

Source: Pooled data, SILC 2015 and 2016.

Note: $\quad{ }^{*}$ The number of cases in the cell is too low to be reported due to reliability issues and potential statistical disclosure. ${ }^{* *}$ The total income is not equal to the sum of the individual income components presented in Table 3.3, as some income components did not fit the statistical requirement mentioned for *. 


\subsection{SUMMARY AND CONCLUSIONS}

Older people in Ireland have had, for quite some time, the lowest income poverty and material deprivation rates compared to the working age population and children. The latest CSO poverty figures show that in 2017, the AROP rate was less than 9 per cent for older people, 16 per cent for the working-age population and 18 per cent for children. The material deprivation rates show a similar pattern across these groups, with respective rates of almost 10 per cent, 19 per cent and 23 per cent. As the Great Recession hit Ireland, one of the policy responses from the government was to cut public spending by reducing social welfare benefits, with the exception of old age pensions (contributory and non-contributory) to protect older people from poverty and social exclusion. While during the recent period the pension rate was very close to the income poverty threshold for a single household, we have examined in this chapter the reasons why some older people, though quite a low number, might still be in income poverty.

An examination of the living arrangements of income-poor older people showed that almost 80 per cent live in either single or couple households; this refutes the hypothesis that the presence of other household members would impact on their household equivalised income (on which the income poverty thresholds are determined). A close examination of the household and personal income of older people showed, not surprisingly, a high dependence on old-age benefits (mostly occupational pensions), which represent almost 80 per cent of their total personal income.

A gender breakdown revealed some gender disparities among older people, with a lower rate of receipt and average level of contributory pensions for women. While there is a gender gap in pension entitlements, there is no overall gender poverty gap for older people, suggesting that the pension system provides a good safety net to all. Not surprisingly, poor older people were also characterised by a lower mean level of contributory pension but also lower levels of receipt, with similar gender disparities. This could be explained by the fact that some older people are not in receipt of a contributory pension while being eligible for it, and also that some older people are not in receipt of a full-rate pension due to their specific labour market history (working abroad, absence from the labour market, etc.).

\subsection{APPENDIX: FURTHER ANALYSIS USING TILDA}

\subsubsection{Introduction}

This part of the study uses data from the Irish Longitudinal Study on Ageing (TILDA) to complement the earlier analysis using EU-SILC. While TILDA is not a household survey, and is therefore not appropriate for an analysis of income poverty in older 
age, it does contain additional information on wealth and migration history that is not available in SILC and may be informative for understanding patterns of income poverty in older age. ${ }^{32}$ Section 2.4.1 describes the TILDA study in greater detail. In this section, we analyse data from Wave 4, conducted in 2016, in order to be broadly comparable with the timeline for the SILC data used in Chapter 3.

\subsubsection{Sample}

As TILDA is not a household survey, we focus here on single individuals, and individuals in couples with no other household members. In addition, we focus just on couples in which both partners respond to the TILDA questionnaire. The reason we impose these restrictions is that TILDA does not collect information on income from non-eligible individuals (e.g. adult children) and/or non-participating but eligible respondents (e.g. the husband/wife of an individual who responds to the TILDA survey), meaning that a total household income variable cannot be derived for these households. This reduces the sample size to 2,583 , just under 50 per cent of the original sample. Of these individuals, 45.0 percent are in single households, while the remaining 55.0 per cent are in couple households (see Table A1). For the full TILDA wave 4 sample $(n=5,171), 25.1$ per cent of individuals are in single households, 50.5 per cent are in couple households and the remainder (24.4 per cent) are in other household types (e.g., couple households with children).

\begin{tabular}{|l|c|c|}
\hline Household type & $\boldsymbol{n}$ (individuals) & $\%$ \\
\hline Single adult, aged <66 & 317 & 12.3 \\
\hline Single adult, aged 66+ & 845 & 32.7 \\
\hline Couple, both aged <66 & 388 & 15.0 \\
\hline Couple, one aged 66+ & 288 & 11.1 \\
\hline Couple, both aged 66+ & 745 & 28.8 \\
\hline Total & 2,583 & 100.0 \\
\hline
\end{tabular}

Table A2 illustrates that this sample is on average 71 years of age, 45 per cent are male, 55 per cent are married, 35 per cent have a third-level education, and 63 per cent are retired. ${ }^{33}$

32 In addition, with the exception of Wave 1 (collected in 2010), TILDA does not contain information on household disposable income, which is necessary to calculate income poverty risk.

33 In comparison with the full Wave 4 sample (i.e., including individuals in other household types, and those with missing income), this sample is slightly older, less likely to be married, and more likely to be retired and not employed or selfemployed. Their average household equivalised weekly income is also approximately 20 per cent higher than that for the full Wave 4 sample; $€ 550.59$ vs $€ 453.45$ 


\begin{tabular}{|c|c|c|c|c|c|c|c|}
\hline Household type & Age & $\begin{array}{c}\% \\
\text { Male } \\
\end{array}$ & $\begin{array}{c}\% \\
\text { Married }\end{array}$ & $\begin{array}{l}\% \text { Third } \\
\text { level }\end{array}$ & $\begin{array}{c}\% \\
\text { Retired }\end{array}$ & $\begin{array}{c}\% \\
\text { Employed }\end{array}$ & $\begin{array}{c}\text { \% Self- } \\
\text { employed }\end{array}$ \\
\hline $\begin{array}{l}\text { Single adult, aged } \\
<66\end{array}$ & 61.4 & 46.4 & 3.1 & 44.8 & 29.1 & 33.5 & 11.1 \\
\hline $\begin{array}{l}\text { Single adult, aged } \\
66+\end{array}$ & 76.5 & 35.1 & 3.7 & 29.6 & 79.3 & 3.1 & 3.0 \\
\hline $\begin{array}{l}\text { Couple, both aged } \\
<66\end{array}$ & 61.1 & 52.3 & 97.4 & 39.4 & 22.8 & 38.2 & 15.6 \\
\hline $\begin{array}{l}\text { Couple, one aged } \\
66+\end{array}$ & 67.8 & 54.2 & 97.9 & 38.9 & 61.9 & 15.0 & 6.3 \\
\hline $\begin{array}{l}\text { Couple, both aged } \\
66+\end{array}$ & 73.9 & 49.8 & 97.6 & 33.3 & 79.4 & 2.4 & 5.0 \\
\hline Total & 70.6 & 45.4 & 55.3 & 35.0 & 62.8 & 13.2 & 6.8 \\
\hline All 56+ & 68.9 & 46.0 & 67.9 & 36.4 & 51.8 & 18.7 & 10.8 \\
\hline
\end{tabular}

\subsubsection{Wealth}

To reduce respondent burden in TILDA, wealth information is collected from one respondent in each household, the nominated financial respondent. We first calculate three broad indicators of household wealth, namely net financial wealth, net housing wealth and net total wealth. Net financial wealth is derived by aggregating data on savings, stocks/shares, investment property, other assets (land, art, jewellery, etc.) and cars, and subtracting non-mortgage debt. Nonannuitised pension wealth is not included. Net housing wealth is derived by subtracting mortgage debt from the value of the principal private residence. Financial and housing wealth are also summed to generate total net household wealth. All wealth measures are then assigned to all respondents in the household, and adjusted for household size and composition using the national equivalence scale. ${ }^{34}$

Table A3 illustrates that on average, over 90 per cent of individuals report positive net financial wealth and a similar proportion have positive net housing wealth. As wealth data are typically highly skewed, it is more informative to examine median rather than average values. The data indicate that couples where both partners are aged less than 66 have the highest median net financial wealth $(€ 60,843)$, while older households have the highest median housing wealth values. ${ }^{35}$ An analysis of the main financial wealth components in Tables $A 4$ and $A 5$ reveals that the main form of financial wealth held by older households is savings; nearly 85 per cent of individuals have positive savings, although the proportion with positive savings is considerably lower among single individuals aged less than $66 .{ }^{36}$ While about 25

34 While the concept of equivalisation is appropriate for income in order to reflect economies of scale in consumption, no internationally agreed equivalence scales exist for household wealth, and there is no consensus on whether the scales used for income are also appropriate for wealth (OECD, 2018b).

35 The lower values for younger households reflect outstanding mortgage debt.

36 Data for wealth held in cars are not presented here. 
per cent of households have positive stock wealth, this proportion varies considerably across household types, being much higher in couple households (a similar pattern is evident for investment property and, to a lesser extent, other assets).

TABLE A3

HOUSEHOLD EQUIVALISED WEALTH (\%, MEAN, MEDIAN)

\begin{tabular}{|c|c|c|c|c|c|c|c|c|c|}
\hline Household type & \multicolumn{3}{|c|}{ Financial wealth } & \multicolumn{3}{|c|}{ Housing wealth } & \multicolumn{3}{|c|}{ Total wealth } \\
\hline & $\%$ & Mean & Median & $\%$ & Mean & Median & $\%$ & Mean & Median \\
\hline Single adult, aged <66 & 82.2 & 126,986 & 19,000 & 77.7 & 160,931 & 140,000 & 90.8 & 284,904 & 175,000 \\
\hline Single & 90.1 & 103,109 & 0 & 4.4 & 29 & 00 & 5.3 & 310,688 & 000 \\
\hline $\begin{array}{l}\text { Couple, both aged } \\
<66\end{array}$ & 91.3 & 157,477 & 60,843 & 94.8 & 148,262 & 120,482 & 97.5 & 313,272 & 9,639 \\
\hline Couple, one aged $66+$ & 94.1 & $1 \angle U, 689$ & ग0,404 & 94.3 & 180,990 & 144,578 & 97.2 & 296,565 & 209,639 \\
\hline $\begin{array}{l}\text { Couple, both aged } \\
66+\end{array}$ & 95.8 & 29 & 77 & 98.9 & 82 & 2 & 99.6 & 95 & 215,361 \\
\hline Total & 91.3 & 123,494 & 30,120 & 90.3 & 196,750 & 150,000 & 96.4 & 310,950 & 207,916 \\
\hline All $56+*$ & 90.8 & 107,837 & 25,301 & 91.4 & 172,415 & 125,628 & 96.6 & 273,765 & 180,723 \\
\hline
\end{tabular}

Note: * These data refer to Wave 4, collected in 2016, when the youngest TILDA respondents were 56 years of age.

TABLE A4 COMPONENTS OF FINANCIAL EQUIVALISED WEALTH (\%, MEAN, MEDIAN)

\begin{tabular}{|l|c|c|c|c|c|c|}
\hline Household type & \multicolumn{3}{|c|}{ Savings } & \multicolumn{3}{c|}{ Stocks } \\
\hline & $\%$ & Mean & Median & $\%$ & Mean & Median \\
\hline Single adult, aged <66 & 75.5 & 30,383 & 7,000 & 17.8 & 18,621 & 0 \\
\hline Single adult, aged 66+ & 83.1 & 45,557 & 15,000 & 17.2 & 12,694 & 0 \\
\hline Couple, both aged <66 & 84.0 & 27,106 & 12,048 & 37.1 & 27,466 & 0 \\
\hline Couple, one aged 66+ & 88.1 & 33,162 & 12,048 & 26.4 & 16,289 & 0 \\
\hline Couple, both aged 66+ & 89.7 & 58,371 & 15,060 & 31.9 & 12,779 & 0 \\
\hline Total & 84.7 & 43,365 & 15,000 & 25.4 & 16,023 & 0 \\
\hline & & & & & & \\
\hline All 56+* & 83.5 & 32,849 & 9,638 & 25.8 & 13,399 & 0 \\
\hline
\end{tabular}

Note: $\quad$ * These data refer to Wave 4, collected in 2016, when the youngest TILDA respondents were 56 years of age.

TABLE A5 COMPONENTS OF FINANCIAL EQUIVALISED WEALTH (\%, MEAN, MEDIAN)

\begin{tabular}{|l|c|c|c|c|c|c|}
\hline Household type & \multicolumn{3}{|c|}{ Investment property } & \multicolumn{3}{c|}{ Other assets } \\
\hline & $\%$ & Mean & Median & $\%$ & Mean & Median \\
\hline Single adult, aged $<66$ & 9.5 & 25,587 & 0 & 14.6 & 51,093 & 0 \\
\hline Single adult, aged 66+ & 6.0 & 16,194 & 0 & 12.1 & 25,356 & 0 \\
\hline Couple, both aged <66 & 19.4 & 33,049 & 0 & 24.2 & 57,406 & 0 \\
\hline Couple, one aged 66+ & 18.6 & 29,291 & 0 & 23.8 & 30,102 & 0 \\
\hline Couple, both aged 66+ & 17.5 & 29,134 & 0 & 18.3 & 29,444 & \\
\hline Total & 13.0 & 24,973 & 0 & 17.2 & 34,995 & 0 \\
\hline All 56+* & & & & & & \\
\hline
\end{tabular}

Note: $\quad$ * These data refer to Wave 4, collected in 2016, when the youngest TILDA respondents were 56 years of age. 


\subsubsection{Migration history}

All TILDA respondents are asked about where they were born and about time spent living abroad. Table A6 shows that 24 per cent of men and 21 per cent of women in this sample had lived abroad for a period of six months or more. For women, the proportion is highest among singles, while for men the proportions are highest for older singles and those in couples. Of those who have lived abroad for over six months, the average length of time spent abroad is approximately 11 years for both men and women. 
TABLE A6 MIGRATION HISTORY (\%)

\begin{tabular}{|c|c|c|c|c|c|c|c|c|}
\hline \multirow{2}{*}{$\begin{array}{l}\text { Household } \\
\text { type }\end{array}$} & \multicolumn{4}{|c|}{ Men } & \multicolumn{4}{|c|}{ Women } \\
\hline & $\begin{array}{l}\text { Born } \\
\text { outside } \\
\text { Rol }\end{array}$ & $\begin{array}{l}\text { Born in Rol and } \\
\text { never lived } \\
\text { abroad }\end{array}$ & $\begin{array}{c}\text { Born in Rol and } \\
\text { lived abroad }<6 \\
\text { months }\end{array}$ & $\begin{array}{l}\text { Born in Rol and } \\
\text { lived abroad } \geq 6 \\
\text { months }\end{array}$ & $\begin{array}{l}\text { Born } \\
\text { outside } \\
\text { Rol }\end{array}$ & $\begin{array}{l}\text { Born in Rol and } \\
\text { never lived } \\
\text { abroad }\end{array}$ & $\begin{array}{c}\text { Born in Rol and } \\
\text { lived abroad }<6 \\
\text { months }\end{array}$ & $\begin{array}{c}\text { Born in Rol and } \\
\text { lived abroad } \geq 6 \\
\text { months }\end{array}$ \\
\hline $\begin{array}{l}\text { Single adult, } \\
\text { aged }<66\end{array}$ & 6.1 & 53.1 & 16.3 & 24.5 & 10.6 & 32.9 & 27.6 & 28.8 \\
\hline $\begin{array}{l}\text { Single adult, } \\
\text { aged } 66+\end{array}$ & 8.4 & 44.4 & 17.8 & 30.3 & 9.8 & 40.9 & 22.3 & 27.0 \\
\hline $\begin{array}{l}\text { Couple, both } \\
\text { aged }<66\end{array}$ & 6.9 & 41.4 & 30.0 & 21.7 & 15.1 & 42.7 & 25.4 & 16.8 \\
\hline $\begin{array}{l}\text { Couple, one } \\
\text { aged } 66+\end{array}$ & 9.6 & 40.4 & 22.4 & 27.6 & 18.2 & 26.5 & 35.6 & 19.7 \\
\hline $\begin{array}{l}\text { Couple, both } \\
\text { aged } 66+\end{array}$ & 9.2 & 38.5 & 24.0 & 28.3 & 10.2 & 37.4 & 28.9 & 23.5 \\
\hline Total & 8.3 & 42.3 & 22.3 & 27.1 & 11.5 & 37.9 & 26.3 & 24.3 \\
\hline All 56+* & 8.1 & 45.9 & 22.0 & 24.0 & 10.9 & 42.6 & 25.4 & 21.1 \\
\hline
\end{tabular}

* These data refer to Wave 4, collected in 2016, when the youngest TILDA respondents were 56 years of age. 


\subsubsection{Discussion}

Social welfare pension payments should generally be sufficient to keep people out of income poverty, yet in 2017, approximately 9 per cent of the over-65s were classified as 'at risk of poverty'. While TILDA cannot analyse the extent to which income poverty risk in these older households may be accounted for by household composition, as it is not a household survey, information on household and individual characteristics such as wealth, work history and migration history can be informative in understanding patterns of income poverty in older age.

In interpreting the patterns presented in this Appendix, it must be remembered that the data refer to a selected group of the older population, i.e., those aged 56+ in 2016, who completed all previous TILDA waves, in single and couple households (with no other members such as children), and with complete information on household income from all TILDA respondents in the household. This group is older, less likely to be married and less likely to be employed or self-employed, but has higher household incomes, than the full TILDA sample.

Notwithstanding these caveats around sample composition, two key points of relevance to discussions around income poverty in older age emerge from this analysis of the Wave 4 TILDA data. First, among this cohort of older individuals (aged 56+ in 2016), while most of the household wealth is accounted for by the principal private residence (over 60 per cent), the median value of net financial wealth is just over $€ 30,000$. To the extent that asset wealth (non-principal private residence) is taken into account in the calculation of the non-contributory state pension, further analysis of the wealth holdings of older households might shed some light on why some older individuals are in income poverty.

Second, among this cohort of older individuals, over 20 per cent of men and women had lived abroad for a period of six months or more, and the average length of time spent living and working abroad was 11 years. Given these patterns, an issue to consider is the extent to which foreign income sources are captured accurately in datasets such as SILC that are used to monitor income poverty in older age. 


\section{CHAPTER 4}

\section{Gender and financial decision-making}

\subsection{INTRODUCTION}

As noted in Chapter 1, demographic trends mean that older women, who live longer than men, will make up a larger share of the population, and will be increasingly likely to live alone. This means that older women will need to assume greater responsibility for their own financial security in older age. In order for policymakers to tackle gender inequalities in economic outcomes at older age, it is also important to understand how men and women may differ in terms of financial decision-making. Decisions about many aspects of economic life are shaped by attitudes to risk, time preferences, and financial literacy skills, and by the ways in which households allocate decision-making responsibility for financial matters.

In this chapter, we first review the literature on three key characteristics related to financial decision-making that differ between men and women, namely preferences, numeracy/financial literacy and household decision-making roles (Section 4.2). Ascertaining the extent to which these factors may contribute to explaining the gender differences in economic outcomes in older age is outside the scope of the current study, although the literature on gender wealth gaps points to differences in lifetime income, education and employment trajectories between men and women as the main explanations (Neelakantan and Chang, 2010; Sierminksa, 2017; Ruel and Hauser, 2013). We evaluate the extent to which information on these aspects of financial decision-making is available in existing national data sources in Ireland (Section 4.3). Section 4.4 gives a summary of the findings and some implications for future research and data collection.

\subsection{LITERATURE REVIEW}

\subsubsection{Preferences}

It is often hypothesised that gender differences in economic outcomes are due partly to differences in preferences between men and women (Croson and Gneezy, 2009; Olivetti and Petrongolo, 2016). ${ }^{37}$ Risk and time preferences are the key parameters in economic models determining consumption and savings over the lifecycle. They play an important role in an individual's decision to invest in education, pensions, health, etc. (Brown and van der Pol, 2015).

37 Croson and Gneezy (2009) review the experimental literature on gender differences in three types of preferences: risk preferences, social preferences (i.e. the degree to which others' utility enters into an individual's utility function) and reaction to competition. They find clear evidence that women are more risk-averse than men, and are more averse to competition than men. Barber and Odean (2001) find that men are more overconfident than women, and this leads them to trade more frequently in the stock market and experience greater stock market losses than women. 


\section{Risk preferences}

Risk and uncertainty play a role in many economic decisions. Therefore, understanding individual attitudes to risk is closely linked to understanding and predicting economic behaviour. Individuals have differing attitudes to risk. For example, when given a chance to purchase a lottery ticket with equal chances of winning $€ 10$ or $€ 0$, a risk-neutral individual will be willing to pay $€ 5$. Individuals who are only willing to pay less than $€ 5$ are considered to be risk-averse, while those willing to pay more are considered to be risk-seeking or risk-tolerant (Charness et al., 2013).

Individual-level information on risk preferences is generally elicited from either surveys or field experiments, and there is a lively debate on the relative merits of different methods for eliciting risk preferences (Charness et al., 2013; Dohmen et al., 2010). ${ }^{38}$ There is clear evidence from both survey and experimental evidence that women are more risk-averse than men. Using survey data from the German Socioeconomic Panel (GSOEP), Dohmen et al. (2011) find that women are significantly more risk-averse than men, based on responses to a general selfreported risk question, and also from five domain-specific risk questions (car driving, financial matters, sports and leisure, health, career). They validate the use of the general self-reported risk question using data from a sample of $450 \mathrm{German}$ adults who participated in a field experiment to elicit risk preferences, while also answering the same risk question that was used in the GSOEP. They also find that risk attitudes are strongly but not perfectly correlated across contexts. Gender differences are most pronounced for car driving and financial matters. Sahm (2012), using data from the HRS (adults aged 50+), finds large differences in risk preferences by gender and race. Similarly, Banks et al. (2019), using data from the Survey of Health, Ageing and Retirement in Europe (SHARE), find that men are more risk-tolerant than women in terms of financial risk-taking.

Using experimental data on a large sample of Dutch adults, von Gaudecker et al. (2011) also find gender differences in risk preferences. Charness and Gneezy (2012), using data from 15 sets of experiments with one simple underlying investment game, find a very consistent result that women invest less, and thus appear to be more financially risk-averse than men (the optimal strategy in each experiment is to invest more). Eckel and Grossman (2008b) review the results from experimental measures of risk aversion for evidence of systematic differences in the behaviour of men and women. For most studies, they find that women are more averse to risk than men. Eckel and Grossman (2008a), using data from a sample of US university students, also find significant differences in risk preferences between men and women, as well as significant differences in the 
perceptions of risk aversion of men and women (which in turn may lead to negative stereotyping of women).

Why are women more risk-averse than men? Croson and Gneezy (2009) discuss a number of hypotheses, including greater emotional responses to risk among women, greater overconfidence on the part of men and gender differences in the assessment of risk as a challenge (men) or a threat (women). Borghans et al. (2009), using data on Dutch high-school students, find that the gender difference in risk aversion can be partly, but not fully, explained by gender differences in personality traits (i.e. those who are less agreeable and less neurotic are less risk averse).

However, it has been suggested that these individual-level differences in risk preferences may be artefactual, resulting from the different methodologies adopted, particularly when the framing of questions and the influence of familiarity and skill on decision-making are not taken into account (Powell and Ansic, 1997). Indeed, Schubert (1999), in an experimental study of Swiss undergraduates, shows that gender differences in financial risk attitudes are possibly confounded with wealth effects due to gender-specific differences in the underlying income and wealth levels of participants.

Risk aversion is generally associated with lower levels of income and wealth (Dohmen et al., 2011; Sahm, 2012), as well as other choices relevant to financial wellbeing such as the share of wealth in equities, occupation, etc. (Banks et al., 2019; Kettlewell, 2018). It is difficult to conclude that risk aversion causes lower income and wealth, however, as the relationship is likely to be endogenous (e.g. having higher income or wealth may also lead to higher risk tolerance). Indeed, Kettlewell (2018), using data from the Household Income and Labour Dynamics Survey in Australia (HILDA), finds that improvements in finances are associated with increased risk tolerance, while worsening finances, parenthood and the death of a spouse or child are associated with increased risk aversion. However, he also finds that preferences are mean-reverting, i.e. the impact of life events tends to be stronger closer to the event date and disappears over time (although there is evidence that mean reversion is less for women in response to a negative financial shock). Malmendier and Nagel (2011) similarly find that those exposed to greater financial losses in the US over the period 1960 to 2007 became more risk-averse. Using data on clients of an Italian bank, Guiso et al. (2018) find that risk aversion increased following the 2008 financial crisis.

Risk preferences are also associated with other factors important for economic decision-making, highlighting the difficulty in isolating the causal effect of risk preferences in empirical analyses. Data from the English Longitudinal Study on Ageing (ELSA) show that those who are more risk-tolerant are also more patient (Crossley et al., 2012), while data from the GSOEP show that those who are more risk-tolerant have higher cognitive abilities (Bonsang and Dohmen, 2015; Dohmen 
et al., 2010). Data from the GSOEP and HRS show that those who are more risktolerant have parents with higher levels of education (Dohmen et al., 2011; Sahm, 2012). In other words, risk tolerance is correlated with other characteristics such as time preferences, education and cognition that are also associated with economic outcomes.

\section{Time preferences}

Individual time preferences are important for many economic decisions, particularly those involving a trade-off between immediate and delayed utility (Dittrich and Leipold, 2014). Saving for retirement is a key example of a decision that requires an accurate calculation of future costs and benefits. The rate of time preference is summarised by the discount rate: the rate at which individuals discount future net benefits. Time preferences are generally elicited via observational or experimental studies where respondents are asked to choose over a set of binary choices between smaller, immediate rewards and larger, delayed rewards. This allows for the calculation of a discount rate, with higher discount rates indicative of a greater tendency to discount the value of future rewards (Daly et al., 2009).

In contrast to the extensive literature documenting that men are more risktolerant than women, there is much less agreement in the literature regarding gender differences in time preferences. Dittrich and Leipold (2014), using experimental data from a survey of over 1,000 German adults, find that women are more patient than men. ${ }^{39}$ Using data on the over-70s from the HRS, Huffman et al. (2017) show that while impatience rises with age, ${ }^{40}$ there is no significant difference in time preference rates between older men and women. Daly et al. (2009), using data on 149 Irish university students, similarly find no significant difference in discount rates between men and women. In a survey of nearly 7,000 students across 53 countries, Wang et al. (2016) also find no significant gender difference in time preference rates.

In general, a lower discount rate (i.e. more patience) is associated with better financial outcomes. Using merged administrative and survey data for public sector workers in North Carolina, Clark et al. (2017) examine how workers' characteristics and preferences are associated with planning and saving for retirement. They find that individuals' rates of time preference are associated with the extent of their retirement planning and preparedness. In statistical models with both risk and time preferences, time preferences are more important in explaining retirement planning behaviour. Huffman et al. (2017), using data on the over-70s from the HRS, show that net wealth is significantly lower for those that are more impatient.

39 Dittrich and Leipold (2014) discuss a possible reason for the finding that women are more patient than men. They cite evidence from evolutionary psychology that due to evolutionary selection processes, women are better able than men to delay gratification and tend to be more self-disciplined.

40 As the time preference module was fielded only in 2014, they cannot rule out the possibility that the age effect is also partly capturing a cohort effect. 
Examining the relationship between childhood 'self-control' and later life pension coverage using data from the British Cohort Study (BCS) and the National Child Development Study (NCDS), Lades et al. (2017) find that higher self-control in childhood is associated with a significantly higher probability of having a pension (at ages 42 and 50). Much of this association is explained by the fact that childhood self-control is associated with economic success in adulthood (i.e. better education, economic status and higher home ownership), characteristics that are in turn associated with higher pension coverage. In contrast, Ameriks et al. (2003) and Binswanger and Carman (2012) find little predictive power for time preferences in retirement planning or wealth accumulation.

As with risk preferences, time preferences are also correlated with other characteristics that are important for economic decision-making such as numeracy (Borghans et al., 2008) and conscientiousness (Daly et al., 2009; Wang et al., 2016). ${ }^{41}$ There is also much debate on the extent to which time (and risk) preferences are fixed throughout the life course and the extent to which parental preferences are transmitted to children (Bettinger and Slonim, 2007; Brown and van der Pol, 2015; Delaney and Doyle, 2012; Olivetti and Petrongolo, 2016). For example, Banks et al. (2019) show that nearly half of the variation in risk preferences by age in Europe is due to health and other shocks (e.g. widowhood) that are correlated with age.

\subsubsection{Numeracy and financial literacy}

Numeracy/financial literacy is "knowledge of fundamental financial concepts and the ability to do simple financial calculations' (Lusardi and Mitchell, 2011b). Declines in the coverage and generosity of public programmes mean that individuals now need to assume responsibility for a greater share of their future retirement saving, and health and long-term care costs (Banks, 2010). In addition, financial products are becoming increasingly complex (Lusardi and Tufano, 2015, Skagerlund et al., 2018). In this context, the skills required to ensure adequate financial protection are demanding, requiring an understanding of discounted values, interest rates, the role of inflation, survival probabilities, etc. (Lusardi and Mitchell, 2007, 2008). Studies examining the association between financial literacy and wealth or other indicators of financial wellbeing generally find that financial literacy is as important as education and cognition in determining financial outcomes (Banks and Oldfield, 2007).

Levels of financial literacy vary considerably across the population. A consistent finding is that women have lower levels of financial literacy than men. Standard and Poor carried out a global financial literacy survey of over 150,000 adults across 140 countries in 2014 (Klapper et al., 2016). They found that worldwide, 35 per

41 McCarthy (2011), using data from the Financial Capability surveys in Ireland and the UK, found that behavioural factors such as self-control, planning and patience were statistically significant determinants of financial distress, even after controlling for education and financial literacy. 
cent of men were financially literate, compared with 30 per cent of women (being financially literate was defined as getting three out of four questions relating to numeracy, interest, inflation and diversification correct). While women were less likely to provide correct answers to the financial literacy questions, they were also more likely to indicate that they 'don't know' the answer, a finding consistently observed in many other studies. Interestingly, the gender gap was observed in both advanced and emerging economies, ${ }^{42}$ and women had weaker financial skills than men even after considering differences in age, education and income profiles. Even in the sample of those who were 'unbanked' (i.e., without a current account), men had higher financial literacy than women.

Bucher-Koenen et al. (2017) provide an overview of the literature on gender differences in financial literacy, and examine the gender gap in financial literacy in a cross-country context. They note that not only do women answer a lower percentage of questions correctly but a higher proportion answer 'don't know' to financial literacy questions. They find a persistent gender gap in financial literacy in the US, Germany and the Netherlands (using the same three questions but different fieldwork methods) that is independent of socioeconomic background and cultural and institutional context. They also find a significant gender gap among younger individuals, and argue therefore that differences in financial literacy in older age are not purely driven by a cohort effect associated with traditional gender roles among older women. Looking at financial literacy differences within couples, they find that even when women are the financial decision-maker, they display lower levels of financial literacy than corresponding men.

Lusardi and Mitchell (2008) show that women are unlikely to plan for retirement (less than one-third of older women had ever attempted to plan for retirement), and illustrate how planning behaviour is strongly related to financial literacy, i.e. those with high levels of financial literacy are much more likely to plan, and to stick to a retirement savings plan. Of the three aspects of financial literacy measured, being able to correctly answer a question about risk diversification was most strongly related to planning behaviour (more so than knowledge of interest rates and inflation).

Fonseca et al. (2012) note that understanding how and why men and women have different levels of financial literacy is crucial to developing policies aimed at reducing the gender gap in financial outcomes at older age. Using data from the American Life Panel on a sample of those aged 18+, they find that the effects of age, race and income do not differ by gender, but that men gain more than women from education in terms of financial literacy. Marriage has a particularly strong effect on financial literacy for women, with married women having higher rates of 
financial literacy than married men. They find that most of the gender gap in financial literacy is not explained by differences in observed covariates, but rather by differences in the returns to those covariates, i.e. in how financial literacy is produced. They suggest that this may be due to the division of labour for financial decisions within couples (see also Section 4.2.3), although they find little evidence to support this hypothesis.

Focusing on the possibility that the gender gap in financial literacy may be due to the division of labour within couples, Smith et al. (2010) use data on married couples from the HRS to assess the association between observed wealth outcomes for households and cognitive abilities of both spouses. To illustrate the importance of numeracy for wealth, they note that wealth is $\$ 1.7 \mathrm{~m}$ for couples where both answer all three numeracy questions correctly, but only $\$ 200,000$ for couples where both partners answer all questions incorrectly. The divergence is even greater for financial wealth (more than ten times). They also find a tendency for financial wealth to be higher when the financial respondent has the higher numeracy score. The associations also hold for the outcome of the proportion of the wealth portfolio held in stocks. For regression analyses, they examine both levels and changes in levels of wealth between 2000 and 2006 and, once again, the effect for the numeracy score of the financial respondent is much larger than the numeracy score for the non-financial respondent. Of the three broad measures of cognition they use, numeracy has by far the largest impact on wealth.

McArdle et al. (2011), using data from the HRS, also use the spousal information in the HRS to assess whether cognitive abilities of both spouses predict wealth holdings, and whether cognition of one spouse is more important than that of the other for financial outcomes. Similar to Smith et al. (2010), they show that all measures of wealth are more strongly related with the numeracy of the financial respondent rather than the non-financial respondent. Banks and Oldfield (2007) show that the association between numeracy and wealth is stronger when numeracy reflects the higher of the values for the two individuals in a benefit unit.

Financial capability refers to the study of a person's knowledge of financial products, their understanding of their own financial position and their ability to choose products appropriate to that position, along with their ability to plan ahead financially and to seek and act on appropriate advice when necessary. It has been argued that it is a broader concept than financial literacy (McCarthy, 2011; O'Donnell and Keeney, 2009, 2010). A survey of approximately 1,500 individuals in Ireland in $2007 / 2008^{43}$ found that while there was little difference between men

43 The Irish survey was based on a 2005 survey in the UK, which additionally fielded a module on financial literacy (O'Donnell and Keeney, 2009). 
and women in overall levels of financial capability (measured across four domains: managing money, planning ahead, choosing products and staying informed), there were areas of divergence. For example, women were less likely than men to 'stay informed' about financial matters and to plan ahead. ${ }^{44}$

Why do women display lower levels of financial literacy than men? Given the high correlation between numeracy and financial literacy (Smith et al., 2010; Skagerlund et al., 2018), the wider literature on gender gaps in numeracy and mathematics offers some potential explanations. Focusing on family influences, Dossi et al. (2019), using linked data on Florida public schools and birth certificates, find that girls raised in 'boy biased' families perform worse on maths than girls raised in other families. ${ }^{45}$ Using data from the National Longitudinal Survey of Youth, they also show that more traditional gender attitudes among mothers are associated with lower maths scores for daughters (but not sons). Fryer and Levitt (2010) provide evidence to show that the gender gap in mathematics begins in school; using data on more than 20,000 US children, they find that there is no gender gap in mathematics ability at the start of school, but that six years later, girls have fallen behind boys by an average of 2.5 months. At a societal level, there is some evidence that the gender gap in mathematics is correlated with the degree of gender equality (Guiso et al., 2008). ${ }^{46}$

There is also an emerging literature on gender differences in 'financial socialisation' among children and young adults. For example, Brown et al. (2018) found that the relatively higher levels of financial literacy among German-speaking students in Switzerland in comparison with their French-speaking peers may be explained by differences in financial socialisation between the two groups, i.e. German-speaking students were more likely to have access to their own bank account and to have received pocket money from a young age. Gender differences in financial socialisation have been documented in young children, with some evidence that they partly explain later gender differences in financial literacy (Agnew and Cameron-Agnew, 2015; Agnew et al., 2018).

\subsubsection{Household decision-making}

Two aspects of the way in which households make decisions are relevant to the discussion of possible gender differences in financial decision-making. First, the gender gap in financial behaviours and outcomes could also be explained by differences in decision-making within households, e.g. if husband and wife divide household tasks and the husband specialises in the accumulation of financial

44 A further survey was carried out in 2018 , although the published results do not disaggregate by gender (Competition and Consumer Protection Commission, 2018).

45 To measure family gender attitudes, the researchers examine fertility patterns within families. 'Boy biased' families are those in which all children are girls except for the last born.

46 There is some debate over whether this finding is robust to changing the sample of included countries (Fryer and Levitt, 2010). 
knowledge (Bucher-Koenen et al., 2017).

Second, understanding the extent to which the members of a household pool resources has implications for the extent of the gender pension gap (the data tend to focus on gender differences in individual pension income, but neglect to point out that many individuals live in couple or other multi-person households). A related literature on intra-household wealth inequality notes that inequality is higher when individual-level data are used instead of household-level data (Grabka et al., 2015). However, to the extent that women are more likely to be widows, and women of lower socio-economic status can expect to spend a longer period of time in widowhood than higher socio-economic status women (Nivakoski and Nolan, 2018), the allocation of household decision-making responsibility has important implications for the welfare of future widows.

So how do households allocate financial decision-making? Johnston et al. (2016) examine the allocation of financial decision-making responsibilities using eight waves of Australian survey data. They find that the relative age, education, employment and wages of male and female partners are important in explaining who 'holds the purse strings'. In particular, more highly educated females, employed females, and females with higher wages are significantly less likely to be in a relationship where the male is the main decision-maker. Using data from Italy, Bertocchi et al. (2014) similarly find that the probability that the wife is responsible for economic and financial decisions increases as the wife's characteristics in terms of age, education and income become closer to or higher than the husband's corresponding ones.

Using data from the 2010 SILC for Ireland, Watson and Maitre (2013) analyse the implications of income pooling and household decision-making for the measurement of poverty and deprivation. They find only small differences in income pooling by gender, but large differences by the person's position in the household. In terms of decision-making, they find that most couples share responsibility for decisions. They describe a 'four systems of money management' classification of household control and management processes: the whole-wage system, allowance system, shared management system and independent management system. They find that most adults do not make all of their income available for household use: only about half of them contribute all of their personal incomes to the total household income. In couple households, they find that on average, the personal income of the female partner amounts to 30 per cent of the gross personal income of the couple. In households where the female partner is over the age of 65 , the proportion of couple income received by the female partner is only 25 per cent.

Grabka et al. (2015) examine the intra-household wealth gap among couples in 2007 in Germany using data from the GSOEP. The find that the wealth gap is 
significantly larger in couples where the man 'has the last word in financial matters' than in couples with joint decision-making. On the other hand, the wealth gap is smaller when the woman manages the household finances alone (in comparison with couples where all money is shared), but these are largely low-wealth households. While these results may also reflect reverse causality (e.g. couples with a smaller wealth gap might allocate decision-making responsibility more equally than couples with a larger wealth gap), they do suggest that traditional gender financial decision-making roles may be associated with poorer financial outcomes for women.

\subsection{DATA SOURCES}

As noted, the second objective of this chapter is to assess the extent to which existing national data sources can be used to provide data on preferences, numeracy/financial literacy and household decision-making roles. As part of this exercise, we focus on the two national longitudinal surveys, Growing up in Ireland (GUI) and The Irish Longitudinal Study on Ageing (TILDA), as well as other crosssectional datasets such as the Household Finance and Consumption Survey (HFCS). The Appendix contains more details on each of the national surveys examined in this report. Where available, we also discuss the potential use of international datasets such as the European Social Survey (ESS), Programme for the International Assessment of Adult Competencies (PIAAC) and Programme for International Student Assessment (PISA).

\subsubsection{Preferences}

To our knowledge, two national data sources contain information on attitudes to risk, albeit not necessarily in the financial domain. The HFCS is a household survey that collects data on household consumption and finances. The Irish survey is part of a larger consortium of studies across the Eurozone. The first wave of the survey in Ireland was conducted with over 5,000 households in 2013. The nominated household reference person (HRP) ${ }^{47}$ is asked a self-assessment question on risk attitudes. As is evident from Figure 4.1, men and women differ in their responses to this question, with men more likely to take financial risks (the gender difference is statistically significant). Overall however, 70 per cent of men, and 83 per cent of women, state that their household is not willing to take any financial risk in making saving and investment decisions.

47 It is up to the household to nominate a reference person who answers most of the core questions relating to the household as a whole, including questions on real assets and their financing, other liabilities/credit constraints, private businesses, financial assets, intergenerational transfers and gifts, and consumption and saving. 


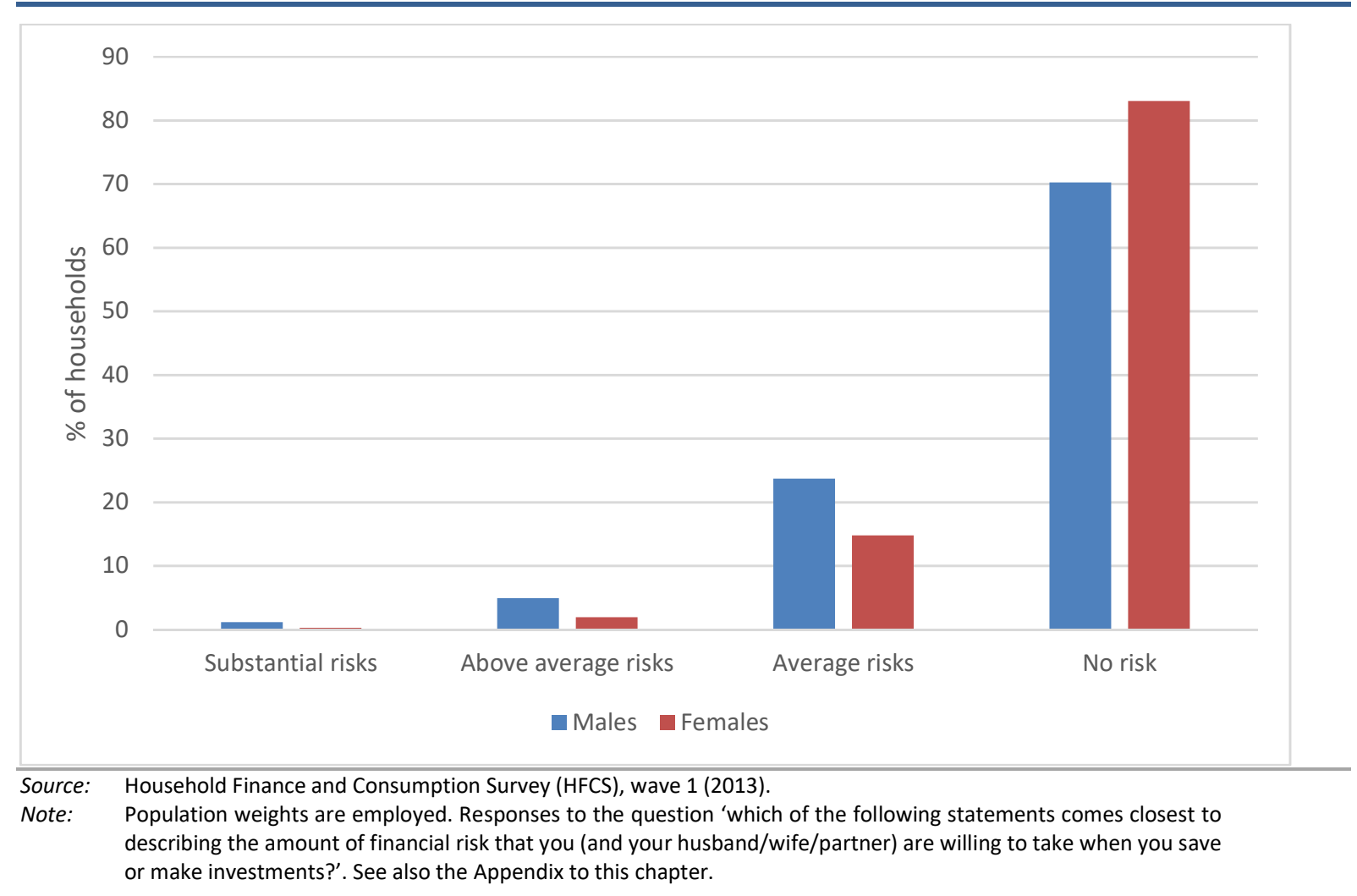

The ESS contains a module on 'human values', and one of the 21 questions in that module captures a very broad conceptualisation of attitudes towards risk (the exact domain, e.g., financial, health, etc. is not specified). ${ }^{48}$ The ESS has been conducted biennially across Europe since 2002, and Ireland has participated in all rounds of data collection. ${ }^{49}$ Figure 4.2 illustrates how men and women aged $16+$ in Ireland in 2016 differ in terms of their responses to the ESS 'risk' question. The data reveal that women are more 'risk-averse' than men, consistent with research from other settings that women are more risk-averse than men across a number of domains of risk; see for example Dohmen et al. (2011). Further analysis of the patterns in a multivariate regression analysis reveals that the significant gender effect persists, even after controlling for age and education. ${ }^{50}$

48 The core ESS questionnaire includes a well-established 21-item measure of human values. The Human Values Scale is designed to classify respondents according to their basic value orientations. See https://zis.gesis.org/skala/SchwartzBreyer-Danner-Human-Values-Scale-(ESS) for further details. One of the two items capturing 'stimulation' makes a general reference to risk as follows: 'Now I will briefly describe some people. Please listen to each description and tell me how much each person is or is not like you. She/he looks for adventures and likes to take risks. She/he wants to have an exciting life.' Responses are: 1 'very much like me', 2 'like me', 3 'somewhat like me', 4 'a little like me', 5 'not like me', 6 'not like me at all'. 


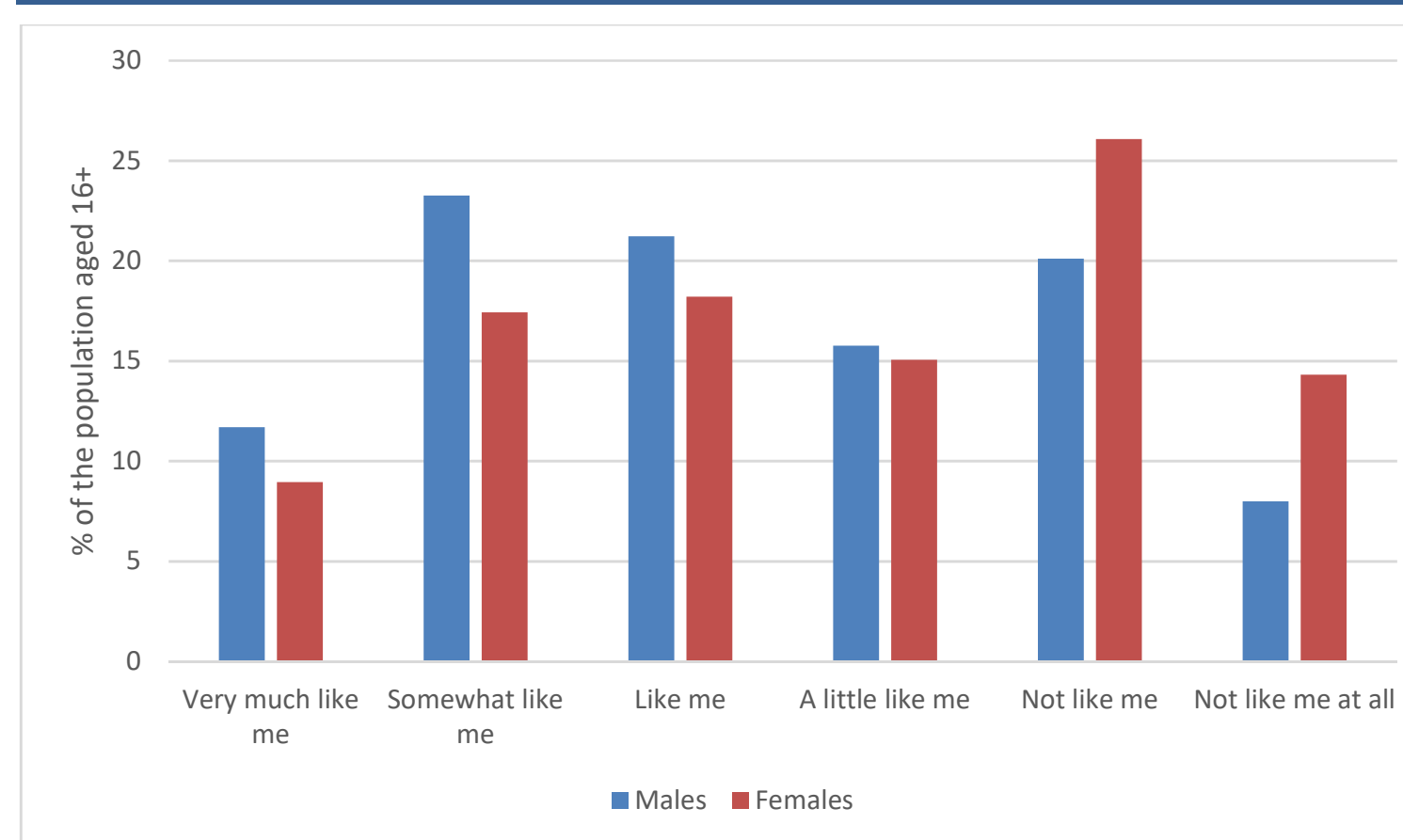

Sources: $\quad$ European Social Survey (ESS), round 8 (2016).

Note: Population weights are employed. Responses to the question: 'Now I will briefly describe some people. Please listen to each description and tell me how much each person is or is not like you: She/he looks for adventures and likes to take risks. She/he wants to have an exciting life.'

\subsubsection{Numeracy and financial literacy}

A number of national micro-data sources contain information on numeracy and financial literacy, including GUI and TILDA.

A very similar numeracy and financial module, comprising three questions that ask about knowledge of percentages, fractions and simple/compound interest, was fielded in the GUI Child Cohort at age 17 (2016) and in TILDA at Wave 3 (2014). ${ }^{51}$ As is evident from Tables 4.1 and 4.2, there are statistically significant gender differences in the total numeracy/financial literacy score (i.e. the number of correct responses), and the percentage getting all three questions correct. For example, using data from GUI, while 29.7 per cent of boys aged 17 answer all three questions correctly, the corresponding figure for girls is 14.0 per cent (Table 4.1). Similar gender differences are evident in the over-50s (Table 4.2). In multivariate regression analyses controlling for age, education and other indicators of

51 The three questions were:

Q1: If the chance of getting a disease is 10 per cent, how many people out of 1,000 would be expected to get the disease?

Q2: If 5 people all have the winning numbers in the lottery and the prize is two million euro, how much will each of them get?

Q3: Let's say you have $€ 200$ in a savings account. The account earns 10 per cent interest per year. How much would you have in the account at the end of two years?

The instructions to participants were slightly different in the two studies (see the Appendix to this chapter for further details). 
cognition, the gender gap in numeracy/financial literacy is evident in both population groups (i.e. young adults aged 17 , and older adults aged $50+$ )..$^{52}$ While GUI has not yet released the detailed responses for each individual question, further analysis of the TILDA data reveals that for each of the three questions, men are significantly more likely to get the answer correct than women. In addition, women are much more likely to answer 'don't know' than men (see Table 4.2). ${ }^{53}$

\begin{tabular}{|l|c|c|}
\hline & Males & Females \\
\hline Total score & 2.66 & 2.01 \\
& {$[2.62-2.70]$} & {$[1.96-2.05]$} \\
\hline \% all correct answers & 29.7 & 14.0 \\
& {$[28.0-31.3]$} & {$[12.8-15.2]$}
\end{tabular}

Source: $\quad$ Growing Up in Ireland (GUI), '98 Cohort, Wave 3 (age 17, 2016).

Note: $\quad$ Population weights are employed. Total score refers to the number of correct responses (range 0-4). See also Section 4.5.1. 95 per cent confidence intervals are presented in parentheses.

\begin{tabular}{|l|c|c|}
\hline Total score & Males & Females \\
\hline \% all correct answers & 2.39 & 1.85 \\
& {$[2.34-2.43]$} & {$[1.80-1.89]$} \\
\hline Q1 correct & {$[15.7-18.6]$} & 7.5 \\
\hline & 85.2 & $72.6 .4]$ \\
\hline Q2 correct & {$[83.9-86.5]$} & {$[70.5-73.6]$} \\
\hline Q3 correct & 69.3 & 53.1 \\
\hline Q1 'don't know' & {$[67.7-71.1]$} & {$[51.3-54.8]$} \\
\hline & 18.6 & 8.2 \\
\hline Q2 'don't know' & {$[17.1-20.0]$} & {$[7.2-9.1]$} \\
\hline Q3 'don't know' & {$[4.0-5.6]$} & {$[10.1-12.2]$} \\
& {$[6.4-8.4]$} & {$[16.0-18.6]$} \\
\hline
\end{tabular}

Source: $\quad$ The Irish Longitudinal Study on Ageing (TILDA), Wave 3 (age 54+, 2014).

Note: $\quad$ Population weights are employed. Total score refers to the number of correct responses (range 0-4). See also Section 4.5.2. 95 per cent confidence intervals are presented in parentheses.

In 2005, the National Adult Literacy Association (NALA) added a financial literacy question to an omnibus telephone polling survey of 1,000 adults. The question asked respondents to identify the correct definition of an annual percentage rate (APR). Men were significantly more likely than women to identify the correct

52 Results available on request from the author.

53 There is no significant difference in the proportions of men and women who answer 'don't know' to Q3; however, those who answered Q1 and/or Q2 incorrectly (and women are more likely to do so) are automatically scored zero for Q3. 
response, and consistent with other studies, women were also much more likely to respond 'don't know' (Conroy, 2005).

The Organisation for Economic Co-operation and Development (OECD) has fielded a number of surveys on adult financial literacy, including the International Survey of Adult Financial Literacy Competencies (OECD, 2016a) and the Report on Adult Financial Literacy in G20 Countries (OECD, 2017a). While Ireland was not featured in either of these studies, they illustrate a significant gender gap in financial literacy. Data from the 2010 pilot survey for International Survey of Adult Financial Literacy Competencies, which included Ireland, indicate that on average, men perform better than women. In Ireland, 68 per cent of men gained high scores in financial literacy, in comparison with 54 per cent of women. In a multivariate regression analysis of the financial literacy score, the significant effect for males persisted even after adjustment for age, education and income level (Atkinson and Messy, 2012). The OECD PISA ${ }^{54}$ contained modules on financial literacy in 2012 and 2015, but Ireland did not participate. The data from PISA for 2015 showed that in some countries and economies girls performed better than boys in financial literacy, in others there were no gender differences, and in just one country boys performed better than girls. ${ }^{55}$ The authors note that this heterogeneity contrasts with gender differences among adults, which are predominantly in favour of men, although they urge caution in making comparisons across studies using different measurement tools (OECD, 2017b).

A number of other data sources contain broader indicators of numerical ability, which is correlated with financial literacy. Data from the PIAAC, administered by the OECD, reveal that once again, men in Ireland perform better than women in terms of numerical ability. A more detailed analysis of the data indicates that the gender difference in numerical ability is evident at all age groups, albeit with evidence that the difference in greater for older age groups. ${ }^{56}$ Finally, data from PISA contain information on mathematics skills. In Ireland, boys perform significantly better than girls, and this is one of the largest gender gaps across the 72 countries examined (OECD, 2016b).

\subsubsection{Household decision-making}

TILDA contains information that indicates how households allocate decisionmaking for financial and family matters among partners in a couple. In TILDA,

54 The PISA is a triennial international survey that aims to evaluate education systems worldwide by testing the skills and knowledge of 15-year-old students. In 2015 over half a million students, representing 28 million 15-year-olds in 72 countries and economies, took the internationally agreed two-hour test. Students were assessed in science, mathematics, reading, collaborative problem-solving and financial literacy. See http://www.oecd.org/pisa/ for further details. performed better than boys. In the Flemish Community of Belgium, Brazil, Beijing-Shanghai-Jiangsu-Guangdong (China), the participating Canadian provinces, Chile, the Netherlands, Peru, Russia and the United States, the difference in performance between boys and girls was not statistically significant (OECD, 2017b). 
where there is more than one respondent in a household, respondents are asked to nominate a financial and a family respondent. These 'types' of respondent represent members of the household who are most knowledgeable in financial and family matters and who agree to answer questions in these domains on behalf of the household. Focusing on couple households with no other household members in Wave 3 (2014), Table 4.3 illustrates that, in general, men are more likely to be a financial respondent than women. However, in couple households where at least one partner is working, there is an approximate 50:50 split in the proportions of men and women nominated as financial respondents. In couples where neither partner is working (which are also more likely to be older households), a more traditional division of gender roles is apparent, with nearly 60 per cent of these households nominating the male as the financial respondent.

\begin{tabular}{|l|c|c|c|c|}
\hline & All couples & $\begin{array}{c}\text { Neither partner } \\
\text { working }\end{array}$ & $\begin{array}{c}\text { One partner } \\
\text { working }\end{array}$ & $\begin{array}{c}\text { Both partners } \\
\text { working }\end{array}$ \\
\hline Male financial + female family & 33.3 & 36.9 & 27.4 & 32.9 \\
\hline Male financial + male family & 21.2 & 22.2 & 22.0 & 17.8 \\
\hline Female financial + male family & 4.4 & 5.0 & 3.3 & 4.6 \\
\hline Female financial + female family & 41.1 & 35.9 & 47.3 & 44.7 \\
\hline
\end{tabular}

Source: $\quad$ The Irish Longitudinal Study on Ageing (TILDA), Wave 3 (age 54+, 2014).

Note: $\quad$ Population weights are employed. In TILDA, both partners in a couple are interviewed. To reduce respondent burden, only one respondent is asked questions about assets/wealth ('financial respondent') and one about family ('family respondent'). The members of the couple decide themselves who will answer as the financial or family respondent (and one member can be both). See also the Appendix to this chapter.

An analysis of financial literacy in these couple households reveals that the husband and wife have the same financial literacy score in just over 40 per cent of households, another 40 per cent are households in which the husband has higher financial literacy and just under 20 per cent are households in which the wife has higher financial literacy. Analysing spousal financial literacy scores by household response type reveals that the differential in financial literacy scores is positive for all couple household types (i.e. the husband's score is higher) (Table 4.4). The differential between spouses is greatest in households in which the husband is nominated as the financial respondent. The differential is smallest for households in which the wife is the financial respondent and the husband the family respondent, although these represent a small proportion of overall couples (just 4 per cent).

TABLE 4.4 FAMILY/FINANCIAL RESPONDENT ROLES AND NUMERACY/FINANCIAL LITERACY (TILDA) (\%)

\begin{tabular}{|l|c|c|c|}
\hline & Male FL score & Female FL score & Difference \\
\hline Male financial + female family & 1.95 & 1.41 & 0.54 \\
\hline Male financial + male family & 1.84 & 1.37 & 0.47 \\
\hline Female financial + male family & 1.90 & 1.82 & 0.08 \\
\hline Female financial + female family & 1.67 & 1.53 & 0.14 \\
\hline
\end{tabular}

Source: $\quad$ The Irish Longitudinal Study on Ageing (TILDA), Wave 3 (age 54+, 2014).

Note: $\quad$ Population weights are employed. 
Although not explicitly related to decision-making or knowledge in financial matters, household datasets such as EU-Survey of Income and Living Conditions (EU-SILC), the Household Budget Survey (HBS) and HFCS also ask the household to nominate an HRP; an examination of gender differences in the HRP over time may be informative of changes in the distribution of household decision-making roles for men and women over time.

\subsection{SUMMARY}

In this chapter, we reviewed the international literature on aspects of financial decision-making that may contribute to the gender gap in economic outcomes in older age. The literature demonstrates that women are more risk-averse and have poorer numeracy/financial literacy skills than men. While risk aversion and lower numeracy/financial literacy are associated with poorer economic outcomes, the literature on gender wealth gaps points to differences in lifetime income, education and employment trajectories between men and women as the main explanations. There is also evidence that the intra-household wealth gap is higher in households in which the male 'holds the purse strings' in comparison with households characterised by joint decision-making. In addition, there is evidence that gender differences in relation to 'financial socialisation', which in turn is associated with poorer numeracy/financial literacy, are apparent in young children and adolescents.

The second objective of this chapter was to scope out the potential for existing national data sources to provide information on these additional aspects of financial decision-making in Ireland. In terms of preferences, the HFCS contains information on attitudes to risk (albeit only for the nominated respondent), while the ESS contains data on attitudes to risk in a more general sense. To our knowledge, no national data source contains information on time preferences, highlighting a substantial gap in our understanding of potential gender differences in time preferences in the Irish context. Data on numeracy/financial literacy are available from the HFCS, GUI and TILDA. TILDA also contains information on the person who is most knowledgeable about 'financial' and 'family' matters, while other datasets such as the HFCS, HBS and EU-SILC would allow for a similar analysis of gender differences in the nomination of the HRP.

\subsection{APPENDIX}

\subsubsection{Growing Up in Ireland}

GUI surveys two cohorts of children, born in 2008 (the 'Infant Cohort') and 1998 (the 'Child Cohort'). At baseline, approximately 11,000 infants and their families were surveyed for the Infant Cohort, and over 8,000 children and their families and teachers for the Child Cohort (Greene et al., 2010). To date, five waves of data collection have been completed with the Infant Cohort, at ages 9 months, 3 years, 
5 years, 7 years and 9 years, while three waves of data collection have been completed with the Child Cohort (at 9 years, 13 years and 17 years) and a fourth wave of data collection (at age 20 years) is currently ongoing.

Data from the Child Cohort at Wave 3 are used to examine gender differences in numeracy/financial literacy. Wave 3 of the Child Cohort was carried out between November 2015 and September 2016 when the young person was aged approximately 17 years of age (Growing up in Ireland, 2016). Numeracy/financial literacy was assessed via three short questions, similar to those fielded in Wave 3 of TILDA (see also Section 4.5.2). The questions were filled out in paper format by the young person. There was no fixed time limit for completing the questions. The three questions were as follows:

Q1: If the chance of getting a disease is 10 per cent, how many people out of 1,000 would be expected to get the disease?

Q2: If 5 people all have the winning numbers in the lottery and the prize is two million euro, how much will each of them get?

Q3: Let's say you have $€ 200$ in a savings account. The account earns 10 per cent interest per year. How much would you have in the account at the end of two years?

If the respondent asked if Q3 referred to simple or compound interest, they were instructed that compound interest was preferred but that points would also be given for simple interest. A total score with one point for each correct answer to Q1 and Q2, one point for simple interest for Q3 and two points for compound interest for Q3 was derived. Total scores range from 0 to 4.

\subsubsection{The Irish Longitudinal Study on Ageing}

TILDA is a nationally representative longitudinal study of adults in Ireland aged 50 and older and their partners of any age. Approximately 8,000 individuals aged 50+ were first surveyed in 2010 (Barrett et al., 2011), with a further four waves of data collection occurring in 2012, 2014, 2016 and 2018. The data from Wave 3, collected between March 2014 and October 2015 (Donoghue et al., 2018), are used to analyse gender differences in numeracy/financial literacy. Numeracy/financial literacy was assessed via the same three questions fielded in the GUI Child Cohort at Wave 3 (age 17). However, in contrast to GUI, only if the respondent answered Q1 or Q2 correctly were they subsequently asked Q3. In other words, those who answered both Q1 and Q2 incorrectly were not asked Q3. In addition, TILDA respondents were not given any guidance in relation to Q3 if they asked whether the question referred to simple or compound interest. The number of correct responses was calculated, with those answering Q3 in terms of simple interest 
getting one point, and those answering $\mathrm{Q} 3$ as compound interest getting two points. Total scores range from 0 to 4 .

TILDA also contains information that indicates how households allocate decisionmaking for financial and family matters among partners in a couple. In TILDA, where there is more than one respondent in a household, respondents are asked to nominate a financial and a family respondent. These 'types' of respondent represent members of the household who are most knowledgeable in financial and family matters and who agree to answer questions in these domains on behalf of the household. The financial and family respondents may be the same individual. An individual in TILDA may therefore be (1) a financial respondent only, (2) both a financial and a family respondent, (3) a family respondent only, (4) neither.

\subsubsection{Household Finance and Consumption Survey}

The HFCS is a Eurozone-wide survey conducted under the auspices of the European Central Bank's Household Finance and Consumption Network (HFCN). ${ }^{57}$ The fieldwork for the first wave of HFCS surveys was carried out in most countries (except for Ireland and Estonia) in 2010 and 2011.

The HFCS is a household survey that collects data on household consumption and finances. A common core questionnaire is fielded in all countries, and non-core extensions to the questionnaire are fielded in most countries. In Ireland the HFCS was done by the Central Statistics Office on behalf of the Central Bank of Ireland, which is a member of the HFCN. The first wave of the survey was conducted in Ireland in 2013. In total, 5,419 households are included in the HFCS for Ireland.

The core questionnaire includes a self-assessment question on risk attitudes, answered by the nominated household reference person, as follows:

Which of the following statements comes closest to describing the amount of financial risk that you/your household is willing to take when you save or make investments?

1 - Take substantial financial risks expecting to earn substantial returns

2 - Take above average financial risks expecting to earn above average returns

3 - Take average financial risks expecting to earn average returns

4 - Not willing to take any financial risk

${ }^{57}$ The HFCN is the guiding body in all matters relating to the HFCS. Its website is at https://www.ecb.europa.eu/home/html/researcher_hfcn.en.html 
In addition, a number of countries, including Ireland, included four questions on financial literacy, capturing knowledge of interest rates, inflation, portfolio diversification and knowledge of risky assets. ${ }^{58}$ Unfortunately, the data from the non-core questionnaire have not been released yet and thus an analysis of gender differences in these four aspects of financial literacy is not yet possible. 



\section{CHAPTER 5}

\section{Summary and policy implications}

\subsection{SUMMARY}

Women may face a number of potential issues both before and during retirement that can have a cumulative impact resulting in significantly lower financial security in retirement than men. Specifically, the gender gap in pensions highlights the percentage by which women's average pension income is lower than that for men. In 2016, a woman aged 65-79 in the EU-28 received a pension that was 38 per cent lower than that of her male counterpart; the corresponding figure for Ireland was 26 per cent (European Commission, 2018). While the older population has fared better than other age groups in terms of the experience of income poverty in Ireland in recent years, there remains a proportion (currently just under 9 per cent) who live in income poverty (CSO, 2018), despite the fact that the level of older age state benefits should be sufficient to keep this group out of income poverty.

Pension income accounts for most of the retirement income of men and women in Ireland (CSO, 2013). Asset wealth may also be used to finance consumption in retirement, and gender differences in wealth have also been documented (Barrett et al., 2011; Sierminska, 2017). Demographic trends mean that older women, who live longer than men, will make up a larger share of the population, and will be increasingly likely to live alone (European Commission, 2018). This means that older women will need to assume greater responsibility for their own financial security in older age.

For any policy to tackle successfully gender differences in economic outcomes in older age, it is also important to understand how men and women may differ in terms of financial decision-making. Decisions about many aspects of economic life are shaped also by attitudes to risk, time preferences and financial literacy skills, and there is evidence that men and women differ in some aspects of these key dimensions of decision-making.

In this report, we focused on three key dimensions of the policy debate around gender and pensions in Ireland. Chapter 2, analysing the gender pension gap in Ireland using data from TILDA, found that in 2010, 88 per cent of men and 93 per cent of women were in receipt of the state pension, while 55 per cent of men and 28 per cent of women were in receipt of occupational and private pensions. The average total weekly pension income of women was $€ 280$ and $€ 433$ for men in 2010 , implying a raw gender pension gap of approximately 35 per cent. This means that in retirement, the pension income of men in Ireland is generally 35 per cent higher than the pension income of women. In line with Ginn and Arber (1996), a key element of this gap is attributed to differences in occupational and private 
pensions across genders. No consistent evidence of a gender state pension gap was found. For occupational and private pensions, higher levels of female educational attainment are found to reduce the impact of the gender pension gap throughout the pension income distribution. In the top three deciles, where approximately 25 to 45 per cent of the raw gap is explained, the principal factors contributing to the gap are found to be the lower relative years of work experience among women.

In Chapter 3, we focused on income poverty in older age, examining the characteristics of those living in income poverty in older age in Ireland, using data from the SILC for 2015 and 2016. The analysis found that almost 80 per cent of income-poor older individuals live in single or couple households (with no other household members), thus refuting the hypothesis that the presence of other household members would impact on household equivalised income and thereby push the household below the poverty threshold. A more detailed analysis of household and personal income sources for the older population revealed their high dependence on old-age benefits (i.e. pensions), with an average 80 per cent of personal income derived from the contributory state and occupational pensions. In terms of gender differences, the rate of receipt and mean level of contributory pensions is much lower among older women, due partly to the fact that their partners are likely to be in receipt of a qualified adult payment but also to the fact that more women could be in receipt of lower personal rates as a consequence of a lower lifetime attachment to the labour market.

Finally, Chapter 4 detailed the results of a literature review that summarised the international evidence on gender differences in key dimensions of financial decision-making (preferences, financial literacy and household decision-making roles). The literature demonstrates clear evidence that women are more riskaverse and have poorer numeracy/financial literacy skills than men. There is also evidence that the intra-household wealth gap is higher in households in which the male 'holds the purse strings' in comparison with households characterised by joint decision-making. The second objective of this chapter was to scope out the potential for existing national data sources to provide information on these additional aspects of financial decision-making in Ireland. One of the major gaps identified was that, to our knowledge, no national data source contains information on time preferences.

\subsection{POLICY IMPLICATIONS}

The gender gap in pensions in the EU (36 per cent) is more than twice the gender gap in pay (16 per cent) (European Commission, 2018). Bettio et al. (2013) note that there is much less information about the gender pensions gap than the gender pay gap, which makes it difficult to monitor progress on gender equity. In general, gaps in lifetime earnings are found to be among the main drivers of the gender gaps in pensions (European Commission, 2018). 
In order to address the gender pension gap, policy measures that reduce the observed differences in occupational and private pension coverage across genders by raising female employment levels and ensure increased continuity in employment are most important. Policy could also focus on measures to promote supplementary pension savings for women, based either on professional activity (occupational pensions) or on individual pension savings contracts (personal pensions), which will provide additional retirement savings and complement statutory pensions for women in order to reduce the gender pension gap.

Reducing pension income inequalities requires equal opportunity policies targeted at both women and men of working age in order to promote equal labour market access (for example, equal distribution of caring responsibilities, equal pay legislation and career break entitlements) and pension policies that adequately protect against care-related interruptions. In this regard, policies regarding the provision of increased and more affordable childcare infrastructures and long-term care services can play a role in increasing female employment levels and ensuring increased continuity in employment (Redmond and McGuinness, 2018). For workers who experience interruptions in their career, it is important for policy to examine the best ways to facilitate the return to work and work transitions, i.e. between both jobs and work statuses. In terms of further research, a deeper understanding of the collective effect of horizontal and vertical segregation and differing career patterns between men and women could also play a key role in explaining the gender pension gap.

The analysis of income poverty among the older population highlights a positive story. In contrast with other population groups, less than 10 per cent of the older population are income poor, reflecting the role that the state pension has played in keeping the majority of the older population out of income poverty. Despite this, there remains a group of older individuals in poverty. Our analysis shows that household composition does not explain why there is a group of older income poor, and that income-poor older people are highly dependent on noncontributory pensions. This suggests a number of issues that are worthy of further investigation.

First, it is possible that some older people are not receiving a state contributory pension while being eligible for such a pension, and second, previous labour market history (periods spent abroad, career gaps, etc.) could explain why they do not qualify for a full rate of this pension. For example, data from TILDA show that among this cohort of older individuals, over 20 per cent of men and women had lived abroad for a period of six months or more, and the average length of time spent living and working abroad was 11 years. Given these patterns, an issue to consider is the extent to which foreign income sources are captured accurately in datasets such as SILC that are used to monitor income poverty in older age. 
Demographic trends mean that older women, who live longer than men, will make up a larger share of the population, and will be increasingly likely to live alone. This means that older women will need to assume greater responsibility for their own financial security in older age. Ensuring that women have the necessary skills to ensure their financial security in older age is crucial and requires an understanding of how financial decisions are made, and how men and women may differ in terms of financial decision-making.

The low level of financial literacy among the older population is of concern, particularly in light of the international evidence that shows a clear relationship between financial literacy and outcomes such as wealth and income, as well as the degree to which individuals plan for retirement (Lusardi and Mitchell, 2011a, 2011b; van Rooij et al., 2012). The gender gap is particularly noteworthy, although not unusual internationally (Klapper et al., 2016). The broader literature on gender differences in numeracy and mathematical skills (which are correlated with financial literacy) suggests that early socialisation in the home and school, as well as broader societal attitudes to gender equality (Dossi et al., 2019; Fryer and Levitt, 2010; Guiso et al., 2008), may play a role in explaining the gender gap in financial literacy skills that emerge in early adulthood and persist throughout the life course. In terms of financial literacy education interventions for adults, the evidence on the efficacy of interventions is poor (Fernandes et al., 2014). Recently, the importance of the wider concept of financial capability, which reflects not only skills but also the accumulation of knowledge, experience, attitudes and motivations to act in a financially capable way, has been highlighted (Bagwell et al., 2014; Lunn, 2012). While the evidence base is still emerging, policies to enhance financial capability across the population will be an important complement to broader efforts to ensure that men and women have equal opportunities to participate in the labour market and accumulate sufficient resources to ensure financial security in retirement. 


\section{REFERENCES}

Agnew, S. and T. Cameron-Agnew (2015). 'The influence of consumer socialisation in the home on gender differences in financial literacy', International Journal of Consumer Studies, Vol. 39, pp. 630-638.

Agnew, S., P. Maras, and A. Moon (2018). 'Gender differences in financial socialization in the home-an exploratory study', International Journal of Consumer Studies, Vol. 42, pp. 275-282.

Ameriks, J., A. Caplin, and J. Leahy (2003). 'Wealth accumulation and the propensity to plan', Quarterly Journal of Economics, Vol. 118, pp. 1007-1047.

Atkinson, A. and F. Messy (2012). Measuring financial literacy, OECD Working Papers on Finance, Insurance and Private Pensions, No. 15, Paris: OECD.

Bagwell, S., C. Hestbaek, E. Harries, and A. Kail (2014). Financial Capability Strategy for the UK, London: NPC.

Banks, J. (2010). 'Cognitive function, financial literacy and financial outcomes at older ages: introduction', Economic Journal, Vol. 120, pp. F357-F362.

Banks, J., E. Bassoli, and I. Mammi (2019). Changing risk preferences at older age, Department of Economics 01/WP/2019, Venice: University of Venice.

Banks, J. and Z. Oldfield (2007). 'Understanding pensions: cognitive function, numerical ability and retirement saving', Fiscal Studies, Vol. 28, pp. 143-170.

Barber, B. and T. Odean (2001). 'Boys will be boys: gender, overconfidence, and common stock investment', Quarterly Journal of Economics, Vol. 116, pp. 261-292.

Bardasi, E. and S. Jenkins (2010). 'The gender gap in private pensions', Bulletin of Economic Research, Vol. 62, pp. 343-363.

Barrett, A., G. Savva, V. Timonen, and R. Kenny (2011). Fifty Plus in Ireland 2011: First results from the Irish Longitudinal Study on Ageing (TILDA). Dublin: The Irish Longitudinal Study on Ageing.

Bertocchi, G., M. Brunetti, and C. Torricelli (2014). 'Who holds the purse strings within the household? The determinants of intra-family decision making', Journal of Economic Behavior \& Organization, Vol. 101, pp. 65-86.

Bettinger, E. and R. Slonim (2007). 'Patience among children', Journal of Public Economics, Vol. 91, pp. 343-363.

Bettio, F., P. Tinios, and G. Betti (2013). The Gender Gap in Pensions in the EU. Brussels: European Commission.

Binswanger, J. and K. Carman (2012). 'How real people make long-term decisions: the case of retirement preparation', Journal of Economic Behavior \& Organization, Vol. 81, 39-60.

Blau, F. and L. Kahn (2003). 'Understanding international differences in the gender pay gap', Journal of Labor Economics, Vol. 21, pp. 106-144. 
Blau, F. and L. Kahn (2006). 'The U.S. gender pay gap in the 1990s: slowing convergence', Industrial and Labor Relations Review, Vol. 60, pp. 45-66.

Blau, F. and L. Kahn (2017). 'The gender wage gap: extent, trends, and explanations', Journal of Economic Literature, Vol. 55, pp. 789-865.

Blinder, A. (1973). 'Wage discrimination: reduced form and structural estimates', Journal of Human Resources, 8, 436-455.

Bonsang, E. and T. Dohmen (2015). 'Risk attitude and cognitive aging', Journal of Economic Behavior \& Organization, 112, 112-126.

Borghans, L., A. Duckworth, J. Heckman, and B. Weel (2008). 'The economics and psychology of personality traits', Journal of Human Resources, Vol. 43, pp. 9721059.

Borghans, L., B. Golsteyn, J. Heckman, and H. Meijers (2009). 'Gender differences in risk aversion and ambiguity aversion', Journal of the European Economic Association, Vol. 7, pp. 649-658.

Brown, H. and M. Van der Pol (2015). 'Intergenerational transfer of time and risk preferences', Journal of Economic Psychology, Vol. 49, pp. 187-204.

Brown, M., C. Henchoz, and T. Spycher (2018). 'Culture and financial literacy: evidence from a within-country language border', Journal of Economic Behavior \& Organization, Vol. 150, pp. 62-85.

Bucher-Koenen, T., A. Lusardi, R. Alessie, and M. Van Rooij (2017). 'How financially literate are women? An overview and new insights', Journal of Consumer Affairs, Vol. 51, pp. 255-283.

Callan, T., B. Nolan, and C. Whelan (1993). 'Resources, deprivation and the measurement of poverty', Journal of Social Policy, Vol. 22, pp. 141-172.

Charness, G. and U. Gneezy (2012). 'Strong evidence for gender differences in risk taking', Journal of Economic Behavior \& Organization, Vol. 83, pp. 50-58.

Charness, G., U. Gneezy, and A. Imas (2013). 'Experimental methods: eliciting risk preferences', Journal of Economic Behavior \& Organization, Vol. 87, pp. 43-51.

Chłoń-Domińczak, A. (2017). Gender Gap in Pensions: Looking Ahead, Brussels: European Parliament.

Clark, R., R. Hammond, C. Khalaf, and M. Sandler Morrin (2017). Planning for Retirement? The Importance of Time Preferences, Washington, DC: NBER.

Competition and Consumer Protection Commission (2018). Financial Capability and Wellbeing in Ireland in 2018, Dublin: CCPC.

Conroy, P. (2005). Financial Literacy: Improving Understanding, Creating Opportunity, Dublin: National Adult Literacy Agency.

Croson, R. and U. Gneezy (2009). 'Gender differences in preferences', Journal of Economic Literature, Vol. 47, 448-474.

Crossley, T., S. Alan, J. Banks, S. Choi, A. Rustini, and N. Woods (2012). Risk and time preferences in older persons: an experimental module using ELSA, paper given at the ELSA Wave 5 Launch, London: ELSA. 
CSO (2013). Thematic Report on the Elderly 2004, 2009, 2010 (revised) and 2011. Survey on Income and Living Conditions (SILC). Dublin: CSO.

CSO (2017a). Census of Population 2016. Profile 3: An Age Profile of Ireland. Dublin: Central Statistics Office .

CSO (2017b). 2016 Results. Survey on Income and Living Conditions (SILC). Dublin: Central Statistics Office.

CSO (2017c). Women and Men in Ireland 2016. Dublin: Central Statistics Office.

CSO (2018). 2017 Results. Survey on Income and Living Conditions (SILC). Dublin: Central Statistics Office.

Daly, M., L. Delaney, and C. Harmon (2009). 'Psychological and biological foundations of time preference', Journal of the European Economic Association, Vol. 7, pp. 659669.

Delaney, L. and O. Doyle (2012). 'Socioeconomic differences in early childhood time preferences', Journal of Economic Psychology, Vol. 33, pp. 237-247.

Department of Employment Affairs and Social Protection (2017). 2015 Actuarial Review of the Social Insurance Fund. Dublin: DEASP.

Dittrich, M. and K. Leipold (2014). 'Gender differences in time preferences', Economics Letters, Vol. 122, 413-415.

Dohmen, T., A. Falk, D. Huffman, and U. Sunde, (2010). 'Are risk aversion and impatience related to cognitive ability?', American Economic Review, Vol. 100, pp. 1238-1260.

Dohmen, T., A. Falk, D. Huffman, U. Sunde, J. Schupp, and G. Wagner (2011). 'Individual risk attitudes: measurement, determinants, and behavioral consequences', Journal of the European Economic Association, Vol. 9, pp. 522-550.

Donoghue, O., C. McGarrigle, M. Foley, A. Fagan, J. Meaney, and R. Kenny (2018). 'Cohort profile update: The Irish Longitudinal Study on Ageing (TILDA)', International Journal of Epidemiology, Vol. 47, pp. 1398-1398l.

Dossi, G., D. Figlio, P. Giuliano, and P. Sapienza (2019). Born in the family: preferences for boys and the gender gap in math, NBER Working Paper 25535, Washington, DC: NBER.

Eckel, C. and P. Grossman (2008a). 'Forecasting risk attitudes: an experimental study using actual and forecast gamble choices', Journal of Economic Behavior \& Organization, Vol. 68, 1-17.

Eckel, C. and P. Grossman (2008b). 'Men, women and risk aversion: experimental evidence', in C. Plott and V. Smith (eds), Handbook of Experimental Economics Results, Amsterdam: North-Holland.

European Commission (2018). Current and Future Income Adequacy in the EU, Luxembourg: European Commission.

Even, W. and D. Macpherson (1990). 'The gender gap in pensions and wages', Review of Economics and Statistics, Vol. 72, pp. 259-265. 
Fernandes, D., J. Lynch, and R. Netemeyer (2014). 'Financial literacy, financial education, and downstream financial behaviors', Management Science, Vol. 60, pp. 18611883.

Firpo, S., N. Fortin, and T. Lemieux, (2009). 'Unconditional quantile regressions', Econometrica, 77, 953-973.

Flory, J. (2011). Gender Pension Gap, Berlin: Bundesministerium für Familie, Senioren, Frauen und Jugend.

Fonseca, R., K. Mullen, G. Zamarro, and J. Zissimopoulos (2012). 'What explains the gender gap in financial literacy? The role of household decision making', Journal of Consumer Affairs, Vol. 46, pp. 90-106.

Fortin, N., T. Lemieux, and S. Firpo (2011). 'Decomposition methods in economics', in O. Ashenfelter and D. Card (eds), Handbook of Labor Economics, San Diego, CA: NorthHolland.

Fryer, R. and S. Levitt (2010). 'An empirical analysis of the gender gap in mathematics', American Economic Journal: Applied Economics, Vol. 2, pp. 210-240.

Ginn, J. (2003). Gender, Pensions and the Lifecourse: How Pensions Need to Adapt to Changing Family Forms, Bristol: Bristol University Press.

Ginn, J. and S. Arber (1996). 'Patterns of employment, gender and pensions: the effect of work history on older women's non-state pensions', Work, Employment and Society, Vol. 10, pp. 469-490.

Government of Ireland (1997). Sharing the Progress: The National Anti-Poverty Strategy, Dublin: Stationery Office.

Government of Ireland (2010). National Pensions Framework, Dublin: Stationery Office.

Grabka, M., J. Marcus, and E. Sierminska (2015). 'Wealth distribution within couples', Review of Economics of the Household, Vol. 13, pp. 459-486.

Greene, S., J. Williams, R. Layte, E. Doyle, E. Harris, C. McCrory, A. Murray, T. O’Dowd, A. Quail, L. Swords, M. Thornton, and C. Whelan (2010). Growing Up in Ireland National Longitudinal Study of Children: Background and Conceptual Framework, Dublin: Office of the Minister for Children and Youth Affairs.

Growing Up in Ireland (2016). 'Risky health behaviours and sexual activity', in Key Findings: Child Cohort at 17/18 Years, Dublin: The Economic and Social Research Institute.

Guiso, L., F. Monte, P. Sapienza, and L. Zingales (2008). 'Culture, gender, and math', Science, Vol. 320, pp. 1164-1165.

Guiso, L., P. Sapienza, and L. Zingales (2018). 'Time varying risk aversion', Journal of Financial Economics, Vol. 128, pp. 403-421.

Hanisch, C. and J. Klos (2014). A decomposition analysis of the German gender pension gap, Discussion Paper Series 4, Freiburg: University of Freiburg.

Huffman, D., R. Maurer, and O. Mitchell, (2017). 'Time discounting and economic decisionmaking in the older population', Journal of the Economics of Ageing, https://doi.org/10.1016/j.jeoa.2017.05.001 
Jefferson, T. (2009). 'Women and retirement pensions: a research review', Feminist Economics, Vol. 15, pp. 115-145.

Johnston, D., S. Kassenboehmer, and M. Shields (2016). 'Financial decision-making in the household: exploring the importance of survey respondent, health, cognitive ability and personality', Journal of Economic Behavior \& Organization, Vol. 132, pp. 42-61.

Kettlewell, N. (2018). Risk preference dynamics around life events, Economics Working Paper Series 2018-7, Sydney: University of Sydney.

Klapper, L., A. Lusardi, and P. Van Oudheusden (2016). 'Financial literacy around the world', Insights from the Standard and Poor's Ratings Services Global Financial Literacy Survey, Washington, DC: World Bank.

Lades, L., M. Egan, L. Delaney, and M. Daly (2017). 'Childhood self-control and adult pension participation', Economics Letters, Vol. 161, pp. 102-104.

Lunn, P. (2012). Can policy improve our financial decision-making? Renewal Series Paper No. 8, Dublin: The Economic and Social Research Institute.

Lusardi, A. and O. Mitchell (2007). 'Baby boomer retirement security: the roles of planning, financial literacy, and housing wealth', Journal of Monetary Economics, Vol. 54, pp. 205-224.

Lusardi, A. and O. Mitchell (2008). 'Planning and financial literacy: how do women fare?' American Economic Review, Vol. 98, pp. 413-417.

Lusardi, A. and O. Mitchell (2011a). 'Financial literacy and retirement planning in the United States', Journal of Pension Economics and Finance, Vol. 10, pp. 509-525.

Lusardi, A. and O. Mitchell (2011b). 'Financial literacy around the world: an overview', Journal of Pension Economics and Finance, Vol. 10, pp. 497-508.

Lusardi, A. and P. Tufano (2015). 'Debt literacy, financial experiences, and overindebtedness', Journal of Pension Economics and Finance, Vol. 14, pp. 332368.

Machado, J. and J. Mata, (2005). 'Counterfactual decomposition of changes in wage distributions using quantile regression', Journal of Applied Econometrics, Vol. 20, pp. 445-465.

Maitre, B., B. Nolan, and C. Whelan (2006). Reconfiguring the measurement of deprivation and consistent poverty in Ireland, Policy Research Series Report No. 58, Dublin: The Economic and Social Research Institute.

Malmendier, U. and S. Nagel (2011). 'Depression babies: do macroeconomic experiences affect risk taking?', Quarterly Journal of Economics, Vol. 126, pp. 373-416.

McArdle, J., J. Smith, and R. Willis (2011). 'Cognition and economic outcomes in the Health and Retirement Survey', in D. Wise (ed.), Explorations in the Economics of Ageing, Chicago: University of Chicago Press.

McCarthy, Y. (2011). Behavioural characteristics and financial distress, ECB Working Paper No. 1303, Frankfurt: European Central Bank.

Modigliani, F. (1986). 'Life cycle, individual thrift, and the wealth of nations', American Economic Review, Vol. 76, No. 3, pp. 297-313. 
Neelakantan, U. and Y. Chang (2010). 'Gender differences in wealth at retirement', American Economic Review, Vol. 100, pp. 362-367.

Nivakoski, S. and A. Barrett (2017). Estimating, and interpreting, retirement income replacement rates, Working Paper No. WP575, Dublin: The Economic and Social Research Institute.

Nivakoski, S. and A. Nolan (2019). 'Expected widowhood duration varies with socioeconomic status', Applied Economics Letters, Vol. 26, pp. 1218-1233.

Oaxaca, R. (1973). 'Male-female wage differentials in urban labor markets', International Economic Review, Vol. 14, pp. 693-709.

O'Donnell, N. and M. Keeney (2009). Financial capability: new evidence for Ireland, Research Technical Paper 1/RT/09, Dublin: Central Bank of Ireland.

O'Donnell, N. and M. Keeney (2010). 'Financial capability in Ireland and a comparison with the UK', Public Money \& Management, Vol. 30, pp. 355-362.

OECD (2014). OECD Reviews of Pensions Systems: Ireland, Paris: OECD.

OECD (2016a). OECD/INFE International Survey of Adult Financial Literacy Competencies, Paris: OECD.

OECD (2016b). PISA 2015 Results (Volume I), Paris: OECD.

OECD (2017a). G20/OECD INFE Report on Adult Financial Literacy in G20 Countries, Paris: OECD.

OECD (2017b). PISA 2015 Results (Volume IV): Students' Financial Literacy, Paris: OECD.

OECD (2018a). Health at a Glance Europe: 2018. State of Health in the EU Cycle, Paris: OECD.

OECD. (2018b). Inequalities in Household Wealth Across OECD Countries: Evidence from the OECD Wealth Distribution Database, OECD Working Paper No. 88, Paris: OECD.

Olivetti, C. and B. Petrongolo (2016). 'The evolution of gender gaps in industrialized countries', Annual Review of Economics, Vol. 8, pp. 405-434.

Plantega, J. and C. Remery (2006). The Gender Pay Gap: Origin and Policy Responses. A Comparative Review of 30 European Countries. Luxembourg: Office for Official Publications of the European Communities.

Powell, M. and D. Ansic (1997). 'Gender differences in risk behaviour in financial decisionmaking: an experimental analysis', Journal of Economic Psychology, Vol. 18, pp. 605-628.

Redmond, P. and S. McGuinness (2019). 'The gender wage gap in europe: job preferences, gender convergence and distributional effects', Oxford Bulletin of Economics and Statistics, Vol. 81, pp. 564-587.

Ruel, E. and R. Hauser (2013). 'Explaining the gender wealth gap', Demography, Vol. 50, pp. 1155-1176.

Russell, H., B. Maitre, and B. Nolan (2010). Monitoring poverty trends in Ireland 2004-2007: key issues for children, people of working age and older people, Research Series No. 17, Dublin: The Economic and Social Research Institute. 
Sahm, C. (2012). 'How much does risk tolerance change?', Quarterly Journal of Finance, Vol. 2, 1250020 .

Schubert, R. (1999). 'Financial decision-making: are women really more risk-averse?', American Economic Review, Vol. 89, No. 2, pp. 381-385.

Sierminska, E. (2017). Wealth and Gender in Europe, Brussels: EU Directorate-General for Justice and Consumers.

Skagerlund, K., T. Lind, C. Strömbäck, G. Tinghög, and D. Västfjäll (2018). 'Financial literacy and the role of numeracy-How individuals' attitude and affinity with numbers influence financial literacy', Journal of Behavioral and Experimental Economics, Vol. 74, pp. 18-25.

Smith, J., J. McArdle, and R.Willis, (2010). 'Financial decision making and cognition in a family context', Economic Journal, Vol. 120, pp. F363-F380.

Townsend, P. (1979). Poverty in the United Kingdom, London: Allen Lane and Penguin Books.

Van Rooij, M., A. Lusardi, and R. Alessie (2012). 'Financial literacy, retirement planning and household wealth', Economic Journal, Vol. 122, pp. 449-478.

Von Gaudecker, H., A. Van Soest, and E. Wengstrom (2011). 'Heterogeneity in risky choice behavior in a broad population', American Economic Review, Vol. 101, pp. 664694.

Wang, M., M. Rieger, and T. Hens, (2016). 'How time preferences differ: evidence from 53 countries', Journal of Economic Psychology, Vol. 52, pp. 115-135.

Watson, D. and B. Maitre (2013). Implications of income pooling and household decisionmaking for the measurement of poverty and deprivation, Technical Paper No. 4, Dublin: Department of Social Protection.

Wren, M.-A., C. Keegan, B. Walsh, A. Bergin, J. Eighan, A. Brick, S. Connolly, D. Watson, and J. Banks (2017). Projections of demand for healthcare in Ireland, 2015-2030: first report from the Hippocrates Model, Dublin: Economic and Social Research Institute. 
Whitaker Square,

Sir John Rogerson's Quay, Dublin 2

Telephone +35318632000

Email admin@esri.ie

Web www.esri.ie

Twitter @ESRIDublin

ISBN 978-0-7070-0490-7 